Florida International University FIU Digital Commons

8-20-1991

\title{
Chemical and evaporative behaviors of synthetic liquid nuclear waste
}

Donna MacGrath Cline

Florida International University

DOI: $10.25148 /$ etd.FI14060860

Follow this and additional works at: https://digitalcommons.fiu.edu/etd

Part of the Mechanical Engineering Commons

\section{Recommended Citation}

Cline, Donna MacGrath, "Chemical and evaporative behaviors of synthetic liquid nuclear waste" (1991). FIU Electronic Theses and Dissertations. 2390.

https://digitalcommons.fiu.edu/etd/2390

This work is brought to you for free and open access by the University Graduate School at FIU Digital Commons. It has been accepted for inclusion in FIU Electronic Theses and Dissertations by an authorized administrator of FIU Digital Commons. For more information, please contact dcc@fiu.edu. 


\begin{abstract}
OF THE THESIS
by

Donna MacGrath Cline

Florida International University, 1991

Miami, Florida

Dr. M. Ali Ebadian, Major Professor
\end{abstract}

Chemical and Evaporative Behaviors of Synthetic Liquid Nuclear Waste

In the 1960's the Department of Energy at Oak Ridge National Laboratory designed eight 50,000 gallon storage tanks for the liquid nuclear waste. Each tank was designed with its own ventilation system to purge radiolytic hydrogen and oxygen from the tank. This design induced water removal and necessitated the additional requirement of entraining radioactivity from the exiting system by the use of demisters and HEPA filters.

Up until the 1980's this was a sufficient method, via the hydrofracture process, of disposing the liquid nuclear waste. However since then, this method has been terminated and the tanks are nearing capacity. In the transfer of the liquid waste to the holding tanks, large amounts of water are used to prevent line clogging and solid build up in the pipes. Utilizing the existing system, this thesis proposes the idea of sparging air into the liquid waste and increasing the tank temperature in order to eliminate excess water. Parameters such as increasing the sparging air temperature, and dehumidifying and eliminating carbon dioxide from the sparging air, are investigated theoretically and experimentally in small scale experiments. In addition, the effects of vapor pressure lowering and its simultaneous effect on the evaporation rate are investigated through the activity coefficient of sodium nitrate, the major component of the liquid waste. Precipitate blockage formations in the sparging tube have also been addressed. 


\title{
FLORIDA INTERNATIONAL UNIVERSITY
}

Miami, Florida

Chemical and Evaporative Behaviors of Synthetic Liquid Nuclear Waste

\author{
A thesis submitted in partial satisfaction of the \\ requirements for the degree of Master of Science \\ in Mechanical Engineering
}

by

Donna MacGrath Cline 
To Professors Dr. M. Ali Ebadian, Dr. E. Bigzadeh, Dr. W. Kinzy Jones and Dr. T. C. Yih:

This thesis, having been approved in respect to form and mechanical execution, is referred to you for judgement upon its substantial merit.

Dean Gordon R. Hopkins

College of Engineering

The thesis of Donna MacGrath Cline is approved.

Dr. M. Ali Ebadian, Major Professor

Dr. E. Bigzadeh

Dr. W. Kinzy Jones

Dr. T. C. Yih

Date of Examination: August 20, 1991

Dean Richard Campbell

Division of Graduate Studies 


\section{DEDICATION PAGE}

This work is dedicated to my husband, who is my inspiration. 


\section{ACKNOWLEDGEMENTS}

A very special thank you to my parents who allowed me to choose my own paths and who provided never-ending support in all my decisions. I would also like to express my gratitude to my advisor and professor Dr. Ebadian of Mechanical Engineering; whose perseverance and belief in me was more than I had ever dreamed possible. I also want him to know that he has not lost a graduate student, but has guided yet another devoted person into the fulfilling world of engineering. A warm hug goes out to Joi Phelps, my sister-inlaw, who cheered me on and guided me in the organizational process of writing this thesis.

I would also like to take this time to express my respect for Dr. Bigzadeh and thank him for his continual assistance in the experimental work and Dr. Yang whose clarity and expertise helped me visualize the fundamental aspects of my work. Thankyou Mr. Zhang, for your willingness to offer assistance regardless of the situation.

I am also grateful for the caring assistance offered by Helen, Marianne and Ester; who all helped in revising my manuscripts and maintained a smiled at the same time. Thanks Marianne for assisting me in the paperwork necessary to complete this Thesis. And, thank you Helen for sharing your experiences in art and photography with me; your warmth and your philosophies heightened the long working days. Keep up the good work Ester, your energy amazes me.

Finally, I want Grandma to know that her prayers are answered, thank you. 


\section{PUBLICATIONS AND PRESENTATIONS}

\section{TECHNICAL REPORTS}

Ebadian, M. A., Bigzadeh, E., Yang, G. and MacGrath, D. L., "Evaporating Water From the MVSTs for the Purpose of Producing Liquid Concentrate Storage Capacity, Progress Report No. 7," Martin Marietta, Department of Energy, Oak Ridge National Laboratory, Oak Ridge, Tennessee (August, 1990)

Ebadian, M. A., Bigzadeh, E., Yang, G. and MacGrath, D. L., "Evaporating Water From the MVSTs for the Purpose of Producing Liquid Concentrate Storage Capacity, Progress Report No. 9," Martin Marietta, Department of Energy, Oak Ridge National Laboratory, Oak Ridge, Tennessee (January, 1991)

Ebadian, M. A., Bigzadeh, E., Yang, G. and MacGrath, D. L., "Evaporating Water From the MVSTs for the Purpose of Producing Liquid Concentrate Storage Capacity, Progress Report No. 11,” Martin Marietta, Department of Energy, Oak Ridge National Laboratory, Oak Ridge, Tennessee (April, 1991)

Ebadian, M. A., Bigzadeh, E., Yang, G. and MacGrath, D. L., "Evaporating

Water From the MVSTs for the Purpose of Producing Liquid Concentrate Storage Capacity,” Martin Marietta, Department of Energy, Oak Ridge National Laboratory, Oak Ridge, Tennessee (July, 1991) 


\section{REFEREED CONFERENCE AND JOURNALS}

MacGrath, D., Yang, G. and M.A. Ebadian, "Conjugated Heat Transfer in a Concentric AnnularPipe" 27th National Heat Transfer Conference and Exposition, Same paper was accepted for publication by the InternationalJoumal of Nuclear Engineering and Design.

MacGrath, D., Yang, G. and M. A. Ebadian, "The Effects of Mixed Boundary Conditions on the Conjugated Heat Transfer in a Concentric Annulus," ASME Winter Annual Meeting, Atlanta, GE, December, 1991. (Accepted for presentation) Also submitted to ASME Journal of Heat Transfer.

Cline, D., Ebadian, M. A., Bigzadeh, E., and G. Yang, "The Effects of the Activity Coefficient on the Evaporation of Liquid Nuclear Waste," Int. Joumal of Nuclear Engineering and Design (submitted).

Ebadian, M. A, Bigzadeh, E., Yang, G. and D. L. Cline, "Chemical and Evaporative Changes of Synthetic Liquid Nuclear Waste," Int. Joumal of Nuclear Engineering and Design (submitted). 


\section{TABLE OF CONTENTS}

ABSTRACT OF THE THESIS . i

DEDICATIONPAGE iii ACKNOWLEDGEMENTS iv

PUBLICATIONS AND PRESENTATIONS v

TABLE OF CONTENTS vii

LIST OF FIGURES $\mathbf{x}$

LIST OFTABLES xii

NOMENCLATURE xiv

\section{Chapter 1}

\section{INTRODUCTION}

\section{Chapter 2}

EXPERIMENTAL APPARATUS AND PROCEDURE ................4 4

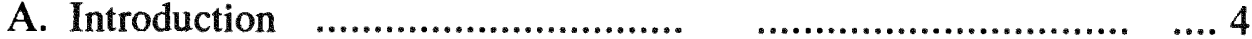

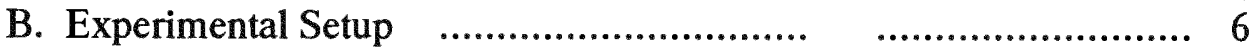

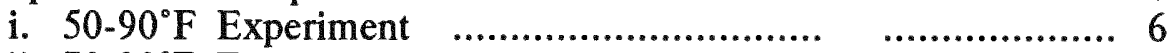

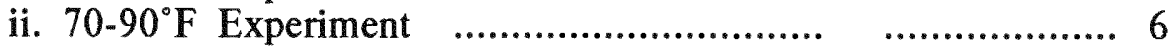

\section{Chapter 3}

RESULTS AND DISCUSSIONS F...................................... 9

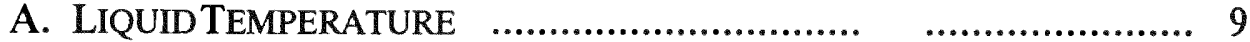

I. Introduction ...................................................... 9

II. Discussion of Results ............................. .................. 9

i. $50-90^{\circ} \mathrm{F}$ Experiment $\quad$............................................ 9

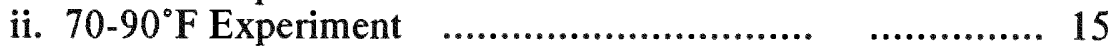

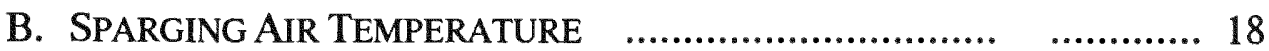

I. Introduction ..................................................... 18

II. Discussion of Results ........................................ 18

C. SOLUTION PH I............................... …............................ ... 27

I. Introduction .............................. .......................... 27

II. Discussion of Results ............................. ................. 27

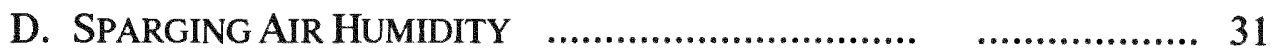

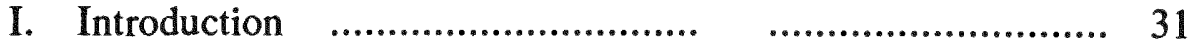

II. Discussion of Results ............................ . ............... 32 


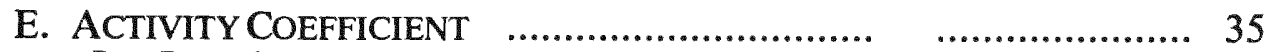

I. Introduction .............................................................. 35

II. Development of Equations According to Meissner and Tester (1972)

III. Development of Equations According to Pitzer and Kim (1974) ......................................................... 40

IV. Comparison of Models _.......................................... 45

V. Vapor Pressure Lowering as Predicted by the Activity Coefficient

F. PRECIPITATION AND CRYSTALLIZATION $\quad$................................ 53

I. Introduction .......................................................... 53

II. Observations …............................ ............................ 53

III. Analysis ............................. .............................. . . 55

\section{Chapter 4}

LARGE SCALE SIMILITUDEMODEL $\quad$....................................6 67

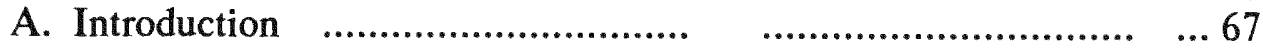

I. Dimensional Analysis [........................................... 67

II. Actual Model of MVSTs .............................................. 69

III. Experimental Model .............................. .................. 70

B. Experimental Procedure $\quad$....................................................... 71

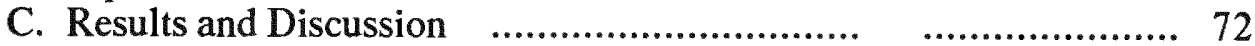

\section{Chapter 5}

CONCLUSION

\section{Bibliography}

\section{Appendix}

\section{A. INSTRUMENTATION:}

METHODS AND MODES OF MEASUREMENT

I. Small Scale Evaporative Model
a. Air Dryer
b. Balance
c. Flow Rate
d. pH Meter
e. Scanning Electron Microscope
f. Solution Cooling/Heating Method
g. Solution Filtering Method
h. Solution Sparging Containers
i. Sparging Air
j. Temperature Measurement and Recording
k. Variable Temperature of the Sparging Air
1. X-Ray Diffractometer 
II. Large Scale Similitude Model
a. Air Compressor
b. Air Dryer/Extractor
c. Pressure Transducers DP154 and DP1033
d. Air Preheater
e. Liquid Heater
f. Hewlett Packard Data Acquisition System(HP - 3852A)
g. Relative Humidity Transmitter

B. PSYCHOMETRIC CHART

..... 84

C. Computer Program For the CAlCulation of the

ACTIVITY COEFFICIENT 


\section{LIST OF FIGURES}

Figure 1. Test apparatus with sparging system..

Figure 2. Cumulative evaporation/condensation(-) of SNW supernatant as a function of $\mathrm{T}_{5}$.

Figure 3. Cumulative evaporation/condensation(-) of deionized $\mathrm{H}_{2} \mathrm{O}$ as a function of $\mathrm{T}_{5}$

Figure 4. Cumulative evaporation/condensation(-) of SNW unfiltered as a function of $\mathrm{T}_{5}$

Figure 5. Effects of liquid temperature on the evaporation rate

A. Liquid temperature, $T_{5}=50^{\circ} \mathrm{F}$

B. Liquid temperature, $\mathrm{T}_{5}=90^{\circ} \mathrm{F}$.

Figure 6. Effects of liquid temperature on the evaporation rate

A. Liquid temperature, $\mathrm{T}_{5}=50^{\circ} \mathrm{F}$

B. Liquid temperature, $\mathrm{T}_{5}=90^{\circ} \mathrm{F}$.

Figure 7. Effects of sparging air temperature on the evaporation rate at $T_{5}=70^{\circ} \mathrm{F}$

A. Liquid temperature, $\mathrm{T}_{3}=73.5^{\circ} \mathrm{F}$

B. Liquid temperature, $\mathrm{T}_{5}=125^{\circ} \mathrm{F}$.

Figure 8. Effects of sparging air temperature on the evaporation rate at $\mathbf{T}_{5}=90^{\circ} \mathrm{F}$

A. Liquid temperature, $\mathrm{T}_{5}=73.5^{\circ} \mathrm{F}$

B. Liquid temperature, $\mathrm{T}_{5}=125^{\circ} \mathrm{F}$.

Figure 9. Cumulative evaporation of SNW supernatant as a function of $\mathrm{T}_{3}$ and $\mathrm{T}_{5}$.

Figure 10. Cumulative evaporation of deionized $\mathrm{H}_{2} \mathrm{O}$ as a function of $\mathrm{T}_{3}$ and $\mathrm{T}_{5} \ldots \ldots \ldots 25$

Figure 11. Cumulative evaporation of $\mathrm{SNW}$ unfiltered as a function of $\mathrm{T}_{3}$ and $\mathrm{T}_{5}, \ldots \ldots 26$

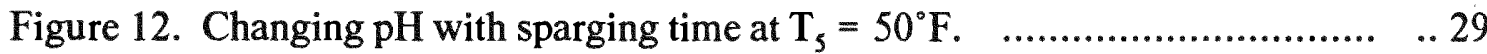

Figure 13. Effects of sparging air humidity on the evaporation rate. ..................... 34

Figure 14. Activities of water for aqueous solutions of pure electrolytes at ionic strengths of 2.0 to 20.0 molal.

Figure 15. Plot of $\Gamma$ versus $\mu$ over an ionic strength range of 0.1 to 2.0 molal. 39

Figure 16. Activity of water versus sodium nitrate concentration as a function of liquid temperature. 
Figure 17. Vapor pressure lowering of water versus sodium nitrate concentration as a function of liquid temperature.

Figure 18. Scanning electron microscope results on the SNW supernatant,

$$
\mathrm{T}_{5}=90^{\circ} \mathrm{F}, \mathrm{T}_{3}=125^{\circ} \mathrm{F} \text {. }
$$

Figure 19. Scanning electron microscope results on the SNW unfiltered,

$$
\mathrm{T}_{5}=90^{\circ} \mathrm{F}, \mathrm{T}_{3}=125^{\circ} \mathrm{F} \text {. }
$$

Figure 20. Scanning electron microscope results on pure Aldrich sodium nitrate, ....... 66

Figure 21. JCPDS diffraction powder file on sodium nitrate. 66 


\section{LIST OF TABLES}

Table I Composition of the Liquid Synthetic Nuclear Waste $\ldots . . . \ldots \ldots \ldots \ldots \ldots . . . . .3$

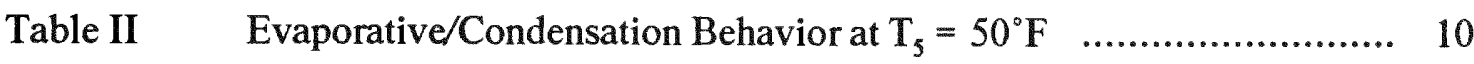

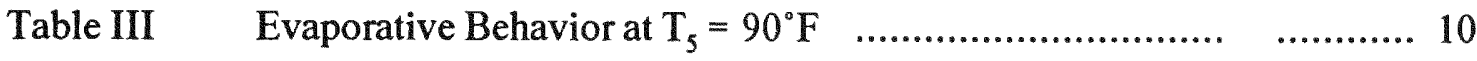

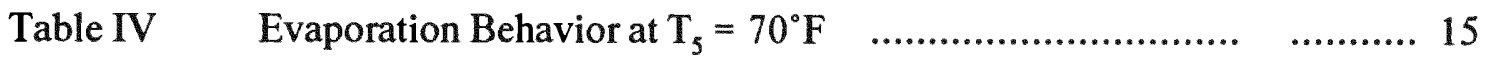

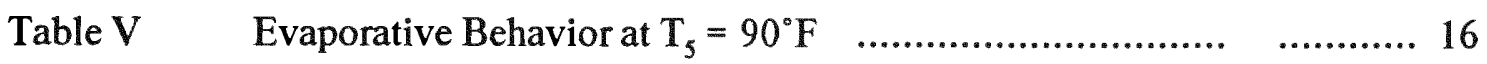

Table VI Evaporation Behavior at $\mathrm{T}_{3}=73.5^{\circ} \mathrm{F}$ and $\mathrm{T}_{5}=70^{\circ} \mathrm{F} \quad \ldots \ldots \ldots \ldots \ldots \ldots$

Table VII Evaporation Behavior at $\mathrm{T}_{3}=125^{\circ} \mathrm{F}$ and $\mathrm{T}_{5}=70^{\circ} \mathrm{F} \quad \ldots \ldots \ldots \ldots \ldots \ldots . \ldots 19$

Table VIII Evaporation Behavior at $\mathrm{T}_{3}=73.5^{\circ} \mathrm{F}$ and $\mathrm{T}_{5}=90^{\circ} \mathrm{F} \quad \ldots \ldots \ldots \ldots \ldots \ldots . \ldots \ldots$

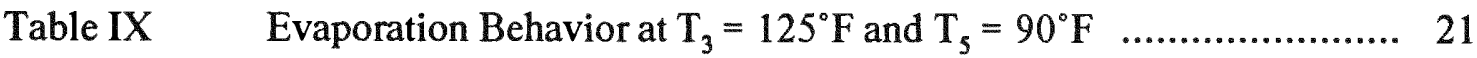

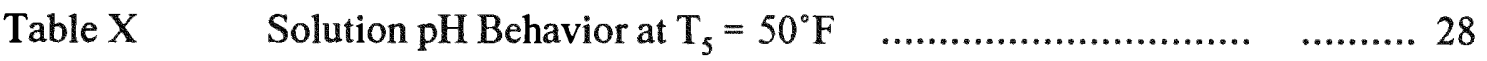

Table XI The Effects of Sparging Air Humidity on SNW Unfiltered at

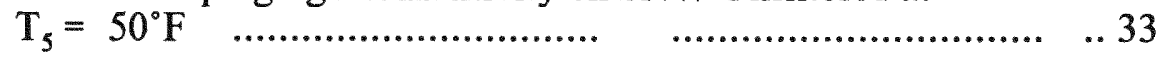

Table XII The Effects of Sparging Air Humidity on SNW Unfiltered at

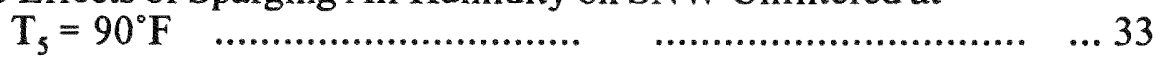

Table XIII Activity Coefficients of $\mathrm{NaNO}_{3}$ Derived From Mesissner and Tester(1972) [....................................................... 38

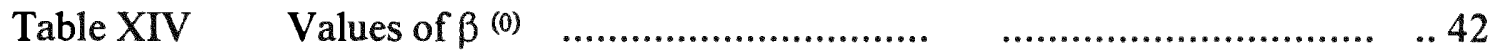

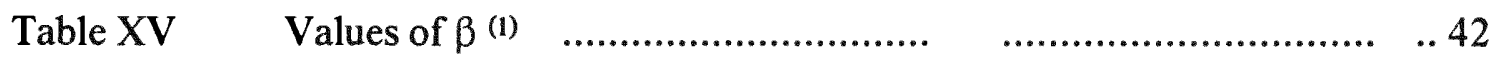

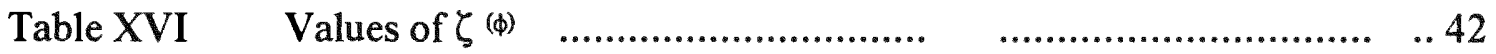

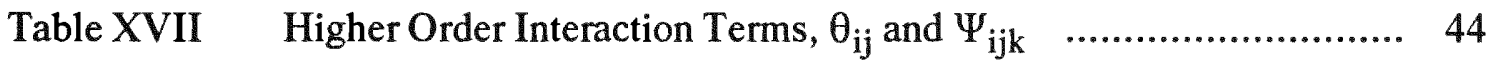

Table XVIII Activity Coefficients Derived From the Pitzer (1974) Equations ....... 45

Table XIX Comparison of Models for the Activity Coefficients of $\mathrm{NaNO}_{3} \ldots \ldots . . .46$

Table XX Activity of Water over a $\mathrm{NaNO}_{3}$ Solution as a Function of Molality and Temperature and Their Effect on Vapor Pressure .... 48

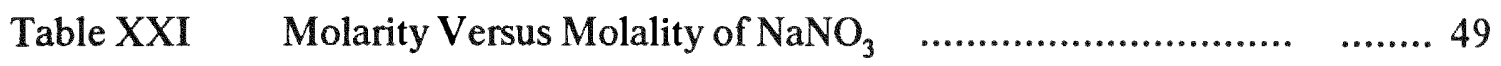


Table XXII Activity of Water over a $\mathrm{NaNO}_{3}$ Solution as a Function of

Molarity and Temperature and Their Effect on Vapor

Pressure

Table XXIII X-Ray Diffraction Results of Pure Aldrich Sodium Nitrate ........... 57

Table XXIV X-Ray Diffraction Results of the Precipitated Blockages in the Sparging Tube of a $4.35 \mathrm{M} \mathrm{NaNO}_{3}$ Solution

Table XXV X-Ray Diffraction Results of the Precipitate Blockages in the Sparging Tube of SNW Supernatant .60

Table XXVI X-Ray Diffraction Results of the Precipitate Blockages in the Sparging Tube of SNW Unfiltered $\ldots 61$

Table XXVII X-Ray Diffraction Results of the Precipitate Formations in SNW Supernatant Solution After Eight Hours of Sparging 62 


\section{NOMENCLATURE}
A
Debye-Hückel constant
a
anion
$a_{i}$
activity of ion, i
B
second viral coefficient related to the interaction of like charged ions
C
third viral coefficient related to triplet interaction
c
cation
cfh
cubic feet per hour $\left[\mathrm{ft}^{3} \mathrm{hr}^{-1}\right]$
cfm
cubic feet per minute $\left[\mathrm{ft}^{3} \mathrm{~min}^{-1}\right]$
D
diameter $[\mathrm{m}]$
d
spacing between a set of planes, Bragg's equation
D.H.
Debye-Hückel constant
$\mathrm{E}$
equivalent molality, $\frac{1}{2} \sum \mathrm{m}_{\mathrm{i}} \mathrm{z}_{\mathrm{i}}$
$\mathbf{F}$
Debye-Hückel constant
$\mathrm{f}^{\gamma}$
coefficient to represent the long-range effect of Coulomb forces
G specific interaction coefficient related to cation-anion interaction
gravitational acceleration $\left[\mathrm{m}^{2} \mathrm{~s}^{-1}\right]$
I
ionic strength, $\frac{1}{2} \sum_{\mathrm{i}} \mathrm{m}_{\mathrm{i}} \mathrm{z}_{\mathrm{i}}^{2}$
ionic component
function related to the electrostatic interaction
length
M
molarity [mol liter $\left.{ }^{-1}\right]$
m
molality [ $\mathrm{mol} \mathrm{kg}^{-1}$ ]

1 
in

MVSTs Melton Valley Storage Tanks

$\mathrm{N}$

$\mathrm{Nu}$

n

ORNL Oak Ridge National Laboratory

$\mathbf{P}$

psia

psig

$\operatorname{Re}$

Sh

SNW

T

$\dot{\mathrm{v}}$

$\mathrm{V}$

W

$\mathrm{X}$

$\mathbf{x}$

Z

\section{Greek Symbols}

$\alpha \quad$ ion size parameter

$\beta$

$\zeta \phi \quad$ constant in third viral coefficient coefficient representing a cation

Nusselt number, $\frac{h \mathrm{D}}{\mathrm{k}}$

integer in Bragg's equation

pressure

pounds per square inch, absolute

pounds per square inch, differential

Reynolds number, $\frac{V D}{v}$

Sherwood number

synthetic nuclear waste

temperature

volume flow rate $\left[\mathrm{m}^{3} \mathrm{~s}^{-1}\right]$

velocity $\left[\mathrm{m} \mathrm{s}^{-1}\right]$

watts

coefficient representing an anion

mole fraction

charge on the ion constant in second viral coefficient 


$\begin{array}{ll}\phi^{*} & \begin{array}{c}\text { coefficient related to the electrostatical unsymmetrical } \\ \text { mixing }\end{array} \\ \gamma_{\mathrm{i}} & \text { relative humidity } \\ \gamma_{\mathrm{NX}} & \text { activity coefficient of an ion } \\ \lambda & \text { wavelength of incedent beam in Bragg's equation } \\ \theta & \text { angle of incidence in Bragg's equation } \\ \theta^{*} & \text { coefficient related to the interaction of ions } \\ \rho & \text { density } \\ v & \text { moles of an ion formed upon complete dissociation of } \\ & 1 \text { mole of an electrolyte }\end{array}$

\section{Subscripts}

3

inlet sparging air

5

storage tank

35

inlet sparging air for 5 pipes

b

bubble chain

i

ion

tank

storage tank

w

water 


\section{Chapter 1 \\ INTRODUCTION}

Safe storage of nuclear waste is of major concern worldwide. In the past, hazardous waste has been discarded with inadequate precautions. This tragic miscalculation carries over to today where the problems of radioactive waste disposal have yet to be solved. This thesis identifies one resourceful method of controlling the liquid nuclear waste dilemma. Nuclear waste in the liquid state poses a great threat due to its potential of seeping into ground water supplies.

In the late 1960's, the Department of Energy at Oak Ridge National Laboratory (ORNL) designed eight 50,000 gallon storage tanks for low level radioactive waste. These tanks, the Melton Valley Storage Tanks (MVSTs), were designed such that four tanks were placed in two specially made ventilated vaults. Each tank was initially designed with its own ventilation system to purge radiolytic hydrogen and oxygen from the tank. The design induced water removal from the tanks and thus imposed the additional requirement of entraining radioactivity from exiting by the use of demisters and HEPA filters.

Up until 1984, the tanks were prevented from reaching capacity by utilizing the hydrofracture process. However, since 1984, this process has been terminated and no alternative long-term disposal method for liquid radioactive waste has been developed. Thus, the problem at hand is severe. Oak Ridge National Laboratory produces 26,000 gallons of waste per year and the tanks are near capacity. The idea of building additional storage tanks is associated with geological barriers and political harassment. The ideal solution would be to optimize the existing tanks, until a permanent disposal method is operative.

In the transfer of the liquid nuclear waste to the holding tanks, large amounts of water are used to rinse out the solid build up and prevent line clogging. Consequently, the 
concentration of the various nuclear waste constituents are not near their saturation limits. It has been proposed by the principal investigator, Dr. Ebadian, that sparging air be utilized to evaporate the excess water from the holding tanks. As a result, the liquid waste would be minimized and could potentially be stored as conventional solid nuclear waste. Furthermore, the storage capacity of the existing tanks would be increased and fully utilized.

Evaporation of liquid waste from the MVSTs is one method that will be implemented to reduce the volume of the liquid waste stored until a permanent disposal site is in operation. In-tank evaporation of liquid waste will be accomplished by introducing $100 \mathrm{scfm}$ of air into the existing sparged system. The air is sparged into the tank, absorbed by the liquid and is discharged at the top of the tank through a 0.6 -in. diameter off-gas pipe. The saturated effluent air is passed through roughing filters, HEPA filters, demisters, and finally discharged from a 12-ft exhaust stack. The desired rate of evaporation from the tanks is a minimum of 26,000 gallons per year of liquid waste by means of five sparger pipes located in each tank.

Before implementing this proposed evaporation process, bench scale tests must be performed to foresee any problems that may occur and to characterize the evaporative and chemical behavior of this surrogate waste. A non-radioactive surrogate solution, Table I, has been provided by the Chemical and Technology Division of Oak Ridge National Laboratory based on the analysis of one of the holding tanks. 


\section{TABLE 1}

Composition of the Liquid Synthetic Nuclear Waste

\begin{tabular}{|c|c|c|c|c|}
\hline Component & $\frac{\text { grams }}{\text { liter }}$ & $\begin{array}{c}\text { Molecular } \\
\text { Weight } \\
\text { [grams] }\end{array}$ & $\begin{array}{c}\text { Molarity } \\
\text { M }\left[\frac{\mathrm{mol}}{\text { liter }}\right]\end{array}$ & $\begin{array}{l}\text { Molality } \\
\mathrm{m}\left[\frac{\mathrm{mol}}{\mathrm{kg}}\right]\end{array}$ \\
\hline $\mathrm{NaNO}_{3}$ & 370.000 & 85.00 & 4.353 & 5.08 \\
\hline $\mathrm{NaCl}$ & 6.600 & 58.40 & 0.113 & 0.132 \\
\hline $\mathrm{KNO}_{3}$ & 12.900 & 101.10 & 0.128 & 0.149 \\
\hline $\mathrm{CsNO}_{3}$ & 0.022 & 257.00 & $8.56 \times 10^{-5}$ & $9.99 \times 10^{-4}$ \\
\hline $\mathrm{Sr}\left(\mathrm{NO}_{3}\right)_{2}$ & 0.036 & 211.62 & $1.70 \times 10^{-4}$ & $1.98 \times 10^{-4}$ \\
\hline $\mathrm{NaOH}$ & 1.270 & 40.00 & 0.032 & $3.73 \times 10^{-2}$ \\
\hline $\mathrm{Mg}(\mathrm{OH})_{2}$ & 0.380 & 58.30 & $6.52 \times 10^{-3}$ & $7.61 \times 10^{-3}$ \\
\hline $\mathrm{Al}(\mathrm{OH})_{3}$ & 6.960 & 78.00 & 0.089 & 0.104 \\
\hline $\mathrm{CaH}_{2} \mathrm{PO}_{4}$ & 2.190 & 136.05 & 0.016 & $1.87 \times 10^{-2}$ \\
\hline $\mathrm{CaCO}_{3}$ & 0.940 & 100.09 & $9.39 \times 10^{-3}$ & $1.10 \times 10^{-2}$ \\
\hline Bentonite & 1.060 & $\ldots$ & $\ldots$ & $\ldots$ \\
\hline $\mathrm{Ca}(\mathrm{OH})_{2}$ & 1.770 & 74.08 & 0.024 & $2.80 \times 10^{-2}$ \\
\hline $\mathrm{Fe}_{2} \mathrm{O}_{3}$ & 0.300 & 159.70 & $1.88 \times 10^{-3}$ & $2.19 \times 10^{-3}$ \\
\hline
\end{tabular}

The focus of this thesis is to design, evaluate and optimize the bench top models. Factors such as activity coefficient, solution $\mathrm{pH}$, temperature, crystallization and sparging air humidity will be used to characterize the evaporation rate in the total analysis.

The final phase of this thesis report is to test the mathematical modeling results developed by Dr. Bigzadeh and Dr. Yang with the large scale similitude model. The similitude model has been constructed based on the dimensions of the actual existing tanks at Oak Ridge National Laboratory. However, there is one discrepancy, the mathematical modeling is based on the properties of pure water. Thus, an additional purpose of this study is to identify which parameters require modification in the mathematical modeling. 


\section{Chapter 2 \\ EXPERIMENTAL APPARATUS AND PROCEDURE}

\section{A. Introduction}

The Chemical and Technology Division of Oak Ridge National Laboratory provided the composition of the liquid synthetic nuclear waste, (SNW), as presented in Table I of Chapter 1. The chemical and evaporative behavior of SNW is characterized by running, simultaneously, three experimental samples: (i.) SNW unfiltered, (ii.) Deionized $\mathrm{H}_{2} \mathrm{O}$ and (iii.) SNW supernatant. Three controlling parameters are investigated: sparging air temperature, $T_{3}$, liquid temperature, $T_{5}$, and sparging air humidity, $\phi_{3}$. The subscript 3 deontes sparging air and the subscript 5 denotes the liquid temperature. This notation will be demontrated in the figures and throughout this report .

The deionized water, as an experimental sample, serves as a "control" since it has known properties. In addition, the water sample provides a direct observation of the effects of increasing salt concentration on the evaporation rate. The choice of filtering, (SNW supernatant), or not filtering, (SNW unfiltered), the solution was chosen out of curiosity. Vapor pressure lowering, a major controlling parameter on the evaporation rate, is dependent only on the concentration of that which is in solution. Thus, an initial assumption was drawn that the insolubles had no effect on the evaporation rate.

Two series of experiments will be described in the following paragraphs. Essentially the procedures are the same for both experiments; however, experience improved the experimental setup for the second series of experiments. The first series of experiments consisted of comparing the evaporative behaviors between the liquid temperatures of 50 and $90^{\circ} \mathrm{F}$. These temperatures reflect the MVSTs temperature ranges. Fifty degree fahreneit is the minimum temperature of the soil in the winter months wheras $90^{\circ} \mathrm{F}$ is the maximum allowed temperature of the liquid nuclear waste as set by the 
Department of Energy. In addition, the sparging air humidity was varied in the first series of experiments. The second experiment varied both the liquid temperature and the sparging air temperature. The liquid temperature was varied between 70 and $90^{\circ} \mathrm{F}$ and the sparging air temperature was varied between ambient condition and $125^{\circ} \mathrm{F}$. These two experiments will be referred to as the $50-90^{\circ} \mathrm{F}$ Experiment and the $70-90^{\circ} \mathrm{F}$ Experiment, respectively. 


\section{B. Experimental Setup}

\section{i. $50-90^{\circ} \mathrm{F}$ Experiment}

Each of the experimental samples in the $50-90^{\circ} \mathrm{F}$ Experiment had an individual pump which provided a flow rate of $0.0375 \mathrm{scfm}$ at ambient condition. This sparging air is carried through Teflon tubing to the Boriscillicate glass sparging tube. The sparging tube is un-supported, i.e., it is simply placed inside the graduated cylinder. A procedure improved in the second experiment. The initial volume of each experimental sample was $50 \mathrm{ml}$ 's in a $100 \mathrm{ml}$ graduated cylinder. The solution sparging containers were not completely immersed in the water bath, therefore, they did not have a uniform wall temperature. This effects the temperature of the air above the solution which has a direct effect on the evaporation rate. Again, this has been corrected in the succeeding experiment.

Two sparging air humidities were observed, ambient condition, $\phi_{3}=70 \%$, and bone dry sparging air, $\phi_{3}=9 \%$. The bone dry sparging air condition was obtained by sparging the air through sodium hydroxide pellets prior to entering the liquid. As a result, this experimental sample exhibited a lower volume flow rate of $0.0205 \mathrm{scfm}$ and a lower relative humidity ratio of $9 \%$.

\section{ii. $70-90^{\circ} \mathrm{F}$ Experiment}

Figure 1 illustrates the set-up of the $70-90^{\circ} \mathrm{F}$ Experiment. The sparging air is generated by a small compressor, after which, the temperature of the air is regulated. The higher sparging air temperature is obtained by wrapping Thermolyne heating tape around a 2 inch steel pipe. This temperature-controlled air is then divided into three separate flows. Each flow is individually controlled by flow meters meters providing flow rates of $9 \mathrm{scfh}$, or $0.150 \mathrm{scfm}$. The air is then directed towards the three graduated cylinders containing the experimental liquid samples. These cylinders are completely immersed in a recirculating water bath to provide a constant wall temperature throughout the cylinder. The air is sparged through the liquid with the aid of a long Boroscillicate sparging tube 
held by a rubber stopper and placed 1 in. above the bottom surface. The effluent air is released through a smaller tube located just above the surface of the water bath. The initial volume for each of the experimental samples is $70 \mathrm{ml}$.

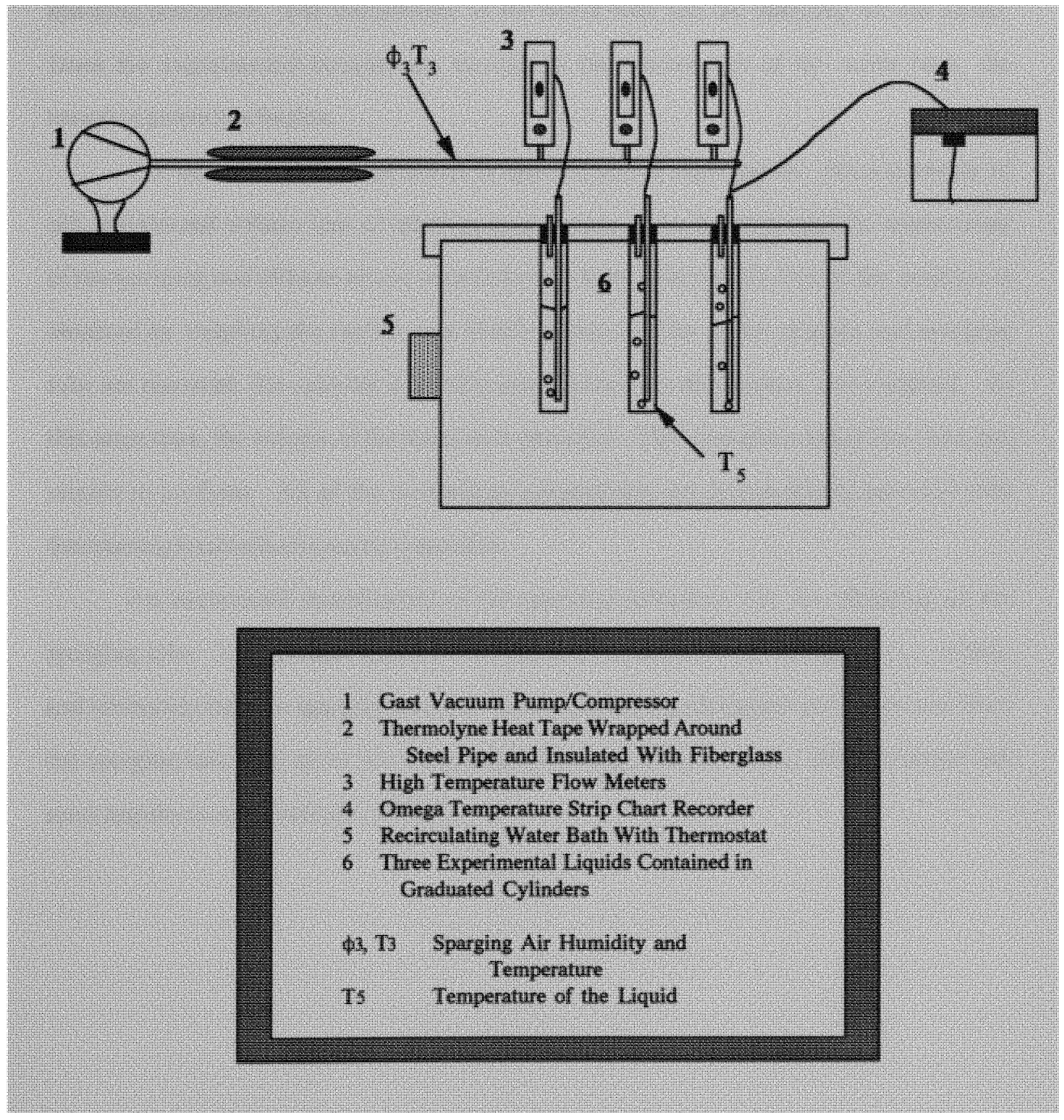

Figure 1. Test apparatus with sparging system. 


\section{Experimental Procedure}

The system, a $100 \mathrm{ml}$ graduated cylinder and its solution, is weighed before and after adding the solution. Thus, the initial weight of the solution is known prior to the sparging procedure. The temperature of the water bath and the sparging air are preset. Once the experimental samples are brought to the temperature of the water bath, the sparging procedure begins.

The duration of the experiment is approximiately eight hours. Measurements of $\mathrm{pH}$, weight and volume loss of solution, temperature of the solution, and the temperature of the sparging and effluent air are recorded every hour. The weight loss of the solution is obtained by weighing the system on a Mettler balance. The rubber stopper and sparging tube are removed, the cylinder is quickly dried, placed on the balance, and weighed. At this same time, the volume of the solution is recorded. This procedure takes less than one minute to perform. All of the controlling temperatures are automatically recorded with thermocouples attached to a strip controller.

An unexpected complication of the sparging procedure was the clogging of the sparging tube. The solution appeared to flux into the outlet of the sparging tube, collect, and ultimately halt the sparging process. These precipitate blockages were removed from the sparging tube and saved for compositional analysis on the $\mathrm{X}$-ray diffractometer and scanning electron microscope, (SEM). 


\section{Chapter 3 \\ RESULTS AND DISCUSSIONS}

\section{A. LIQUID TEMPERATURE}

\section{Introduction}

Increasing the liquid temperature undoubtedly increases the rate of evaporation. In addition, a higher liquid temperature increases the solubility of electrolytes which also enhances the evaporation rate. However, an inverse effect occurs when both the liquid temperature is at $50^{\circ} \mathrm{F}$ and the sparging air is at ambient condition. In this case, there is a net condensation of liquid.

One of the factors which prevents the achievement of a high evaporation rate is the process of the sparging air and effluent air condensating back into the solution. One means of preventing the condensation process is to heat the liquid temperature in the tank. The increased temperature of the liquid simultaneously increases the temperature of the air above the liquid in the tank and of the effluent air.

\section{Discussion of Results}

\section{i. $50-90^{\circ} \mathrm{F}$ Experiment}

There exists extremely different evaporative behaviors between the liquid temperatures of $50^{\circ} \mathrm{F}$, Table II, and $90^{\circ} \mathrm{F}$, Table III. In general, ambient condition air sparged into a liquid at a temperature of $50^{\circ} \mathrm{F}$ undergoes a condensation process, shown in Table II as a negative number. However, at a liquid temperature of $90^{\circ} \mathrm{F}$ there is a net evaporation for all three liquids. 


\section{TABLE II}

Evaporative/Condensation Behavior at $T_{5}=50^{\circ} \mathrm{F}$

\begin{tabular}{|c||c|c|c||}
\hline \multirow{2}{*}{$\begin{array}{c}\text { Cumulative } \\
\text { Air Sparging } \\
\text { Time in Hours }\end{array}$} & \multicolumn{3}{|c|}{$\begin{array}{c}\text { Cumulative Evaporation/ Condensation(-) } \\
\text { in Grams }\end{array}$} \\
\cline { 2 - 4 } & $\begin{array}{c}\text { Deionized } \\
\mathrm{H}_{2} \mathrm{O}\end{array}$ & $\begin{array}{c}\text { Supernatant } \\
\text { SNW }\end{array}$ & $\begin{array}{c}\text { Unfiltered } \\
\text { SNW }\end{array}$ \\
\hline 0 & 0 & 0 & 0 \\
\hline 2 & 0 & - & 0 \\
\hline 3.75 & -0.4 & $-0.60 \pm 0.00$ & $-0.55 \pm 0.07$ \\
\hline 5.75 & -0.6 & $-0.85 \pm 0.21$ & $-0.65 \pm 0.07$ \\
\hline 7.5 & -0.9 & $-1.05 \pm 0.07$ & $-0.80 \pm 0.28$ \\
\hline 9 & -1.0 & $-1.20 \pm 0.14$ & $-0.95 \pm 0.35$ \\
\hline
\end{tabular}

TABLE III

Evaporative Behavior at $\mathrm{T}_{5}=\mathbf{9 0}^{\circ} \mathrm{F}$

\begin{tabular}{||c||c|c|c||}
\hline \multirow{2}{*}{$\begin{array}{c}\text { Cumulative } \\
\text { Air Sparging } \\
\text { Time in Hours }\end{array}$} & \multicolumn{3}{|c|}{$\begin{array}{c}\text { Cumulative Evaporation } \\
\text { in Grams }\end{array}$} \\
\cline { 2 - 4 } & $\begin{array}{c}\text { Deionized } \\
\mathrm{H}_{2} \mathrm{O}\end{array}$ & $\begin{array}{c}\text { Supernatant } \\
\text { SNW }\end{array}$ & $\begin{array}{c}\text { Unfiltered } \\
\text { SNW }\end{array}$ \\
\hline \hline 0 & 0 & 0 & 0 \\
\hline 1 & 2.8 & $2.15 \pm 0.07$ & $1.65 \pm 0.35$ \\
\hline 2.75 & 6.1 & $4.10 \pm 0.14$ & $3.80 \pm 0.28$ \\
\hline 4.5 & 9.5 & $5.70 \pm 0.00$ & $5.90 \pm 0.42$ \\
\hline 6.42 & 13.7 & $7.95 \pm 0.64$ & $8.20 \pm 0.14$ \\
\hline 9 & 19.4 & $9.10 \pm 0.99$ & $10.75 \pm 1.77$ \\
\hline
\end{tabular}

Ambient condition air, $\mathrm{T}_{3}=73.5^{\circ} \mathrm{F}$ and $\Phi_{3}=70 \%$, sparged into a liquid at a temperature of $50^{\circ} \mathrm{F}$ undergoes condensation. This condensation effect was observed for the deionized water and both SNW unfiltered and supernatant. A net weight gain of approximately 1 gram was measured during the 9 hours of sparging for all three liquids, as 
demonstrated in Table II. The condensation behavior is predicted for water upon analyzing the thermodynamic tables. According to the psychometric chart, Appendix B, the moisture in the sparging air with a humidity ratio, $\Phi_{3}=70 \%$, and at a temperature, $T_{3}=73.5^{\circ} \mathrm{F}$, condenses at temperatures lower than $61.7^{\circ} \mathrm{F}$. During the introduction of the sparging air into the liquid its temperature drops below $61.7^{\circ} \mathrm{F}$ because of the lower temperature of the liquid, $50^{\circ} \mathrm{F}$. However, by changing the temperature of the liquid to $90^{\circ} \mathrm{F}$, there is a net evaporation for all three liquids, as demonstrated in Table III. A comparison of the evaporation rates at these two temperatures for the three liquids are demonstrated in Figs.

2,3 and 4.

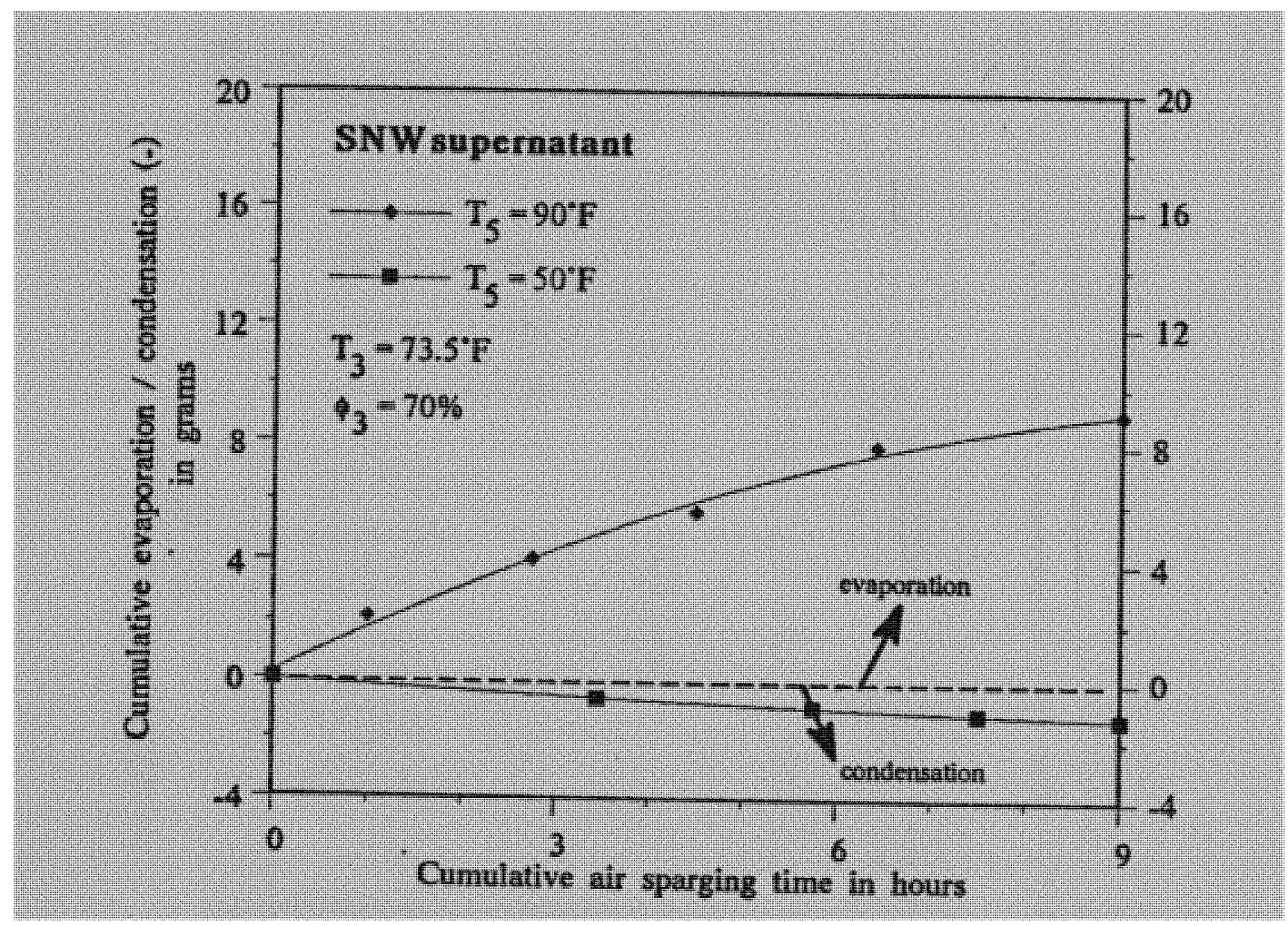

Figure 2. Cumulative evaporation/condensation(-) of SNW supernatant as a function of $T_{5}$. 


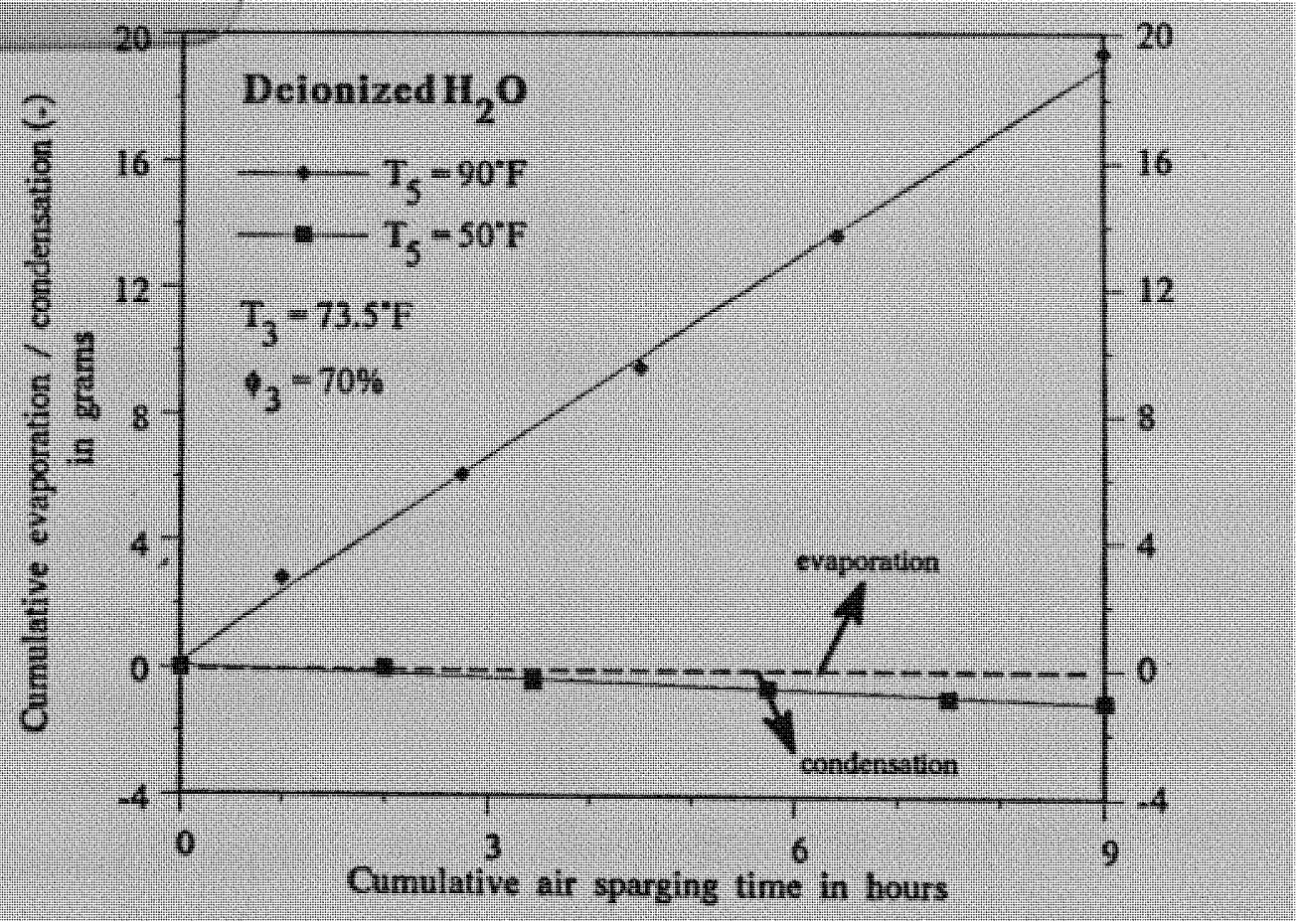

Figure 3. Cumulative evaporation/condensation(-) of deionized $\mathrm{H}_{2} \mathrm{O}$ as a function of $\mathrm{T}_{5}$.

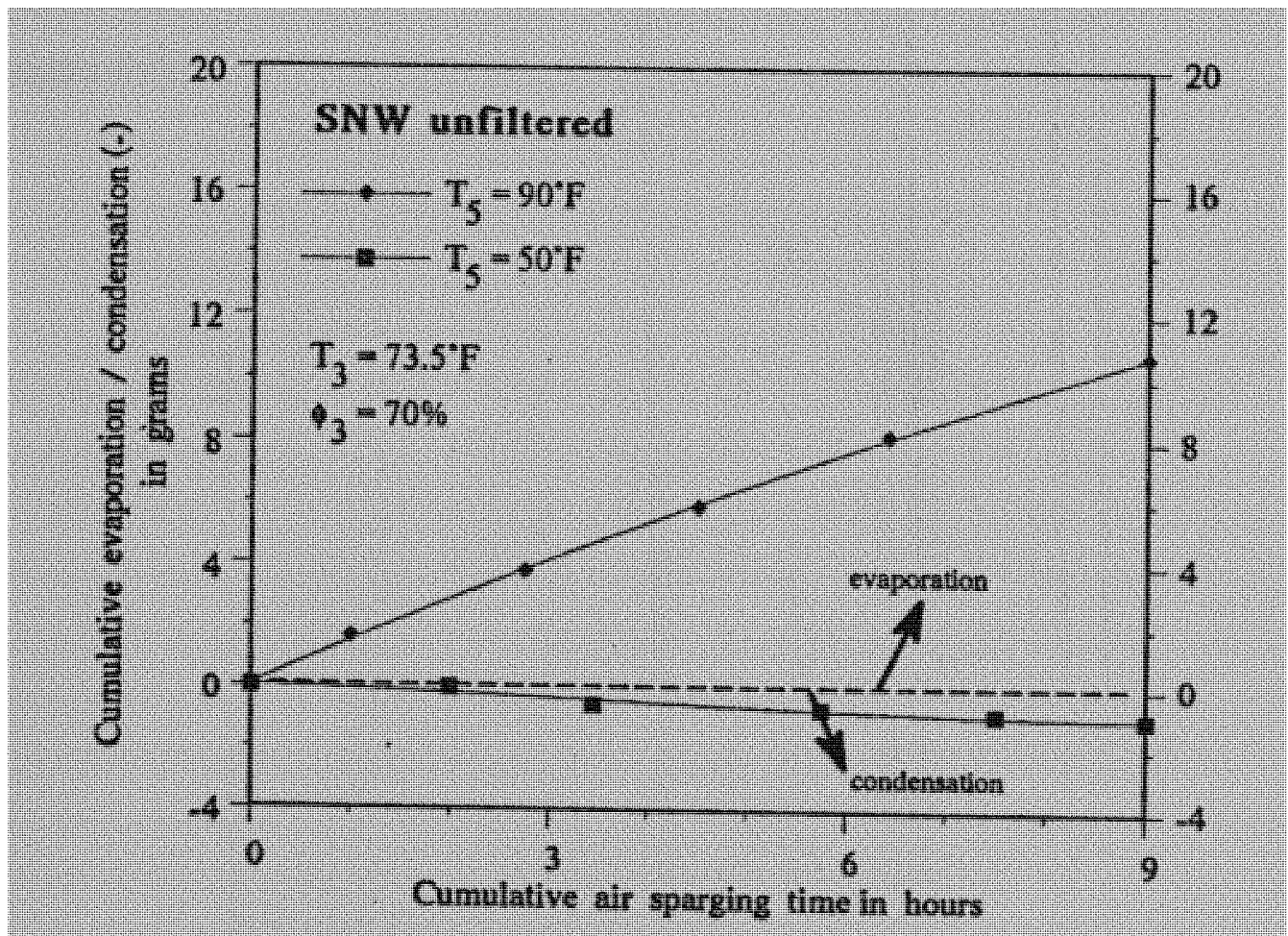

Figure 4. Cumulative evaporation/condensation(-) of SNW unfiltered as a function of $T_{5}$. 
An interesting observation is the linear tendencies of the evaporation with sparging time at $\mathrm{T}_{5}=90^{\circ} \mathrm{F}$ for deionized water as expressed in Fig. 3. Whereas, in Figs. 2 and 4, for the SNW supernatant and unfiltered, the evaporation initially appears linear but levels out after several hours. This tendency of the SNW is dependent on the concentration of the solution. As the solution becomes more concentrated the vapor pressure is simultaneously lowered and the rate of evaporation is decreased.

Figure 5 demonstrates a comparison of the evaporation rate of the three liquids at temperatures of 50 and $90^{\circ} \mathrm{F}$. Figure 5.A. establishes that at a liquid temperature of $T_{5}=$ $50^{\circ} \mathrm{F}$ there is no evaporation, only condensation occurs. However, as shown in Fig. 5.B., at $T_{5}=90^{\circ} \mathrm{F}$ evaporation occurs. In Fig. 5.B., deionized water exhibits the highest rate of evaporation. 


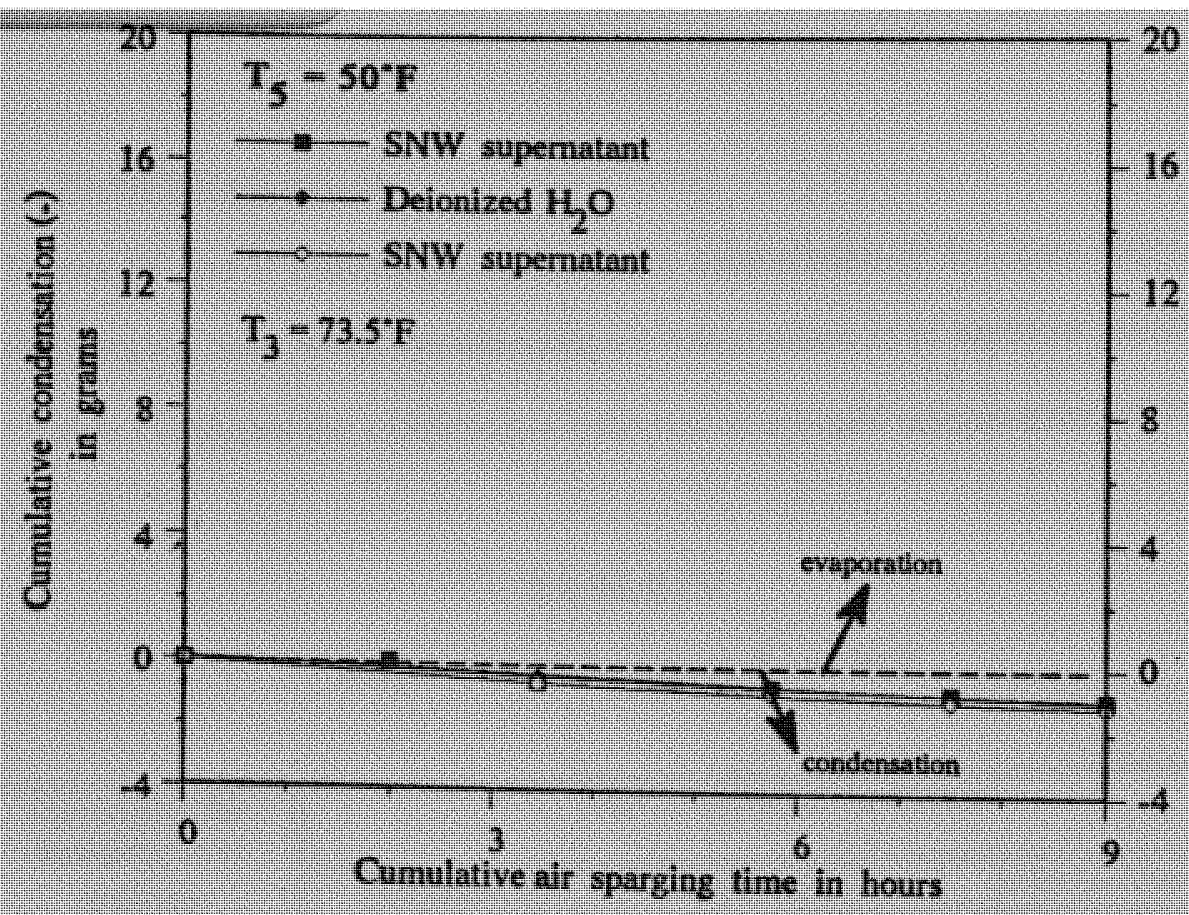

A. Liquid temperature, $T_{5}=50^{\circ} \mathrm{F}$

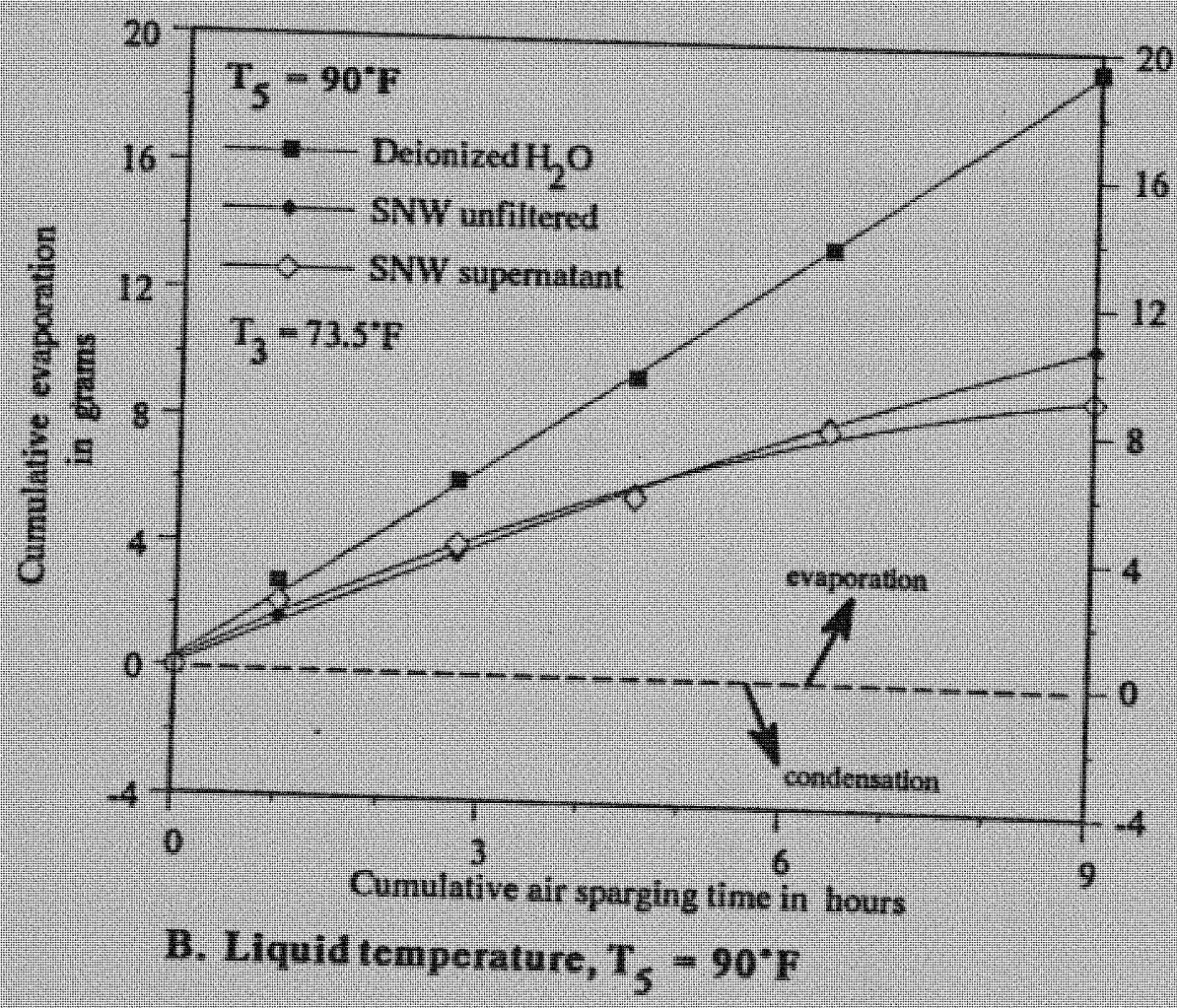

Figure 5. Effects of liquid temperature on the evaporation rate. 


\section{ii. $70-90^{\circ} \mathrm{F}$ Experiment}

Tables IV and V illustrate the cumulative evaporation of the three different liquids versus air sparging time when the sparging air temperature is at ambient condition, $T_{3}=$ $73.5^{\circ} \mathrm{F}$. Table IV shows the evaporation behavior at a liquid temperature of $70^{\circ} \mathrm{F}$ and in Table $\mathrm{V}, 90^{\circ} \mathrm{F}$.

TABLE IV

Evaporation Behavior at $T_{5}=70^{\circ} \mathrm{F}$

\begin{tabular}{||c||c|c|c||}
\hline \multirow{2}{*}{$\begin{array}{c}\text { Cumulative Air } \\
\text { Sparging Time } \\
\text { in Hours }\end{array}$} & \multicolumn{3}{|c|}{ Total Evaporation in Grams } \\
\cline { 2 - 4 } & Deionized $\mathrm{H}_{2} \mathrm{O}$ & SNW Supernatant & SNW Unfiltered \\
\hline 0 & 0 & 0 & 0 \\
\hline 1.03 & 4.4 & 3.5 & 3.0 \\
\hline 2.00 & 7.7 & 5.7 & 5.4 \\
\hline 2.88 & 10.9 & 8.6 & 7.5 \\
\hline 3.89 & 13.7 & 10.3 & 9.6 \\
\hline 5.91 & 19.4 & 13.2 & 12.5 \\
\hline 7.86 & 24.2 & 15.3 & 14.9 \\
\hline
\end{tabular}


TABLE V

Evaporative Behavior at $\mathrm{T}_{5}=90^{\circ} \mathrm{F}$

\begin{tabular}{||c||c|c|c||}
\hline \multirow{2}{*}{$\begin{array}{c}\text { Cumulative Air } \\
\text { Sparging Time } \\
\text { in Hours }\end{array}$} & \multicolumn{3}{|c|}{ Total Evaporation in Grams } \\
\cline { 2 - 4 } & Deionized $\mathrm{H}_{2} \mathrm{O}$ & SNW Supernatant & SNW Unfiltered \\
\hline 0 & 0 & 0 & 0 \\
\hline 1.02 & 9.1 & 11.4 & 11.2 \\
\hline 2.07 & 18.4 & 17.4 & 17.6 \\
\hline 3.04 & 27.2 & 22.0 & 23.7 \\
\hline 3.95 & 35.6 & 27.2 & 27.7 \\
\hline 4.97 & 44.0 & 31.8 & 31.5 \\
\hline 6.09 & 53.5 & 35.1 & 36.5 \\
\hline 8.20 & 71.1 & 37.0 & 37.5 \\
\hline
\end{tabular}

An immediate observation is the great influence the liquid temperature has on the evaporation rate. The sample deionized water has the greatest rate of evaporation in comparison to the other liquids regardless of the liquid temperature, $T_{5}$. A liquid temperature increase of $20^{\circ} \mathrm{F}$, from 70 to $90^{\circ} \mathrm{F}$, increases the amount of evaporation by two orders of magnitude for all the liquids. In addition, note the linear rate of evaporation of the deionized water sample. These same results, although at a much lower volume flow rate, were observed in the $50-90^{\circ} \mathrm{F}$ Experiment. Figures 6.A and 6.B. illustrate the results of Tables IV and V, respectively. 


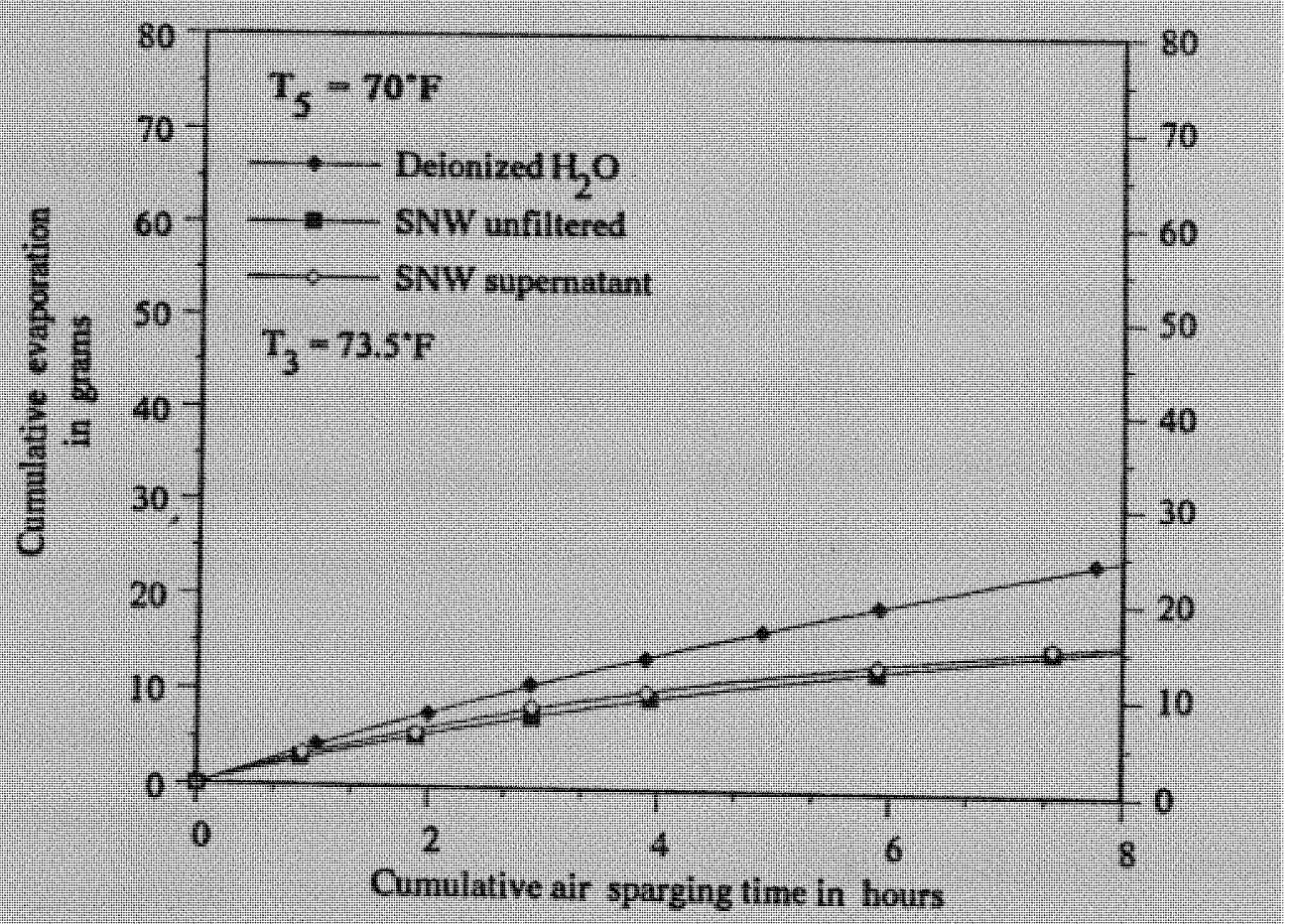

A. Liquid temperature, $T_{5}=70^{\circ} \mathrm{F}$

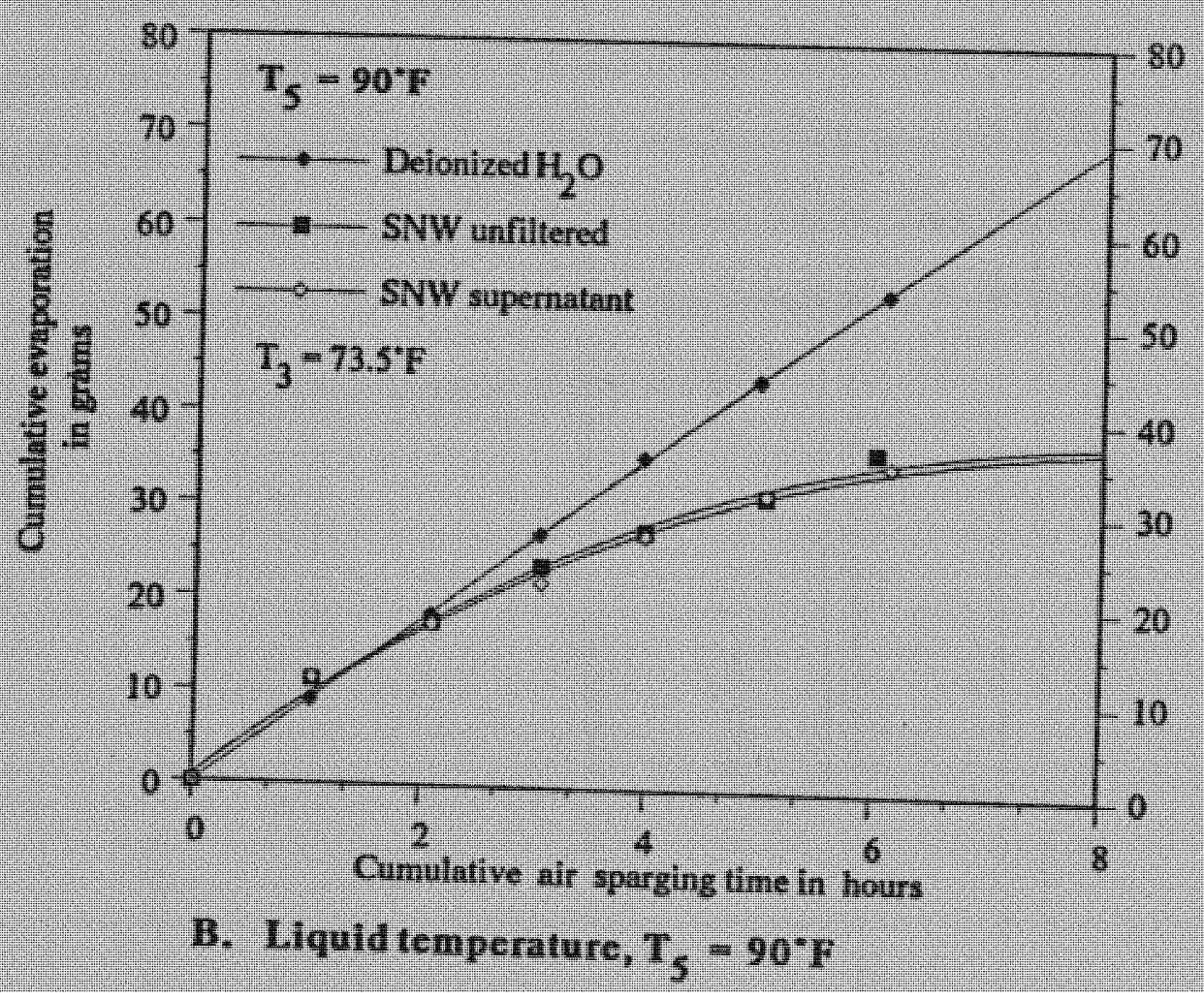

Figure 6. Effects of liquid temperature on the evaporation rate. 


\section{B. SPARGING AIR TEMPERATURE}

\section{Introduction}

The effect of the sparging air temperature on the evaporation process was peculiar. Initially it was thought that the higher sparging air temperature would inhibit the effect of the effluent air condensating and thus provide a greater evaporation rate. However, it appears that a liquid temperature lower than the initial sparging air temperature created an inverse effect. Infact, the sparging pipe, which is at the temperature of the liquid, acts much like a heat exchanger.

\section{Discussion of Results}

Theoretically, evaporation should increase as the sparging air temperature increases. However, the results for the samples deionized water, SNW supernatant, and SNW unfiltered, show that sparging air temperature has a negligible effect on the evaporation rate. Tables VI and VII demonstrate the effects between sparging air temperatures of $\mathrm{T}_{3}=73.5^{\circ} \mathrm{F}$ and $\mathrm{T}_{3}=125^{\circ} \mathrm{F}$ at a liquid temperature of $\mathrm{T}_{5}=70^{\circ} \mathrm{F}$ on the evaporation rate. Table VIII and IX illustrate the respective sparging air temperatures at the liquid temperature, $\mathrm{T}_{5}=90^{\circ} \mathrm{F}$. An immediate observation is the negligible effect the sparging air temperature has on the evaporation rate. 
TABLE VI

Evaporation Behavior at $T_{3}=73.5^{\circ} \mathrm{F}$ and $T_{5}=70^{\circ} \mathrm{F}$

\begin{tabular}{||c||c|c|c||}
\hline \multirow{2}{*}{$\begin{array}{c}\text { Cumulative Air } \\
\text { Sparging Time } \\
\text { in Hours }\end{array}$} & \multicolumn{3}{|c||}{ Cumulative Evaporation in Grams } \\
\cline { 2 - 4 } & Deionized $\mathrm{H}_{2} \mathrm{O}$ & SNW Supernatant & SNW Unfiltered \\
\hline 0 & 0 & 0 & 0 \\
\hline 1.03 & 4.4 & 3.5 & 3.0 \\
\hline 2.00 & 7.7 & 5.7 & 5.4 \\
\hline 2.88 & 10.9 & 8.6 & 7.5 \\
\hline 3.89 & 13.7 & 10.3 & 9.6 \\
\hline 5.91 & 19.4 & 13.2 & 12.5 \\
\hline 7.76 & 24.2 & 15.3 & 14.9 \\
\hline
\end{tabular}

TABLE VII

Evaporation Behavior at $T_{3}=125^{\circ} \mathrm{F}$ and $T_{5}=70^{\circ} \mathrm{F}$

\begin{tabular}{|c||c|c|c||}
\hline \multirow{2}{*}{$\begin{array}{c}\text { Cumulative Air } \\
\text { Sparging Time } \\
\text { in Hours }\end{array}$} & \multicolumn{3}{|c||}{ Cumulative Evaporation in Grams } \\
\cline { 2 - 4 } & Deionized $\mathrm{H}_{2} \mathrm{O}$ & SNW Supernatant & SNWUnfiltered \\
\hline 0 & 0 & 0 & 0 \\
\hline 0.88 & 3.2 & 2.1 & 2.8 \\
\hline 1.89 & 6.0 & 4.6 & 5.3 \\
\hline 2.90 & 9.0 & 6.3 & 7.2 \\
\hline 2.91 & 11.7 & 9.7 & 7.5 \\
\hline 4.86 & 16.5 & 10.9 & 9.3 \\
\hline 7.40 & 20.6 & 14.7 & 14.5 \\
\hline
\end{tabular}




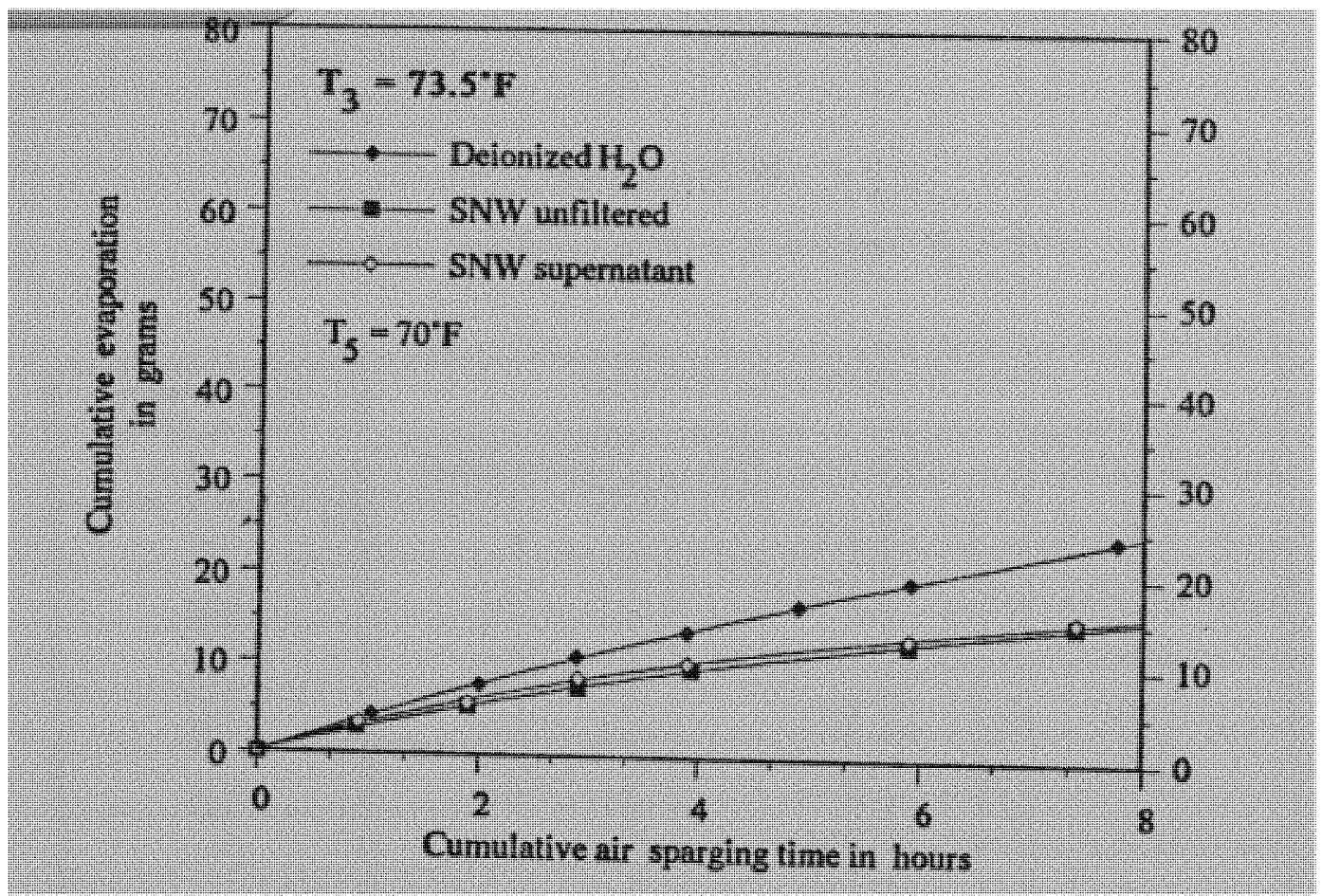

A. Sparging air temperature, $T_{3}=73.5^{\circ} \mathrm{F}$

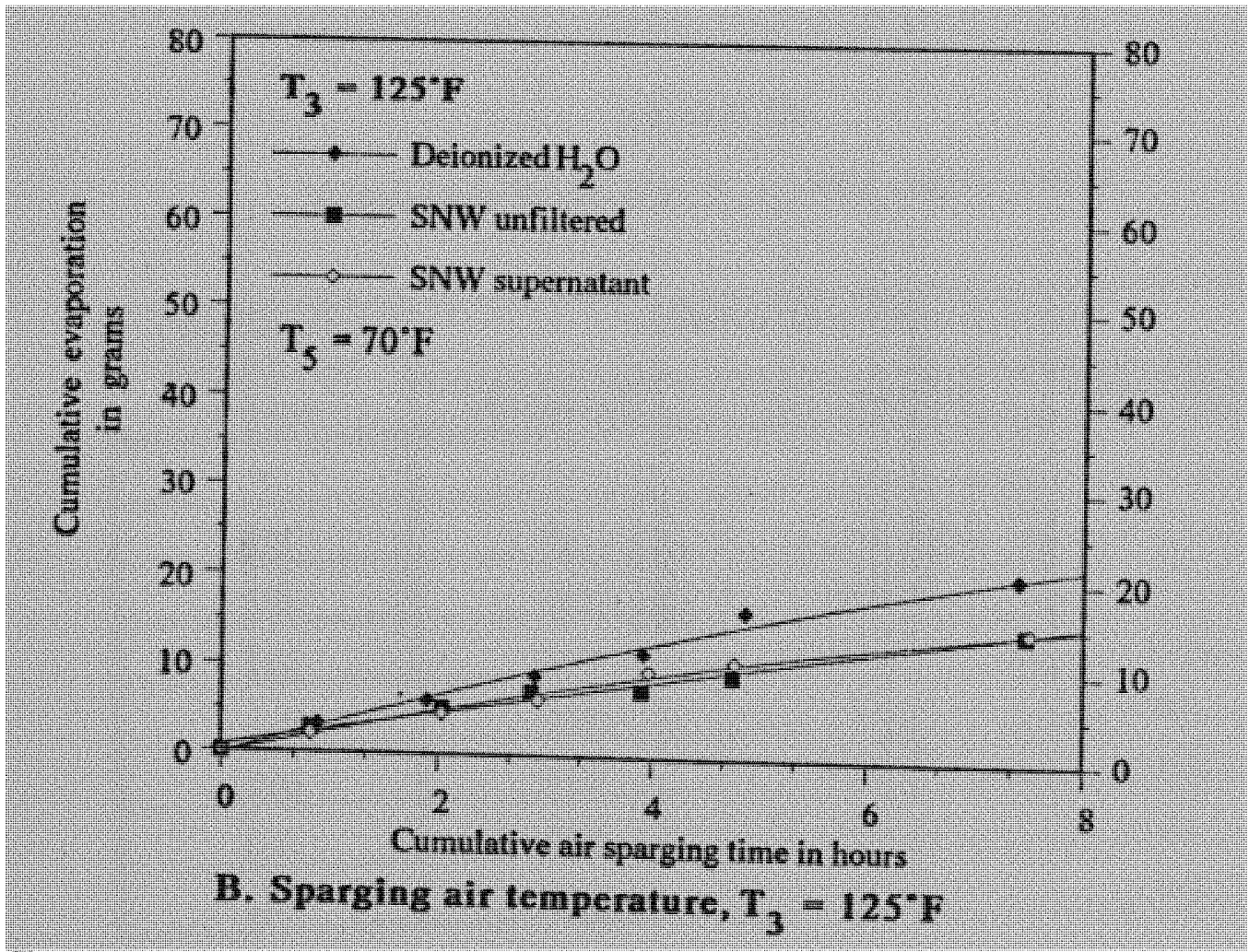

Figure 7. Effects of sparging air temperature on the evaporation rate at $\mathrm{T}_{5}=70^{\circ} \mathrm{F}$. 
TABLE VIII

Evaporation Behavior at $T_{3}=73.5^{\circ} \mathrm{F}$ and $T_{5}=90^{\circ} \mathrm{F}$

\begin{tabular}{||c||c|c|c||}
\hline \multirow{2}{*}{$\begin{array}{c}\text { Cumulative Air } \\
\text { Sparging Time } \\
\text { in Hours }\end{array}$} & \multicolumn{3}{|c|}{ Cumulaitve Evaporation in Grams } \\
\cline { 2 - 4 } & Deionized $\mathrm{H}_{2} \mathrm{O}$ & SNW Supernatant & SNW Unfiltered \\
\hline 0 & 0 & 0 & 0 \\
\hline 1.02 & 9.1 & 11.4 & 11.2 \\
\hline 2.07 & 18.4 & 17.4 & 17.6 \\
\hline 3.04 & 27.2 & 22.0 & 23.7 \\
\hline 3.95 & 35.6 & 27.2 & 27.7 \\
\hline 4.97 & 44.0 & 31.8 & 31.5 \\
\hline 6.09 & 53.5 & 35.1 & 36.5 \\
\hline 8.20 & 71.1 & 37.0 & 37.5 \\
\hline
\end{tabular}

TABLE IX

Evaporation Behavior at $T_{3}=125^{\circ} \mathrm{F}$ and $T_{5}=90^{\circ} \mathrm{F}$

\begin{tabular}{||c||c|c|c||}
\hline \multirow{2}{*}{$\begin{array}{c}\text { Cumulative Air } \\
\text { Sparging Time } \\
\text { in Hours }\end{array}$} & \multicolumn{3}{|c|}{ Cumulative Evaporation in Grams } \\
\cline { 2 - 4 } & Deionized $\mathrm{H}_{2} \mathrm{O}$ & SNW Supernatant & SNW Unfiltered \\
\hline 0 & 0 & 0 & 0 \\
\hline 1.23 & 9.7 & 9.1 & 11.1 \\
\hline 2.23 & 17.9 & 15.4 & 16.9 \\
\hline 3.12 & 24.9 & 20.2 & 21.6 \\
\hline 4.03 & 33.0 & 24.4 & 26.2 \\
\hline 5.00 & 41.2 & 29.3 & 30.9 \\
\hline 6.11 & 50.8 & 33.5 & 35.8 \\
\hline 6.62 & 54.5 & 35.4 & 38.0 \\
\hline
\end{tabular}




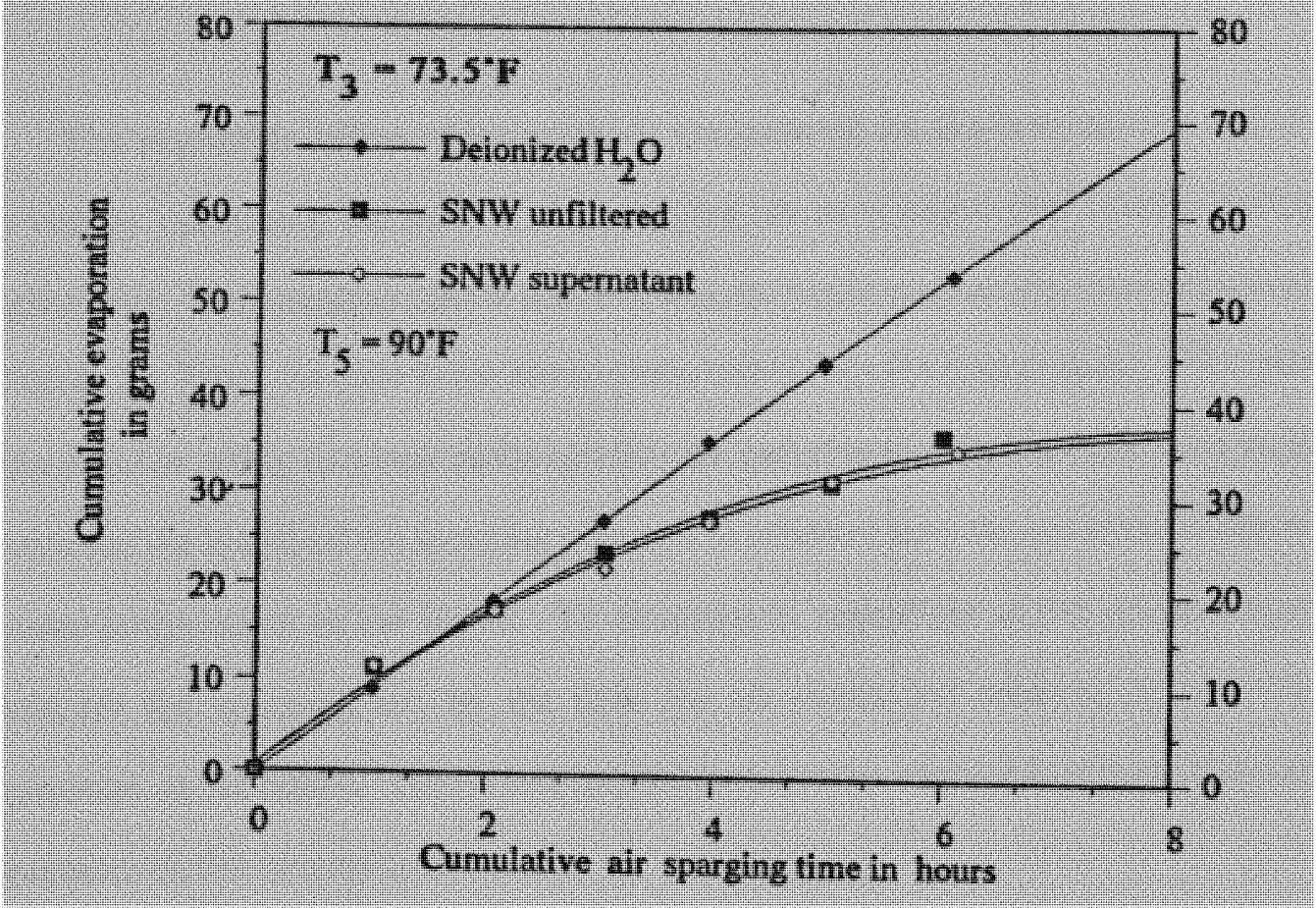

\section{A. Sparging air temperature, $\mathbf{T}_{3}=73.5^{\circ} \mathrm{F}$}

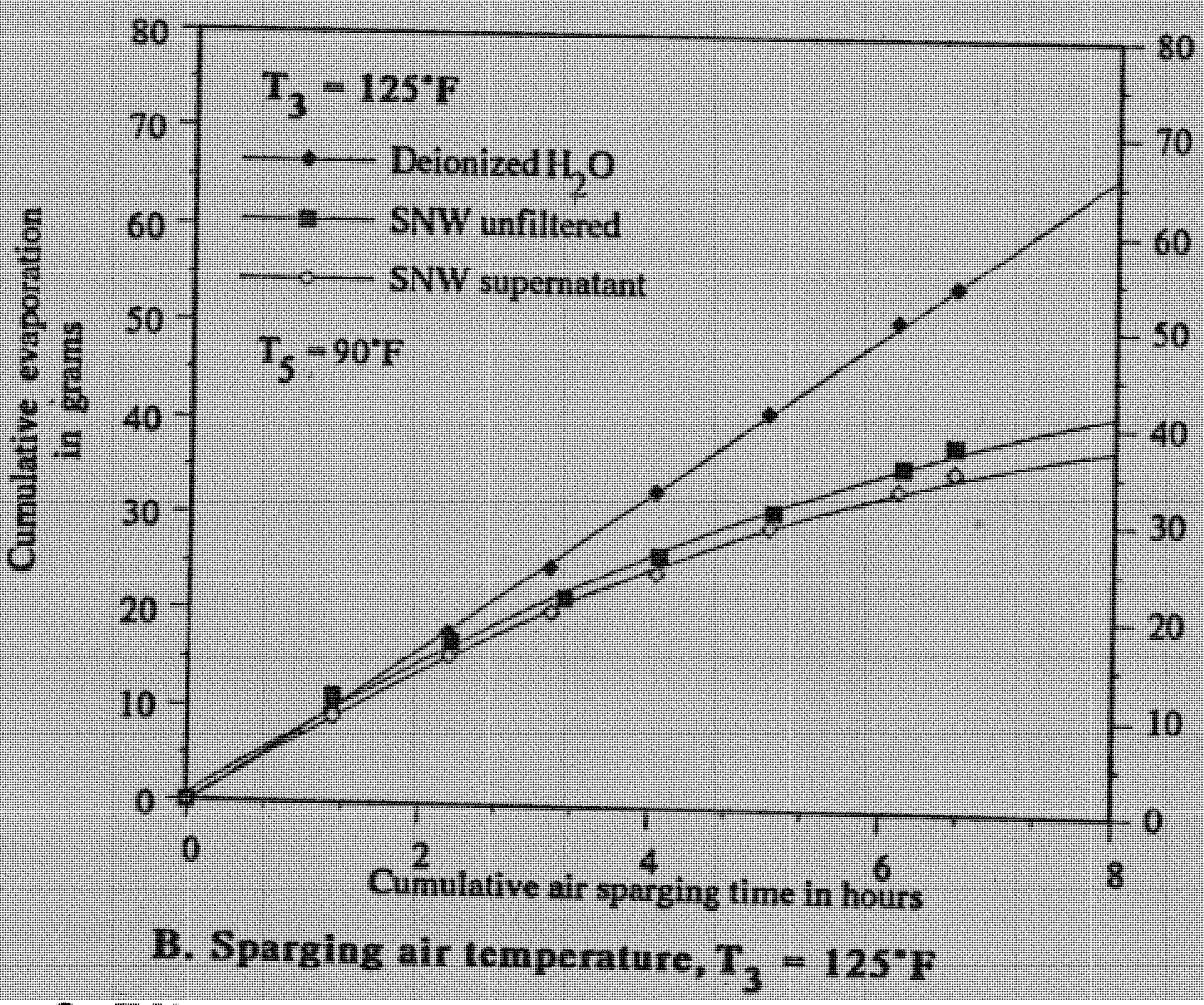

Figure 8 . Effects of sparging air temperature on the evaporation rate at $\mathrm{T}_{5}=90^{\circ} \mathrm{F}$. 
The negligible effect of sparging air temperature on the evaporation rate may be observed by examining the path of the sparging air as it enters and travels through the sparging pipe. The sparging pipe is immersed in the liquid and has the same temperature of the liquid, $T_{5}$. Thus, the pipe has a lower temperature than the sparging air. The pipe may be described as acting as a heat exchanger for the sparging air. By the time the sparging air has traveled the length of the sparging pipe and is released into the solution, it has reached the same temperature as the liquid. To summarize, regardless of the initial temperature chosen for the sparging air, by the time the air enters the solution, it has the same temperature as the liquid. This is one explanation for the negligible effect of sparging air temperature on the evaporation.

Figures 9 through 11 sum up the difference between the liquid temperatures of 70 and $90^{\circ} \mathrm{F}$ and sparging air temperatures of 73.5 and $125^{\circ} \mathrm{F}$ for the three different liquids. These figures also demonstrate that the lower sparging air temperature of $73.5^{\circ} \mathrm{F}$ results in a slightly higher evaporation rate than that of $90^{\circ} \mathrm{F}$. In addition to the pipe acting as a heat exchanger, the lower evaporation rate with the higher sparging air temperature is also attributed to the decreasing mass flow rate with increasing air temperature. When the sparging air has a higher temperature, the volume flow rate must be increased such that the mass flow rate is invariant with temperature. The increased temperature lowers the density of the air. Calculations were performed, and based on the temperature of the sparging air, the volume flow rate was adjusted.

Additional experimental error can be attributed to the fact that each experimental procedure was performed on different days; thus, the ambient temperature and relative humidity were fluctuating with each experiment. 


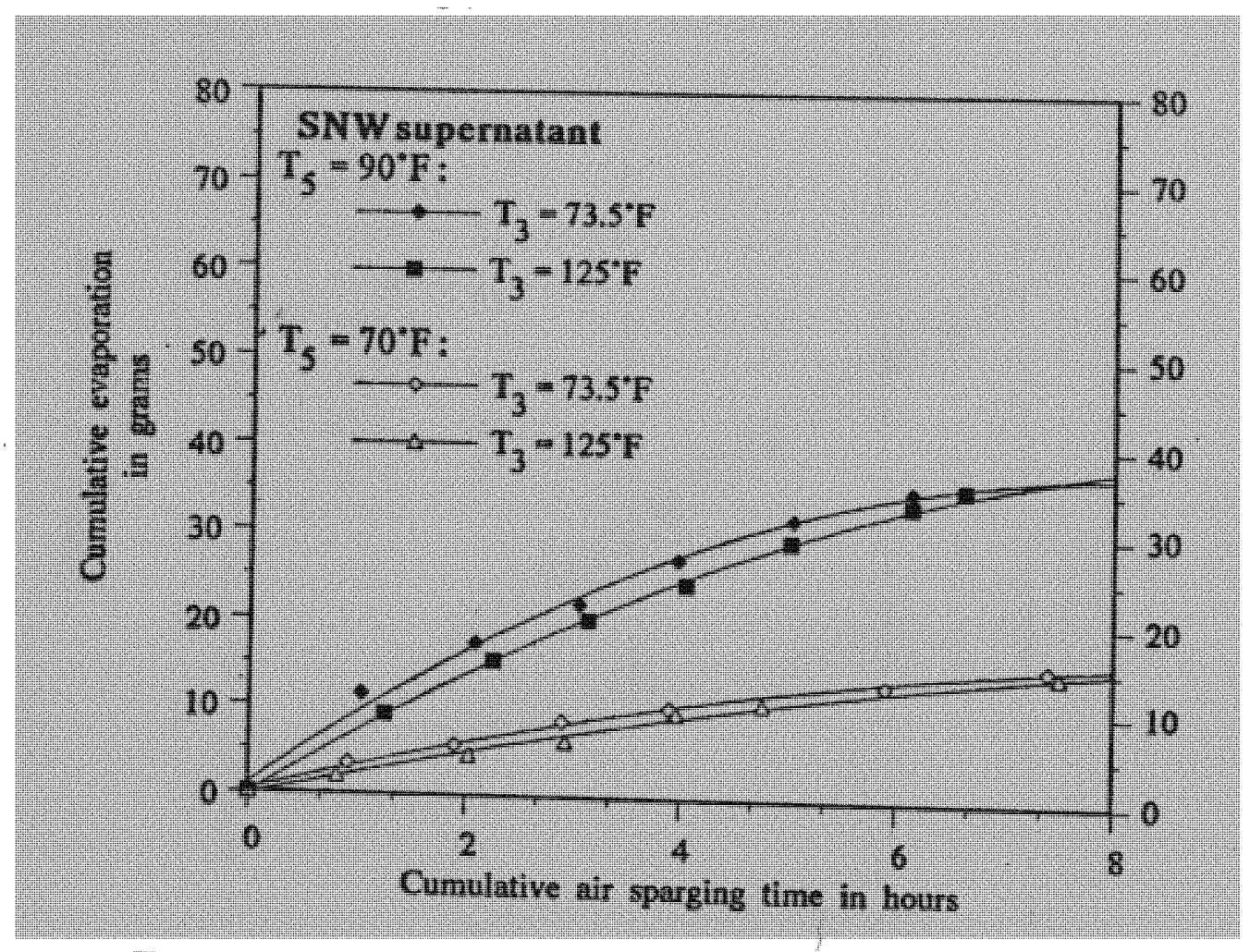

Figure 9. Cumulative evaporation of SNW supernatant as a function of $T_{3}$ and $T_{5}$. 


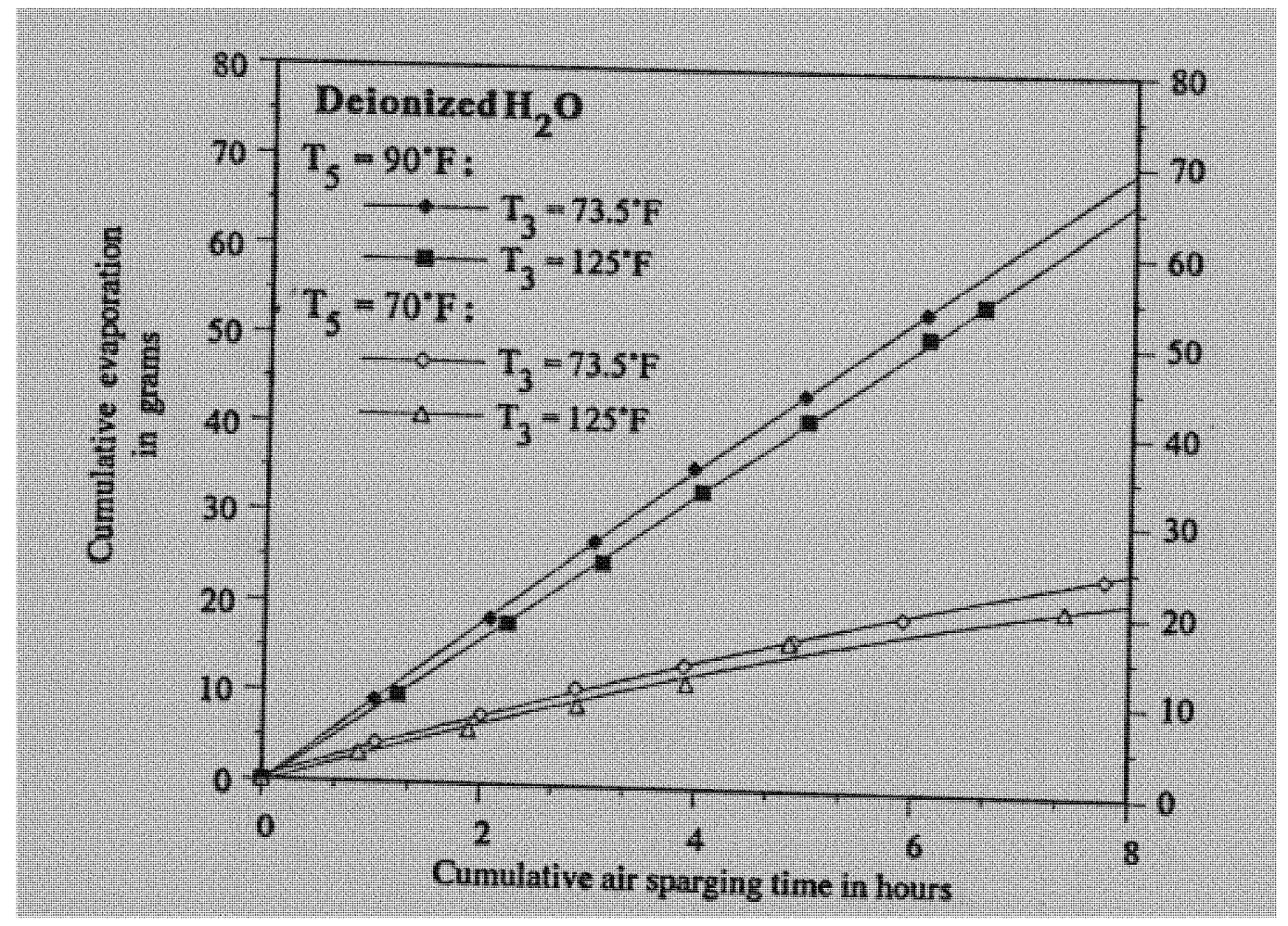

\section{Figure 10. Cumulative evaporation of deionized $\mathrm{H}_{2} \mathrm{O}$ as a} function of $T_{3}$ and $T_{5}$. 


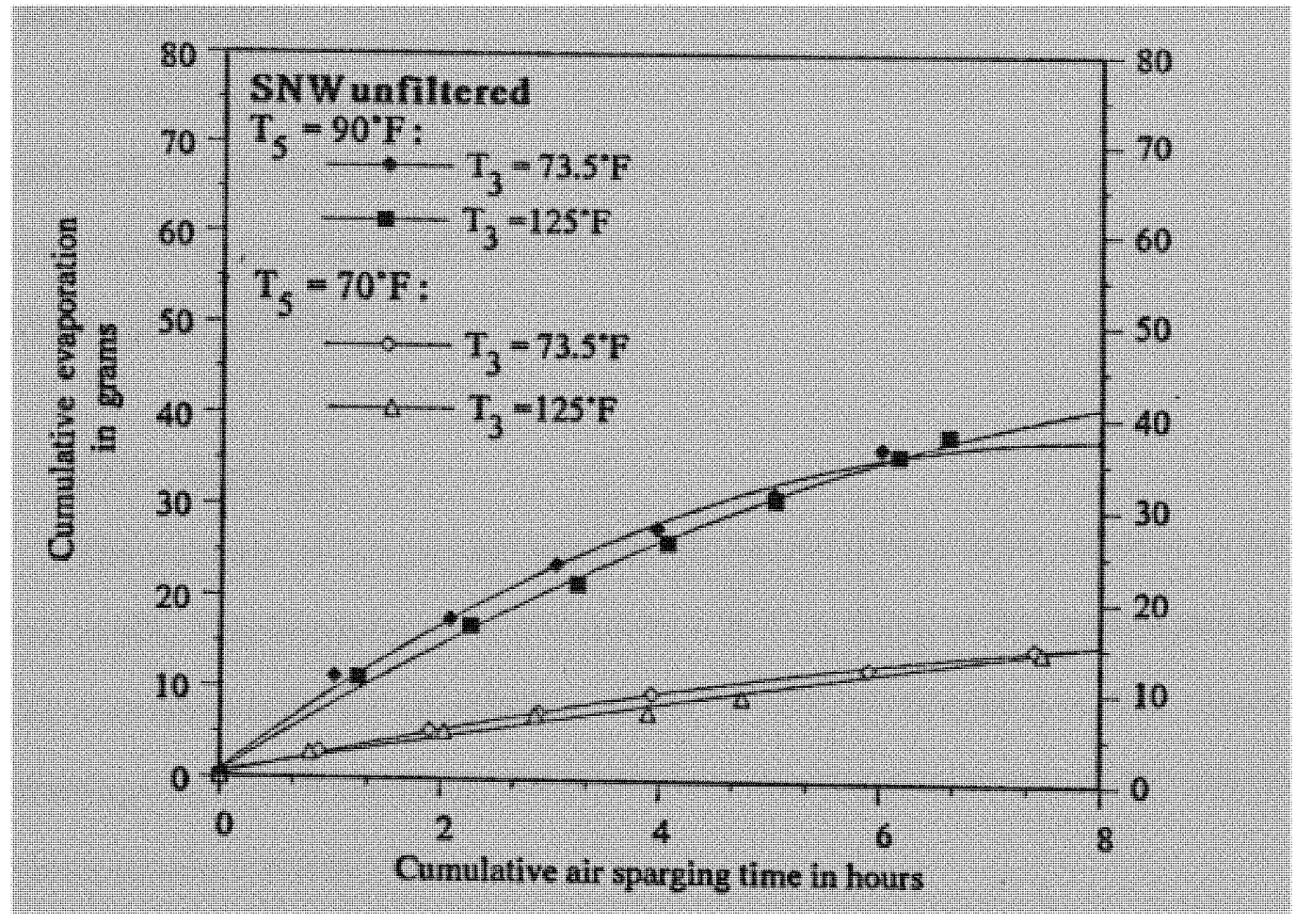

Figure 11. Cumulative evaporation of SNW unfiltered as a function of $T_{3}$ and $T_{5}$. 


\section{SOLUTION PH \\ I. Introduction}

The acidity or basicity of water is expressed as the concentration of free hydrogen or hydroxyl ions in solution. The equilibrium concentrations of hydrogen ions $\left[\mathrm{H}^{+}\right]$in aqueous solutions are expressed in terms of $\mathrm{pH}$. The $\mathrm{pH}$ is defined as the negative $\log$ of the hydrogen ion activity:

$$
\mathrm{pH}=-\log \left[\mathrm{a}_{\mathrm{H}^{+}}\right]
$$

The presence of $\mathrm{CO}_{2}$ in the sparging air causes a very basic solution to become neutral in $\mathrm{pH}$. This lowering of the $\mathrm{pH}$ occurs with $\mathrm{CO}_{2}$ acting as the catalyst and causing $\mathrm{NaCO}_{2}$ 's to precipitate out of solution. Thus, as will be presented in this chapter, by eliminating $\mathrm{CO}_{2}$ from the sparging line prior to entering the solution caused the solution $\mathrm{pH}$ to remain invariant with time.

\section{Discussion of Results}

As presented in Table X, solution pH dropped approximately 2 points in 9 hours for all the experimental samples, except when the sparging air was bone-dry, $\phi_{3}=9 \%$. The solution $\mathrm{pH}$ was monitored with a Hanna portable $\mathrm{pH}$ meter. This $\mathrm{pH}$ meter features a digitized readout and has automatic temperature compensation. 


\section{TABLE X}

Solution pH Behavior at $T_{5}=50^{\circ} \mathrm{F}$

\begin{tabular}{|c|c|c|c|}
\hline \multirow{3}{*}{$\begin{array}{l}\text { Cumulative } \\
\text { Sparging } \\
\text { Air Time } \\
\text { in Hours } \\
\end{array}$} & \multicolumn{3}{|c|}{ Solution $\mathrm{pH}$} \\
\hline & \multicolumn{2}{|c|}{$\phi_{3}=70 \%$} & $\phi_{3}=9 \%$ \\
\hline & $\begin{array}{c}\text { Supernatant } \\
\text { SNW } \\
\end{array}$ & $\begin{array}{c}\text { Unfiltered } \\
\text { SNW } \\
\end{array}$ & $\begin{array}{c}\text { Unfiltered } \\
\text { SNW } \\
\end{array}$ \\
\hline 0 & $10.96 \pm 0.09$ & $11.30 \pm 0.04$ & 11.48 \\
\hline 2 & $10.34 \pm 0.05$ & $10.76 \pm 0.10$ & 11.48 \\
\hline 3.75 & $10.10 \pm 0.09$ & $10.46 \pm 0.17$ & 11.43 \\
\hline 5.75 & $9.88 \pm 0.11$ & $10.21 \pm 0.18$ & 11.58 \\
\hline 7.5 & $9.67 \pm 0.11$ & $9.98 \div 0.23$ & 11.59 \\
\hline 9 & $9.48 \pm 0.11$ & $9.75 \pm 0.23$ & 11.55 \\
\hline
\end{tabular}

During the sparging procedure, crystallization occurred along the edges of the glass beaker and on the sparging tube above the surface of the solution. The $\mathrm{pH}$ of this formed crystal, when diluted with a drop of deionized water, was found to be basic at a $\mathrm{pH}$ of 12.0. Figures 12 indicates that when $\phi_{3}=70 \%$ the $\mathrm{pH}$ decreases as the sparging time increases. The decreasing $\mathrm{pH}$ of the chemical solution can be partially explained by the precipitates occurring above the surface of the solution and along the edges of the glass. However, even though the crystallization that was appearing along the edges of the glass were the same color as the solution, it was a grainy, opaque, white crystal that persisted to clog the sparging tube.

Unfiltered SNW, sparged with bone dry air, $\phi_{3}=9 \%$, exhibited a relatively constant $\mathrm{pH}$. The means of obtaining this bone-dry air condition needs explanation in order to understand this constant $\mathrm{pH}$ behavior. The bone-dry air was obtained by sparging the air through $\mathrm{NaOH}$ pellets prior to entering the solution. Sparging the air through sodium hydroxide pellets not only removes moisture from the sparging air; it also 


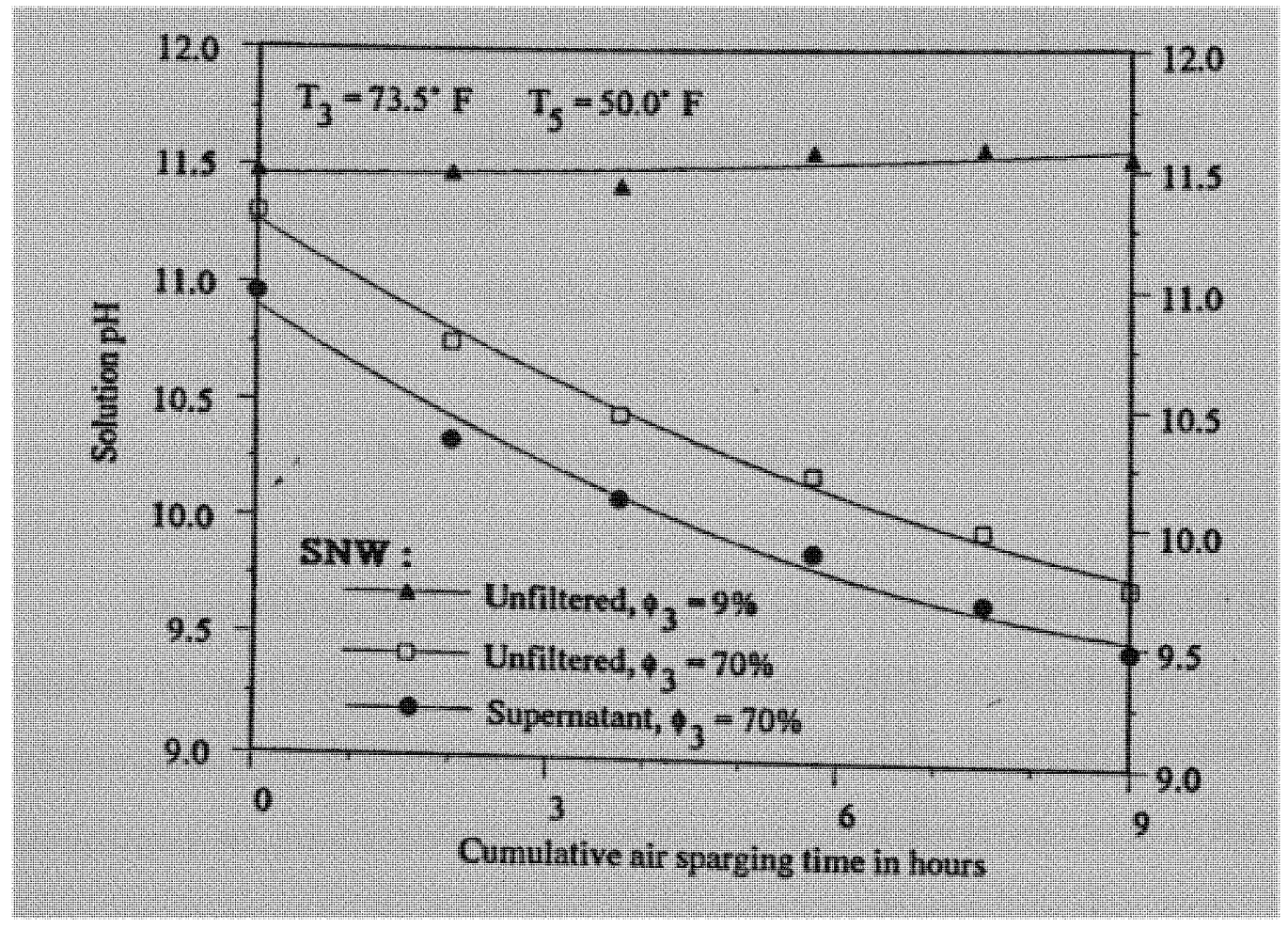

Figure 12. Changing pH with sparging time.

precipitates out $\mathrm{CO}_{2}$, in the form of $\mathrm{NaCO}_{2}$, from the sparging air. Eliminating $\mathrm{CO}_{2}$ from the sparging air prohibited the change in $\mathrm{pH}$ of the SNW unfiltered.

In the case of the other experimental samples, sparged with ambient air, $\phi_{3}=70 \%$, the presence of $\mathrm{CO}_{2}$ in the sparging line caused the $\mathrm{pH}$ of the solution to decrease. Carbon dioxide is a Lewis acid that reacts with any Lewis base, which in this case is a hydroxyl ion $\left(\mathrm{OH}^{*}\right)$, (Brown and LeMay, 1981). By definition, Lewis acids accept an electron pairs whereas Lewis bases donate electron pairs.

The prescence of $\mathrm{CO}_{2}$ in the sparging line creates a simultaneous two step process:

(i.) Hydroxyls, $\mathrm{OH}^{-}$, are removed from the șolution,

$$
\mathrm{CO}_{2(\mathrm{~g})}+\mathrm{OH} \underset{(\mathrm{aq})}{-} \rightarrow \mathrm{CO}_{3(\mathrm{aq})}^{-2}+\mathrm{HCO}_{3(\mathrm{aq})}
$$

producing excess $\mathrm{CO}_{3(\mathrm{aq})}^{\cdot 2}$ and $\mathrm{HCO}_{3(\mathrm{aq})}$. 
(ii.) These forms of carbonate react with $\mathrm{Na}$ to precipitate $\mathrm{Na}_{2} \mathrm{CO}_{3}$ and $\mathrm{NaHCO}_{3}$ out of solution

$$
\begin{aligned}
& \text { (a.) } \mathrm{CO}_{3(\mathrm{aq})}^{-2}+2 \mathrm{Na}+(a q) \\
& \text { (b.) } \mathrm{HCO}_{3(\mathrm{aq})}^{+}+\mathrm{Na}_{2} \mathrm{CO}_{3(\mathrm{~s})}^{+} \Rightarrow \mathrm{NaHCO}_{3(\mathrm{~s})} \text {. }
\end{aligned}
$$

To summarize, the bone dry sparging air was obtained by sparging the air through soddium hydroxide pellets. Thus, this bone dry air has two characteristics, a sparging air relative humidity of $\phi_{3}=9 \%$ and no $\mathrm{CO}_{2}$ in the sparging air. The elimination of $\mathrm{CO}_{2}$ from the sparging air, prior to entering the solution, prevented the precipitation of the $\mathrm{NaCO}_{2}$ 's. This was observed by the invariance of the solution $\mathrm{pH}$ with sparging time. However, sparging the liquid with ambient condition sparging air caused a decrease in the solution pH. 


\section{Sparging Air Humidity \\ I. Introduction}

The water-vapor content of the sparging and effluent air is an important parameter in the evaporation process. Attention should be drawn to the terms used to describe the water-vapor mixture. The changes in enthalpy of the water vapor are found from the steam tables whereas the ideal-gas relations are applied to the air.

The relative humidity, $\phi$, is defined as the ratio of the actual mass of vapor to the mass of vapor required to produce a saturated mixture at the same temperature. If the vapor is at the saturation pressure and temperature, $\phi=100 \%$, the mixture is refered to as a saturated mixture. The two relative humidities observed in this experiment are ambient condition sparging air, $\phi_{3}=70 \%$, and "bone-dry" sparging air, $\phi_{3}=9 \%$. An OMEGA HX-550 relative humidity transmitter was used to monitor the relative humidity. This instrument,using a thin film plymer capacitor, provided linearized and temperature compensated relative humidity output.

Assuming the vapor behaves like an ideal gas, $\phi$ reduces to the ratio of the partial pressure of the existing vapor, $\mathrm{P}_{v}$, to the saturation pressure of the vapor at the same temperature, $\mathbf{P}_{\mathrm{g}}$,

$$
\phi=\frac{m_{v}}{m_{\text {sat }}}=\frac{\frac{P_{v} V}{R_{v} T}}{\frac{P_{g} V}{R_{v} T}}=\frac{P_{v}}{P_{g}} .
$$

The specific humidity, or humidity ratio, $\omega$, of an air-water vapor mixture is defined as the ratio of the mass of water vapor, $m_{v}$, to the mass of dry air, $m_{a}$,

$$
\omega=\frac{\mathbf{m}_{v}}{\mathbf{m}_{\mathbf{a}}},
$$

which for and ideal air-water vapor mixture reduces to, 


$$
\omega=\frac{m_{v}}{m_{a}}=\frac{\frac{P_{v} V}{R_{v} T}}{\frac{P_{a} V}{R_{a} T}}=\frac{P_{v} R_{a}}{R_{v} P_{a}}=\frac{M_{v} P_{v}}{M_{a} P_{a}}=0.622 \frac{P_{v}}{P_{a}}
$$

where the subscript $a$ refers to the gas, exclusive of the vapor.

For an air-water vapor mixture, the relation between the relative humidity, $\phi$, and the humidity ratio, $\omega$, can be found by combing Eqs. (5) and (7):

$$
\phi=\frac{\omega \mathrm{P}_{\mathrm{a}}}{0.622 \mathrm{P}_{\mathrm{g}}}
$$

\section{Discussion of Results}

Tables XI and XII demonstrate the effects of two sparging air relative humidities, $\phi_{3}$ $=70 \%$ and $9 \%$, on the evaporation process. In Table XI the liquid temperature is at $50^{\circ} \mathrm{F}$ and Table XII demonstrates a liquid temperature of $90^{\circ} \mathrm{F}$. An interesting observation was the net increase in mass, i.e. condensation, of the SNW unfiltered solution at a liquid temperature, $\mathrm{T}_{5}=50^{\circ} \mathrm{F}$, sparged with ambient condition air. This condensation effect is denoted by the negative number as shown in Table XI. The sparging air experiences a decrease in temperature as it enters a liquid temperature of $50^{\circ} \mathrm{F}$. Moisture in the sparging air, with a relative humidity of $70 \%$ and a temperature of $73.5^{\circ} \mathrm{F}$, condenses for all temperatures lower than its corresponding dew point of $64.0^{\circ} \mathrm{F}$, with $P_{g}=0.4280 \mathrm{lbf} / \mathrm{in}^{2}$. It is our assumption that the lowering temperature change of the sparging air as it enters into the lower temperature solution induces condensation to occur along the inside the sparging tube. This would also explain the nonclogging effects of the sparging tube for the lower liquid temperature of $50^{\circ} \mathrm{F}$. However, for bone-dry sparging air, $\phi_{3}=9 \%$, the inverse condition occurs, whereby 6.2 grams are evaporated in the 9 hours of sparging time. 
TABLE XI

The Effects of Sparging Air Humidity on SNW Unfiltered at $T_{5}=50^{\circ} \mathrm{F}$

\begin{tabular}{|c||c|c|}
\hline $\begin{array}{c}\text { Cumulative } \\
\text { Sparging } \\
\text { Air Time } \\
\text { in Hours }\end{array}$ & \multicolumn{2}{c|}{$\begin{array}{c}\text { Condensation(-)/Evaporation } \\
\text { of SNW Unfiltered } \\
\text { in Grams }\end{array}$} \\
\cline { 2 - 3 } & $\phi_{3}=70 \%$ & $\phi_{3}=9 \%$ \\
\hline 0 & 0 & 0 \\
\hline 2 & 0 & 0.9 \\
\hline 3.75 & $-0.55 \pm 0.07$ & 2.5 \\
\hline 5.75 & $-0.65 \pm 0.07$ & 3.8 \\
\hline 7.5 & $-0.80 \pm 0.28$ & 5.1 \\
\hline 9 & $-0.95 \pm 0.35$ & 6.2 \\
\hline
\end{tabular}

TABLE XII

The Effects of Sparging Air Humidity on SNW Unfiltered at $T_{5}=90^{\circ} \mathrm{F}$

\begin{tabular}{|c||c|c|}
\hline $\begin{array}{c}\text { Cumulative } \\
\text { Sparging } \\
\text { Air Time } \\
\text { in Hours }\end{array}$ & \multicolumn{2}{|c|}{$\begin{array}{c}\text { Evaporation } \\
\text { of SNW Unfiltered } \\
\text { in Grams }\end{array}$} \\
\hline \hline 0 & $\phi_{3}=70 \%$ & $\phi_{3}=9 \%$ \\
\hline 1 & $1.65 \pm 0.35$ & 0 \\
\hline 2.75 & $3.80 \pm 0.28$ & 2.5 \\
\hline 4.5 & $5.90 \pm 0.42$ & 5.2 \\
\hline 6.42 & $8.20 \pm 0.14$ & 9.4 \\
\hline 9 & $10.75 \pm 1.77$ & 13.2 \\
\hline
\end{tabular}

Irrespective of the sparging air humidity, evaporation occurs with a liquid temperature, $\mathrm{T}_{5}=90^{\circ} \mathrm{F}$. In addition, a relative humidity, $\phi_{3}=9 \%$, demonstrates the 
grcatest evaporation holding liquid temperature constant. Recall in the last chapter that the bone-dry sparging air was obtained by sparging the air through sodium hydroxide pellets. Thus, this sparging air has not only been dried but is also void of $\mathrm{CO}_{2}$. The elimination of $\mathrm{CO}_{2}$ in the sparging line, prevented the $\mathrm{pH}$ of the solution from decreasing. Figure 13 demonstrates the results of Tables XI and XII.

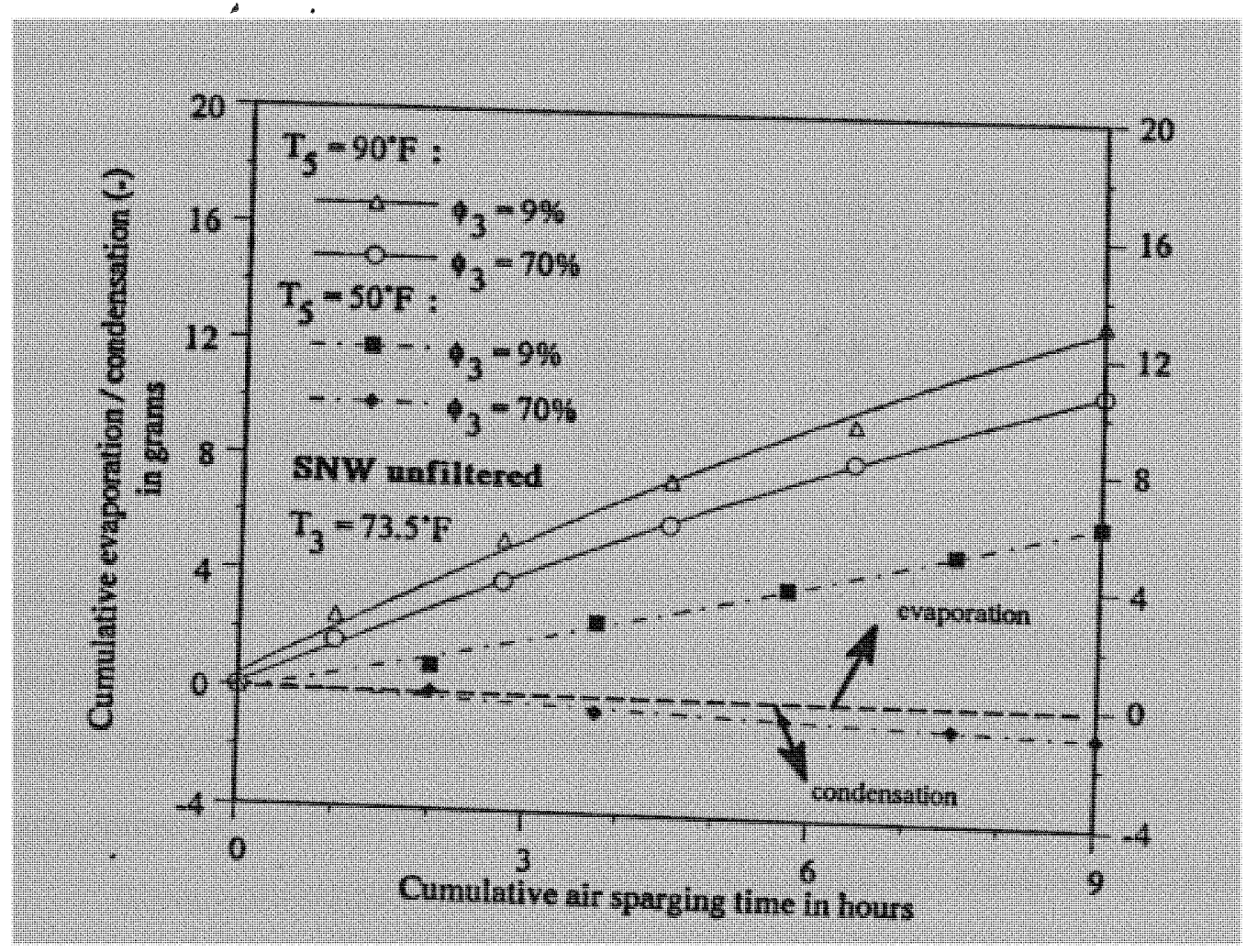

Figure 13. Effects of sparging air humidity on the
evaporation rate. 


\section{E. ACtivity CoEfFicient \\ I. Introduction}

The composition of the liquid synthetic nuclear waste, SNW, is presented in Table 1 of Chapter 1. The thermodynamic properties of mixed electrolytes at various concentrations and their effect on the evaporation rate are the concerns of this section. The activity coefficient is introduced to characterize these thermodynamic behaviors. The activity is an "effective concentration" of the ions in an electrolyte solution.

Thus, in order to explain the behavior of electrolyte solutions it is necessary to know the thermodynamic activity, $a_{i}$, rather than the total concentration or molality of the ionic components. Activity and concentration of an ionic component are related by the introduction of the activity coefficient, $\gamma_{i}$, where,

$$
\mathrm{a}_{\mathrm{i}}=\gamma_{\mathrm{i}} \mathrm{m}_{\mathrm{i}}
$$

and $m_{i}$ is the molality of the ionic component $i$. The activity coefficient, $\gamma_{i}$, may be described as a type of correction factor for the ions in order to express their thermodynamic effects, such as vapor pressure lowering, by the familiar laws of perfect solutes. This is attributed to the non-ideal behavior of the solute due to the ionic interactions of the solution.

When ionic crystals dissolve, the solution consists of a distribution of positive and negative ions. This charged environment has many effects on the anions and cations in an electrolyte solution. A particular ion, in its desire to form an ionic atmosphere, attracts ions of opposite charge. This charged atmosphere makes it less probable for the ions to take part in reactions. In such a solution, there is a greater degree of dissociation prevalent, and as a result, a greater degree of solubility. That is, their activities become less than their molarities, corresponding to a fractional value of $\gamma_{\mathrm{i}}$ or a negative value of $\ln \gamma_{\mathrm{i}}$. Thus, instead of speaking in terms of the concentration of the ions it is more significant to speak in terms of their activities. 
To summarize, the activity coefficient can be thought of as a quantitative measure of the effectiveness of an ion in influencing its equilibrium environment. For a very dilute solution, this effectiveness becomes a constant, $\gamma_{i}=1.0$, and $a_{i}$ and $m_{i}$ are equivalent. As the ionic strength increases, the ion becomes less effective and $\gamma_{\mathrm{i}}$ decreases.

The earliest model used to estimate the activity coefficients of ions were based on the Debye-Hückel model. The activity coefficient for an ion i is given by (Millero, 1978):

$$
\ln \gamma_{\mathrm{i}}=\mathrm{A} \mathrm{I}^{0.5} /\left(1+\mathrm{F} \alpha_{\mathrm{i}} \mathrm{I}^{0.5}\right)+\mathrm{G}_{\mathrm{i}},
$$

where $A$ and $F$ are Debye-Hückel constants, $\alpha$ is the ion size parameter, $G_{i}$ is a specific interaction coefficient related to cation-anion interactions and a strong function of ionic strength, I where,

$$
I=\frac{1}{2} \sum_{\mathrm{i}} \mathrm{m}_{\mathrm{i}} \mathrm{Z}_{\mathrm{i}}^{2}
$$

and $Z_{\mathrm{i}}$ is the charge of the ion.

The magnitude of the activity coefficient is strongly dependent upon the ionic strength of a solution. It is apparent that the ionic strength of an electrolyte solution, made up of singly charged ions, is simply the sum of the molarities of the salts present. However, for multiply charged ions, the ionic strength is much greater than the formal concentration. The limitation of the Debye-Hückel approach is its inability to calculate activity coefficients of ionic strength greater than 0.3 molal.

In the next sections, two very different models will be presented to describe the activity coefficient. One model uses the methods of Meissner and Tester (1972) and Kusik and Meissner (1973) to determine the thermodynamic properties of the surrogate solution. This method assumes a pure solution of $\mathrm{NaNO}_{3}$ and ignores the effects of any other electrolytes. Another model is based on the method of Pitzer(1974), commonly referred to 
as the Pitzer equations. The Pitzer equations are significant for determining the activity of an electrolyte in a mixed electrolyte solution.

\section{Development of Equations According to Meissner and Tester (1972)}

Meissner and Tester (1972) presented a simple graphical method for representing the activity coefficient of pure, strong electrolytes in an aqueous solution, applicable from low concentrations to saturated solutions. To use this method a value for $\gamma_{i}$ must be known at a concentration above the application of the Debye-Hückel equation, i.e. above 0.03 molal.

In the following methodology, extensive use is made of the term $\Gamma$, where

$$
\Gamma=\gamma_{\mathrm{i}}^{1 / \mathrm{Z}+\mathrm{Z}} \text {. }
$$

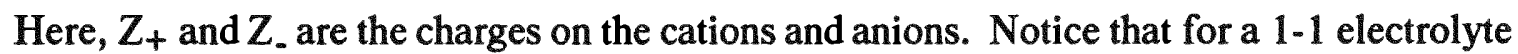
such as $\mathrm{NaNO}_{3}, Z_{+}=Z_{-}=1$ and $\Gamma=\gamma_{i}$. Thus, in the remaining paragraphs of this section $\gamma_{i}$ will replace $\Gamma$. Concentrations are expressed as $\mu$, the ionic strength, where for a pure electrolyte solution, is defined as

$$
\mu=0.5 \mathrm{~m}\left(v_{+} z_{+}^{2}+v_{-} z_{-}^{2}\right),
$$

where $\mathrm{m}$ is the molality and $v_{+}$and $v_{-}$are the moles of the cations and anion, respectively, formed upon complete dissociation of 1 mole of electrolyte. Again, for a 1-1 electrolyte $\mu$ is equivalent to $\mathrm{m}$ and will therefore be represented as such in the succeeding paragraphs of this section.

As presented in Figs. 14 and 15, the ionic strength, $\mu$, or in this case $\mathrm{m}$, is the abscissa and $\log \Gamma$, or $\log \gamma_{i}$, is the ordinate. All the curves converge at low molality and terminate at a value of $\gamma_{\mathrm{i}}$, equal to unity when $\mathrm{m}$ is zero. Figure 14 is best utilized for ionic strengths greater than 2; while Fig. 15 is implemented for ionic strengths ranging from 0.1 
to 2.0. In order to use these curves, a value of $\gamma_{\mathrm{i}}$ at a molality, $\mathrm{m}$, value greater than the Debye-Hückel approximationmust be known. The values of $\log \gamma_{\mathrm{i}}$ and $\mathrm{m}$ intersect on a curve; after which one extrapolates to the molality in question.

Following this methodology, the activity coefficients for sodium nitrate at various concentrations are obtained in Table XIII.

\section{TABLE XIII}

Activity Coefficients of $\mathrm{NaNO}_{3}$ Derived From Mesissner and Tester(1972)

\begin{tabular}{|c|c|c|}
\hline$\left[\frac{\text { Molality, } \mathrm{moles}}{\mathrm{kg}}\right]$ & $\log _{10} \gamma_{\mathrm{i}}$ & $\gamma_{\mathrm{i}}$ \\
\hline 1 & -0.26 & 0.550 \\
\hline 2 & -0.32 & 0.479 \\
\hline 3 & -0.36 & 0.432 \\
\hline 4 & -0.40 & 0.398 \\
\hline 5 & -0.42 & 0.380 \\
\hline 6 & -0.44 & 0.363 \\
\hline 7 & -0.47 & 0.339 \\
\hline 8 & -0.49 & 0.324 \\
\hline
\end{tabular}




\section{Development of Equations According to Pitzer and Kim} (1974)

The unique characteristic of the Pitzer equation's are that they determine the mean activity coefficients of both individual ions and the electrolytes in a mixed aqueous solution. The Pitzer method is unlike that of Meissner and Tester since their method is only valid for pure solutions of one electrolyte.

Pitzer and Kim (1974) improved the Debye-Hückel ion distribution function by observing the dependence of short range forces between ion pairs, i.e, the second viral coefficients dependence on the ionic strength. The Pitzer and Kim equations, an extension of the Debye-Hückel method, accurately calculates $\gamma_{i}$ to ionic strengths greater than four molal(Millero, 1982):

$$
\ln \gamma_{i}=\text { D.H. }+\sum_{j} B_{i j} m_{j}+\sum_{k} C_{i j k} m_{j k}
$$

This equation has the unique ability of estimating the activity coefficients of specific ions: a) in mixed electrolyte solution and b) for ionic strengths greater than 4 molal.

The following equations pertain to mixed electrolyte solutions of high ionic strengths. In the simplest form, the activity coefficient of a cation $\mathrm{N}$ and anion $\mathrm{X}$ are given by:

$$
\begin{aligned}
\ln \gamma_{N}=Z_{N}^{2} \mathrm{f}^{y} & \sum \mathrm{m}_{\mathrm{a}}\left(\mathrm{B}_{\mathrm{Na}}+\mathrm{EC}_{\mathrm{Na}}\right)+\mathrm{Z}_{\mathrm{N}}^{2} \sum \sum \mathrm{m}_{\mathrm{c}} \mathrm{m}_{\mathrm{a}} \mathrm{B}_{\mathrm{ca}}^{\prime} \\
& +\mathrm{Z}_{\mathrm{N}} \sum \sum \mathrm{m}_{\mathrm{c}} \mathrm{m}_{\mathrm{a}} \mathrm{C}_{\mathrm{ca}}
\end{aligned}
$$

$$
\begin{aligned}
\ln \gamma_{X}=Z_{X}^{2} f^{\gamma} & \sum_{a} m_{a}\left(B_{X a}+E C_{X_{a}}\right)+z_{X}^{2} \sum \sum m_{c} m_{a} B_{c a}^{\prime} \\
& +z_{X} \sum \sum_{a} m_{c} m_{a} c_{c a}
\end{aligned}
$$


where $Z_{i}$ is the charge of the ion, $m_{i}$ is the molality of the cation(c) and anion(a) in the mixed solution. The equivalent molality, $\mathrm{E}$, is given by:

$$
E=\sum\left|Z_{c}\right| m_{c}=\sum_{a}\left|Z_{a}\right| m_{a}=\frac{1}{2} \sum\left|Z_{i}\right| m
$$

The function, $\mathrm{f}^{\gamma}$, depends on the ionic strength, $I$, and represents the long-range effects of Coulomb forces, where (Pitzer and Kim, 1974):

$$
\mathrm{f}^{\gamma}=-0.392\left[\frac{\mathrm{I}^{0.5}}{1+1.2 \mathrm{I}^{0.5}}+\frac{2}{1.2} \ln \left(1+1.2 \mathrm{I}^{0.5}\right)\right]
$$

The second and third viral coefficients are given by:

$$
\begin{aligned}
& \mathrm{B}_{\mathrm{NX}}=\beta_{\mathrm{NX}}^{\mathrm{o}}+\frac{\beta_{\mathrm{NX}}^{1}}{2 \mathrm{I}}\left\{1-\left(1+2 \mathrm{I}^{0.5}\right) \exp \left(-2 \mathrm{I}^{0.5}\right)\right\} \\
& \mathrm{B}_{\mathrm{NX}}^{\prime}=\frac{\beta_{\mathrm{NX}}^{1}}{2 \mathrm{I}^{2}}\left\{-1+\left(1+2 \mathrm{I}^{0.5}+2 \mathrm{I}\right) \exp \left(-2 \mathrm{I}^{0.5}\right)\right\} \\
& \mathrm{C}_{\mathrm{NX}}=\zeta_{\mathrm{NX}}^{\phi}\left(2\left|\mathrm{Z}_{\mathrm{N}} Z_{\mathrm{X}}\right|^{0.5}\right)
\end{aligned}
$$

Tabulations of $\beta_{\mathrm{NX}}^{\circ}, \beta_{\mathrm{NX}}^{1}$, and $\zeta_{\mathrm{NX}}^{\phi}$ are presented below in Tables XIV, XV, and XVI (Pitzer,1973 and Pitzer,1979) for the ions of interest in this system. 
TABLE XIV

Values of $\beta(0)$

\begin{tabular}{|c||c|c|c|}
\hline & $\mathrm{Cl}$ & $\mathrm{NO}_{3}$ & $\mathrm{OH}$ \\
\hline \hline $\mathrm{Cs}$ & 0.300 & -0.0758 & 0.150 \\
\hline $\mathrm{K}$ & 0.04835 & -0.0816 & 0.1298 \\
\hline $\mathrm{Na}$ & 0.0765 & 0.0068 & 0.0864 \\
\hline $\mathrm{Sr}$ & 0.2858 & 0.1346 & $\ldots$ \\
\hline
\end{tabular}

\section{TABLE XV}

Values of $\beta^{\text {(1) }}$

\begin{tabular}{|c||c|c|c|}
\hline & $\mathrm{Cl}$ & $\mathrm{NO}_{3}$ & $\mathrm{OH}$ \\
\hline $\mathrm{Cs}$ & 0.0558 & -0.0669 & 0.3000 \\
\hline $\mathrm{K}$ & 0.2122 & 0.0494 & 0.3200 \\
\hline $\mathrm{Na}$ & 0.2664 & 0.1783 & 0.2530 \\
\hline $\mathrm{Sr}$ & 1.6672 & 1.3800 & $\ldots$ \\
\hline
\end{tabular}

TABLE XVI

Values of $\zeta(\phi)$

\begin{tabular}{|c||c|c|c|}
\hline & $\mathrm{Cl}$ & $\mathrm{NO}_{3}$ & $\mathrm{OH}$ \\
\hline $\mathrm{Cs}$ & 0.00038 & $\ldots$ & $\ldots$ \\
\hline $\mathrm{K}$ & -0.00084 & 0.00660 & 0.00410 \\
\hline $\mathrm{Na}$ & 0.00127 & -0.00072 & 0.00440 \\
\hline $\mathrm{Sr}$ & -0.00130 & -0.01992 & $\ldots$ \\
\hline
\end{tabular}


The complexity of the Pitzer equation's in determining the activity coefficient is presented below for cesium:

$$
\begin{aligned}
& \ln \gamma_{\mathrm{Cs}}=\mathrm{Z}_{\mathrm{Cs}}^{2} \mathrm{f}^{\gamma}+2\left\{\mathrm{~m}_{\mathrm{Cl}}\left(\mathrm{B}_{\mathrm{CsCl}}+\mathrm{E}_{\mathrm{CsCl}}\right)+\mathrm{m}_{\mathrm{NO}_{3}}\left(\mathrm{~B}_{\mathrm{CsNO}_{3}}+\mathrm{E}_{\mathrm{CsNO}_{3}}\right)\right. \\
& \left.+\mathrm{m}_{\mathrm{OH}}\left(\mathrm{B}_{\mathrm{CsOH}}+\mathrm{E}_{\mathrm{CsOH}}\right)\right\}+\mathrm{z}_{\mathrm{Cs}}^{2}\left\{\mathrm{~m}_{\mathrm{Cs}} \mathrm{m}_{\mathrm{Cl}} \mathrm{B}_{\mathrm{CsCl}}^{1}+\right. \\
& +\mathrm{m}_{\mathrm{Cs}} \mathrm{m}_{\mathrm{NO}_{3}} \mathrm{~B}_{\mathrm{CsNO}_{3}}^{1}+\mathrm{m}_{\mathrm{Cs}} \mathrm{m}_{\mathrm{OH}} \mathrm{B}_{\mathrm{CsOH}}^{1}+\mathrm{m}_{\mathrm{K}} \mathrm{m}_{\mathrm{Cl}} \mathrm{B}_{\mathrm{KCl}}^{1} \\
& +\mathrm{m}_{\mathrm{K}} \mathrm{m}_{\mathrm{NO}_{3}} \mathrm{~B}_{\mathrm{KNO}_{3}}^{1}+\mathrm{m}_{\mathrm{K}} \mathrm{m}_{\mathrm{OH}} \mathrm{B}_{\mathrm{KOH}}^{1}+\mathrm{m}_{\mathrm{Na}} \mathrm{m}_{\mathrm{Cl}} \mathrm{B}_{\mathrm{NaCl}}^{1} \\
& +\mathrm{m}_{\mathrm{Na}} \mathrm{m}_{\mathrm{NO}_{3}} \mathrm{~B}_{\mathrm{NaNO}_{3}}^{1}+\mathrm{m}_{\mathrm{Na}} \mathrm{m}_{\mathrm{OH}} \mathrm{B}_{\mathrm{NaOH}}^{1} \\
& \left.+\mathrm{m}_{\mathrm{Sr}} \mathrm{m}_{\mathrm{Cl}} \mathrm{B}_{\mathrm{SrCl}_{2}}^{1}+\mathrm{m}_{\mathrm{Sr}} \mathrm{m}_{\mathrm{NO}_{3}} \mathrm{~B}_{\mathrm{Sr}\left[\mathrm{NO}_{3}\right]_{2}}^{1}+\mathrm{m}_{\mathrm{Sr}} \mathrm{m}_{\mathrm{OH}} \mathrm{B}_{\mathrm{Sr}[\mathrm{OH}]_{2}}^{1}\right\} \\
& +\mathrm{Z}_{\mathrm{Cs}}\left\{\mathrm{m}_{\mathrm{Cs}} \mathrm{m}_{\mathrm{Cl}} \mathrm{C}_{\mathrm{CsCl}}+\mathrm{m}_{\mathrm{Cs}} \mathrm{m}_{\mathrm{NO}_{3}} \mathrm{C}_{\mathrm{CsNO}_{3}}\right. \\
& +\mathrm{m}_{\mathrm{Cs}} \mathrm{m}_{\mathrm{OH}} \mathrm{C}_{\mathrm{CsOH}}+\mathrm{m}_{\mathrm{K}} \mathrm{m}_{\mathrm{Cl}} \mathrm{C}_{\mathrm{KCl}}+\mathrm{m}_{\mathrm{K}} \mathrm{m}_{\mathrm{NO}_{3}} \mathrm{C}_{\mathrm{KNO}_{3}} \\
& +\mathrm{m}_{\mathrm{K}} \mathrm{m}_{\mathrm{OH}} \mathrm{C}_{\mathrm{KOH}}+\mathrm{m}_{\mathrm{Na}} \mathrm{m}_{\mathrm{Cl}} \mathrm{C}_{\mathrm{NaCl}}+\mathrm{m}_{\mathrm{Na}} \mathrm{m}_{\mathrm{NO}_{3}} \mathrm{C}_{\mathrm{NaNO}_{3}} \\
& +\mathrm{m}_{\mathrm{Na}} \mathrm{m}_{\mathrm{OH}} \mathrm{C}_{\mathrm{NaOH}}+\mathrm{m}_{\mathrm{Sr}} \mathrm{m}_{\mathrm{Cl}} \mathrm{C}_{\mathrm{SrCl}_{2}}+\mathrm{m}_{\mathrm{Sr}} \mathrm{m}_{\mathrm{NO}_{3}} \mathrm{C}_{\mathrm{Sr}\left[\mathrm{NO}_{3}\right]_{2}} \\
& \left.+\mathrm{m}_{\mathrm{Sr}} \mathrm{m}_{\mathrm{OH}} \mathrm{C}_{\mathrm{Sr}[\mathrm{OH}]_{2}}\right\}
\end{aligned}
$$

For activity coefficients in the mixed electrolyte solution, additional terms related to the short range interaction of ions of like charge and triplet interactions are included. The equations in ionic form are:

$$
\begin{aligned}
\ln \gamma_{N}=Z_{N}^{2} \mathrm{f}^{\gamma} & \sum_{\mathrm{a}} \mathrm{m}_{\mathrm{a}}\left(\mathrm{B}_{\mathrm{Na}}+E \mathrm{C}_{\mathrm{Na}}\right)+\mathrm{Z}_{\mathrm{N}}^{2} \sum \sum_{\mathrm{a}} \mathrm{m}_{\mathrm{c}} \mathrm{m}_{\mathrm{a}} \mathrm{B}_{\mathrm{ca}}^{\prime} \\
& +\mathrm{Z}_{\mathrm{N}} \sum \sum_{\mathrm{a}} \mathrm{m}_{\mathrm{c}} \mathrm{m}_{\mathrm{a}} \mathrm{C}_{\mathrm{ca}}+\sum \mathrm{m}_{\mathrm{c}}\left(2 \theta_{\mathrm{Nc}}+\sum_{\mathrm{a}} \mathrm{m}_{\mathrm{a}} \Psi_{\mathrm{Nac}}\right) \\
& +\sum \sum_{\mathrm{a}} \mathrm{m}_{\mathrm{a}} \mathrm{m}_{\mathrm{a}^{\prime}} \Psi_{\mathrm{aa}^{\prime} \mathrm{M}}
\end{aligned}
$$




$$
\begin{aligned}
\ln \gamma_{X}=Z_{X}^{2} f^{\gamma} & \sum m_{a}\left(B_{X a}+E C_{X a}\right)+Z_{X}^{2} \sum \sum m_{c} m_{a} B_{c a}^{\prime} \\
& +z_{X} \sum \sum m_{c} m_{a} C_{c a}+\sum m_{a}\left(2 \theta_{X a}+\sum m_{c} \Psi_{X a c}\right) \\
& +\sum \sum_{c} m_{c} m_{c^{\prime}} \Psi_{c c^{\prime} X}
\end{aligned}
$$

The term, $\theta_{\mathrm{ij}}$ is related to the interaction of ions and is dependent on the ionic strength. Whereas, $\Psi_{\mathrm{ijk}}$ is related to the triple ionic interaction of two similarly charged ions with an ion of opposite charge. Values of $\theta_{\mathrm{ij}}$ and $\Psi_{\mathrm{ijk}}$ for the components of interest in this system are presented in Table XVII, (Pitzer,K. S. and J.J. Kim, 1974)

TABLE XVII

Higher Order Interaction Terms, $\theta_{\mathrm{ij}}$ and $\Psi_{\mathrm{ijk}}$

\begin{tabular}{|c|c|c||c||c||}
\hline $\mathbf{i}$ & $\mathbf{j}$ & $\mathbf{k}$ & $\theta_{\mathrm{ii}}$ & $\Psi_{\mathrm{iik}}$ \\
\hline \hline $\mathrm{Na}$ & $\mathrm{K}$ & $\mathrm{Cl}$ & -0.012 & -0.002 \\
\hline $\mathrm{Na}$ & $\mathrm{K}$ & $\mathrm{NO}_{3}$ & -0.012 & -0.001 \\
\hline $\mathrm{Na}$ & $\mathrm{Cs}$ & $\mathrm{Cl}$ & -0.033 & -0.003 \\
\hline $\mathrm{K}$ & $\mathrm{Cs}$ & $\mathrm{Cl}$ & 0.000 & -0.001 \\
\hline $\mathrm{Cl}$ & $\mathrm{OH}$ & $\mathrm{Na}$ & -0.050 & -0.006 \\
\hline $\mathrm{Cl}$ & $\mathrm{OH}$ & $\mathrm{K}$ & -0.050 & -0.008 \\
\hline $\mathrm{Cl}$ & $\mathrm{NO}_{3}$ & $\mathrm{Na}$ & 0.016 & -0.006 \\
\hline $\mathrm{Cl}$ & $\mathrm{NO}_{3}$ & $\mathrm{~K}$ & 0.016 & -0.006 \\
\hline
\end{tabular}

A computer program has been developed based on the Pitzer Equations and the surrogate solution, and can be found in Appendix C. The values obtained for the activity coefficient of the ions are presented in Table XVIII. Under the assumption that only the soluble components are in solutions, only the soluble components have been considered in the solution. 
TABLE XVIII

Activity Coefficients Derived From the Pitzer (1974) Equations

\begin{tabular}{|c|c|}
\hline Ion & $\gamma_{\mathrm{i}}$ \\
\hline $\mathrm{Cs}$ & 0.13109 \\
\hline $\mathrm{K}$ & 0.16691 \\
\hline $\mathrm{Na}$ & 0.38922 \\
\hline $\mathrm{Sr}$ & $\ldots$ \\
\hline $\mathrm{Cl}$ & 0.91986 \\
\hline $\mathrm{NO}_{3}$ & 0.36908 \\
\hline $\mathrm{OH}$ & 1.00000 \\
\hline
\end{tabular}

The mean activity coefficient for an electrolyte, NX, as a function of ion activity coefficients is determined from:

$$
\gamma_{(\mathrm{NX})}=\left[\gamma_{\mathrm{N}} \gamma_{\mathrm{X}}\right]^{\frac{1}{v_{N}+v_{X}}}
$$

where $v_{\mathrm{i}}$ is the number of cations or anions.

\section{Comparison of Models}

Table XIX shows the predicted results of the activity coefficient by both the Pitzer method and the Meissner and Tester method. An additional column is provided, (Dobos, D.,1975) which was obtained experimentally for a pure $\mathrm{NaNO}_{3}$ solution at the concentrations listed. 


\section{TABLE XIX}

\section{Comparison of Models for the Activity Coefficients of $\mathrm{NaNO}_{3}$}

\begin{tabular}{|c||c|c|c|}
\hline $\begin{array}{c}\text { Molality,m } \\
{\left[\frac{\mathrm{moles}}{\mathrm{kg}}\right]}\end{array}$ & $\begin{array}{c}\text { Kusik and } \\
\text { Meissner } \\
(1973)\end{array}$ & $\begin{array}{c}\text { Pitzer } \\
(1974)\end{array}$ & $\begin{array}{c}\text { Dobos } \\
(1975)\end{array}$ \\
\hline 2 & 0.479 & 0.464 & 0.481 \\
\hline 4 & 0.398 & 0.389 & 0.410 \\
\hline 6 & 0.363 & 0.343 & 0.373 \\
\hline 8 & 0.324 & 0.304 & $\ldots$ \\
\hline
\end{tabular}

Pitzer's estimation for the activity coefficient is less than the other two approximations. This is expected since the Pitzer's equations take into account the other electrolytes in solution.

\section{Vapor Pressure Lowering as Predicted by the Activity Coefficient}

Adding a nonvolatile solute to a solvent, lowers the vapor pressure of the solvent. Experiments have shown that vapor pressure lowering depends not only on the concentration of the solute particles, but also on the charge of the electrolytes cation and ion and the temperature of the solution. Quantitatively, the vapor pressure of ideal solutions is given by Raoult's Law :

$$
\mathbf{P}_{\mathrm{A}}=\mathrm{X}_{\mathrm{A}} \mathbf{P}_{\mathrm{A}}^{\circ} \text {, }
$$

where $P_{A}$ is the vapor pressure of the solution, $X_{A}$ is the mole fraction of the solvent, and $\mathbf{P}_{A}{ }^{\circ}$, is the vapor pressure of the pure solvent. The vapor pressure lowering, $\Delta \mathbf{P}_{A}$, is $\mathbf{P}_{A}{ }^{\circ}$ $\mathbf{P}_{A}$. The activity of water, $a_{w}$, over a solution of a single electrolyte is expressed as :

$$
a_{w}=\frac{P_{w}}{P_{w}^{0}}
$$


namely, the ratio of vapor pressure of a single electrolyte solution, $P_{W}$, over that of pure water, $\mathbf{P}_{W}$. Thus, considering the non-ideal behavior of electrolyte solutions, the vapor pressure of an aqueous solution is:

$$
\mathbf{P}_{\mathrm{w}}=\mathrm{a}_{\mathrm{w}} \mathbf{P}_{\mathrm{w}}{ }^{\circ}
$$

For a single 1-1 electrolyte, NX, the Gibbs-Duhem equation presents an isothermal relationship between $\mathrm{a}_{\mathrm{w}}, \gamma_{\mathrm{NX}}$ and concentration, (Kusik, C.L and H. P. Meissner, 1973):

$$
\log \left(a_{w}\right)_{N X}=-0.0156 \mu_{N X}-(0.036) \int_{0}^{\gamma_{N X}} m d \log \gamma_{N X} .
$$

The results of this equation have been evaluated and are shown in Fig. 19 as curves of constant values of $\log \left(\mathrm{a}_{\mathrm{w}}\right)_{\mathrm{NX}}$.

Kusik and Meissner (1973) also suggested using these curves in Figs. 19 and 20 for any solution temperature between 0 and $150^{\circ} \mathrm{C}$. To determine the value of $\gamma_{N X}$ at a higher temperature, the value of $\gamma_{\mathrm{NX}}$ at an ionic strength of $\mu=10$, or for our case $\mathrm{m}=10$, and $25^{\circ} \mathrm{C}$, must be known. The following equation is used to find the representative curve at the prescribed temperature:

$$
\log \left(\gamma_{\mathrm{T}}\right)_{\mu=10}=[1 .-0.0050(\mathrm{~T}-25)] \log \left(\gamma_{\mathrm{T}}=25^{\circ} \mathrm{C}\right)_{\mu=10}
$$

Thus, once the value of $\log \left(\gamma_{T}\right)_{\mu=10}$ at the prescribed temperature is located, the electrolytes activity and activity coefficient at this temperature is defined for all concentrations.

Table XX presents the activity of water over a $\mathrm{NaNO}_{3}$ solution at concentrations from 1 to 8 molal as a function of temperature and simultaneously its effect on the vapor pressure. 


\section{TABLE XX}

Activity of Water over a $\mathrm{NaNO}_{3}$ Solution as a Function of Molality and Temperature and Their Effect on Vapor Pressure

\begin{tabular}{|c|c|c|c|c|c|c|}
\hline \multirow{3}{*}{$\begin{array}{l}\text { Molality } \\
{\left[\frac{\text { moles }}{\mathrm{kg}}\right]}\end{array}$} & \multicolumn{6}{|c|}{$\mathrm{NaNO}_{3}$} \\
\hline & \multicolumn{2}{|c|}{$50^{\circ} \mathrm{F}$} & \multicolumn{2}{|c|}{$70^{\circ} \mathrm{F}$} & \multicolumn{2}{|c|}{$90^{\circ} \mathrm{F}$} \\
\hline & $a_{W}$ & $P_{W}[p s i g]$ & $a_{W}$ & $\mathrm{P}_{W}$ [psig] & $a_{W}$ & $\mathbf{P}_{W}[p s i g]$ \\
\hline 0 & 1.0 & 0.182 & 1.0 & 0.369 & 1.0 & 0.708 \\
\hline 1.0 & 0.966 & 0.176 & 0.966 & 0.357 & 0.966 & 0.684 \\
\hline 1.5 & 0.955 & 0.174 & 0.952 & 0.351 & 0.954 & 0.675 \\
\hline 2.0 & 0.940 & 0.171 & 0.940 & 0.347 & 0.942 & 0.667 \\
\hline 2.5 & 0.929 & 0.169 & 0.929 & 0.343 & 0.931 & 0.659 \\
\hline 3.0 & 0.917 & 0.167 & 0.918 & 0.339 & 0.920 & 0.652 \\
\hline 3.5 & 0.908 & 0.165 & 0.910 & 0.336 & 0.912 & 0.646 \\
\hline 4.0 & 0.899 & 0.164 & 0.902 & 0.333 & 0.905 & 0.641 \\
\hline 4.5 & 0.891 & 0.162 & 0.893 & 0.330 & 0.897 & 0.635 \\
\hline 5.0 & 0.877 & 0.160 & 0.881 & 0.325 & 0.890 & 0.630 \\
\hline 5.5 & 0.861 & 0.157 & 0.869 & 0.321 & 0.875 & 0.620 \\
\hline 6.0 & 0.851 & 0.155 & 0.854 & 0.312 & 0.861 & 0.610 \\
\hline 6.5 & 0.841 & 0.153 & 0.841 & 0.311 & 0.851 & 0.603 \\
\hline 7.0 & 0.828 & 0.151 & 0.832 & 0.307 & 0.841 & 0.596 \\
\hline 7.5 & 0.818 & 0.149 & 0.826 & 0.305 & 0.832 & 0.589 \\
\hline 8.0 & 0.809 & 0.147 & 0.813 & 0.300 & 0.822 & 0.582 \\
\hline
\end{tabular}

It is sometimes more convenient to express concentration as molarity, $\mathrm{M},\left[\frac{\mathrm{moles}}{\text { liter }}\right]$, instead of molality, $\mathrm{m},\left[\frac{\mathrm{moles}}{\mathrm{kg}}\right]$. For a sodium nitrate solution this may be easily accomplished with the use of two equations, (CRC Handbook of Chemistry and Physics, 1991) 


$$
\mathrm{m}=\frac{1000 \mathrm{M}}{1000 \rho-85 \mathrm{M}} \quad\left[\frac{\mathrm{moles}}{\mathrm{kg}}\right]
$$

where the density, $\rho$, is

$$
\rho=1+0.054 \mathrm{M}-0.00405 \mathrm{M}^{2} \text {. }
$$

From Eqs. (32) and (33), Table XXI and Table XXII are obtained:

TABLE XXI

Molarity Versus Molality of $\mathrm{NaNO}_{3}$

\begin{tabular}{|c|c|c||}
\hline $\begin{array}{c}\text { Molarity } \\
\mathbf{M} \\
{\left[\frac{\mathrm{moles}}{\text { liter }}\right]}\end{array}$ & $\begin{array}{c}\text { Molality } \\
\mathrm{m} \\
{\left[\frac{\mathrm{moles}}{\mathrm{kg}}\right]}\end{array}$ & $\left.\begin{array}{c}\text { Density } \\
\mathrm{p} \\
{\left[\frac{\mathrm{g}}{\mathrm{ml}}\right.}\end{array}\right]$ \\
\hline 0 & 0 & 1.0 \\
\hline 0.5 & 0.508 & 1.028 \\
\hline 1.0 & 1.032 & 1.054 \\
\hline 1.5 & 1.575 & 1.080 \\
\hline 2.0 & 2.136 & 1.106 \\
\hline 2.5 & 2.717 & 1.132 \\
\hline 3.0 & 3.321 & 1.158 \\
\hline 3.5 & 3.948 & 1.184 \\
\hline 4.0 & 4.600 & 1.210 \\
\hline 4.5 & 5.280 & 1.235 \\
\hline 5.0 & 5.989 & 1.260 \\
\hline 5.5 & 6.730 & 1.285 \\
\hline 6.0 & 7.505 & 1.309 \\
\hline 6.5 & 8.319 & 1.334 \\
\hline 7.0 & 9.172 & 1.358 \\
\hline 7.5 & 10.071 & 1.382 \\
\hline 8.0 & 11.018 & 1.406 \\
\hline & & \\
\hline
\end{tabular}




\section{TABLE XXII}

\section{Activity of Water over a $\mathrm{NaNO}_{3}$ Solution as a Function of Molarity}

and Temperature and Their Effect on Vapor Pressure

\begin{tabular}{|c|c|c|c|c|c|c|}
\hline \multirow{3}{*}{$\begin{array}{c}\mathrm{M} \\
\text { Molarity } \\
{\left[\frac{\text { moles }}{\text { liter }}\right]}\end{array}$} & \multicolumn{6}{|c|}{$\mathrm{NaNO}_{3}$} \\
\hline & \multicolumn{2}{|c|}{$50^{\circ} \mathrm{F}$} & \multicolumn{2}{|c|}{$70^{\circ} \mathrm{F}$} & \multicolumn{2}{|c|}{$90^{\circ} \mathrm{F}$} \\
\hline & $a_{W}$ & $\mathrm{P}_{W}$ [psig] & $a_{W}$ & $\mathrm{P}_{W}[\mathrm{psig}]$ & $a_{W}$ & $\mathbf{P}_{W}[$ psig] \\
\hline 0 & 1.0 & 0.182 & 1.0 & 0.369 & 1.0 & 0.708 \\
\hline 1.0 & 0.965 & 0.176 & 0.965 & 0.356 & 0.965 & 0.683 \\
\hline 1.5 & 0.948 & 0.172 & 0.950 & 0.350 & 0.952 & 0.674 \\
\hline 2.0 & 0.937 & 0.171 & 0.937 & 0.346 & 0.939 & 0.665 \\
\hline 2.5 & 0.924 & 0.168 & 0.924 & 0.341 & 0.926 & 0.656 \\
\hline 3.0 & 0.911 & 0.166 & 0.913 & 0.337 & 0.915 & 0.648 \\
\hline 3.5 & 0.900 & 0.164 & 0.903 & 0.333 & 0.905 & 0.641 \\
\hline 4.0 & 0.888 & 0.162 & 0.891 & 0.329 & 0.896 & 0.634 \\
\hline 4.5 & 0.868 & 0.160 & 0.874 & 0.322 & 0.882 & 0.624 \\
\hline 5.0 & 0.851 & 0.155 & 0.854 & 0.315 & 0.861 & 0.610 \\
\hline 5.5 & 0.833 & 0.152 & 0.837 & 0.309 & 0.846 & 0.599 \\
\hline 6.0 & 0.818 & 0.149 & 0.827 & 0.305 & 0.831 & 0.588 \\
\hline 6.5 & 0.800 & 0.146 & 0.807 & 0.298 & 0.815 & 0.577 \\
\hline 7.0 & 0.775 & 0.141 & 0.788 & 0.291 & 0.796 & 0.564 \\
\hline 7.5 & 0.749 & 0.136 & 0.757 & 0.279 & 0.775 & 0.549 \\
\hline 8.0 & 0.733 & 0.133 & 0.741 & 0.267 & 0.750 & 0.531 \\
\hline
\end{tabular}

The activity of water versus sodium nitrate concentration with liquid temperature as a parameter is presented in Fig. 16. For pure water, $\mathrm{m}_{\mathrm{NaNO}_{3}}=0$, the activity of water is unity. As $\mathrm{NaNO}_{3}$ concentration is increased the activity of water deviates from ideality and becomes less than one. At an 8 molal solution of $\mathrm{NaNO}_{3}$, the $\mathrm{a}_{\mathrm{w}}$ falls in the range of 0.733 to 0.750 for a temperature between 50 and $90^{\circ} \mathrm{F}$. The effects of increasing solubility of $\mathrm{NaNO}_{3}$ by increasing the temperature of the solution is also shown in Fig. 16. At low 
concentrations less than 2 molal, the activities of water are approximately equal regardless of the solution temperature. However, at concentrations above 2 molal the activity begins to deviate with solution temperature. The activity of the water at $90^{\circ} \mathrm{F}$ is greater than that at $50^{\circ} \mathrm{F}$ since the solubility of $\mathrm{NaNO}_{3}$ is increased with temperature.

The corresponding vapor pressure of the water as a function of solution temperature is presented in Fig. 17.

The vapor pressure of the water is calculated as

$$
\mathbf{P}_{\mathrm{w}}=\mathrm{a}_{\mathrm{w}} \mathbf{P}_{\mathrm{w}}
$$

where $\mathrm{a}_{\mathrm{w}}$ is the activity of water and $\mathrm{P}_{\mathrm{w}}{ }^{\circ}$ is the vapor pressure of saturated water at the temperature in question. Thus, the activity of water can be seen as a type of correction factor describing the non-ideal behavior of the electrolyte solution.

For pure water, $\mathrm{m}_{\mathrm{NaNO}_{3}}=0$, the vapor pressure of water is the saturated water pressure at the prescribed temperature. As expected, with increasing $\mathrm{NaNO}_{3}$ concentration the vapor pressure of the water deviates from that of pure water and decreases. The effect of the solution temperature is also demonstrated in Fig. 17, where at $90^{\circ} \mathrm{F}$ the vapor pressure is much higher than that at $50^{\circ} \mathrm{F}$. 


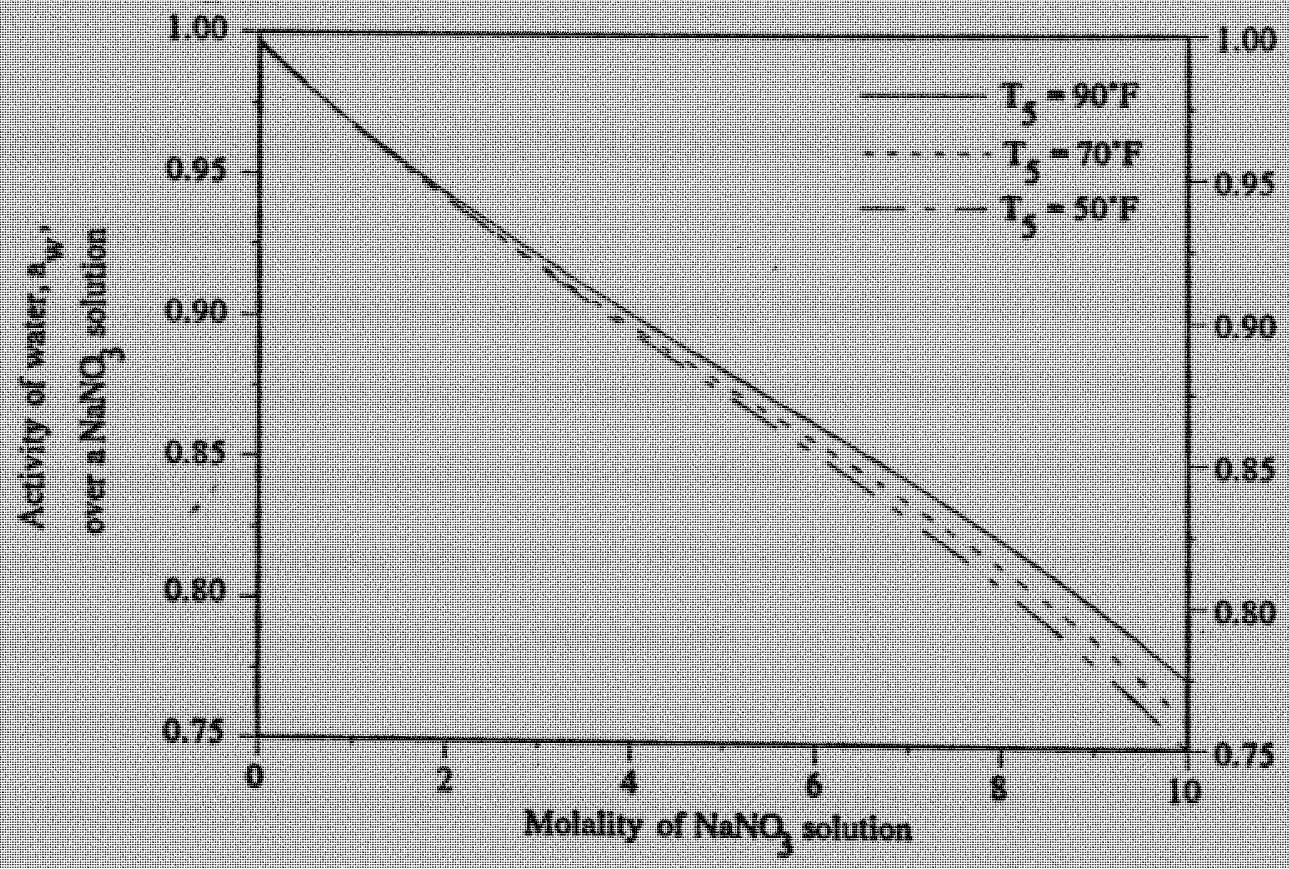

Figure 16. Activity of water versus sodium nitrate concentration as a function of liquid temperature.

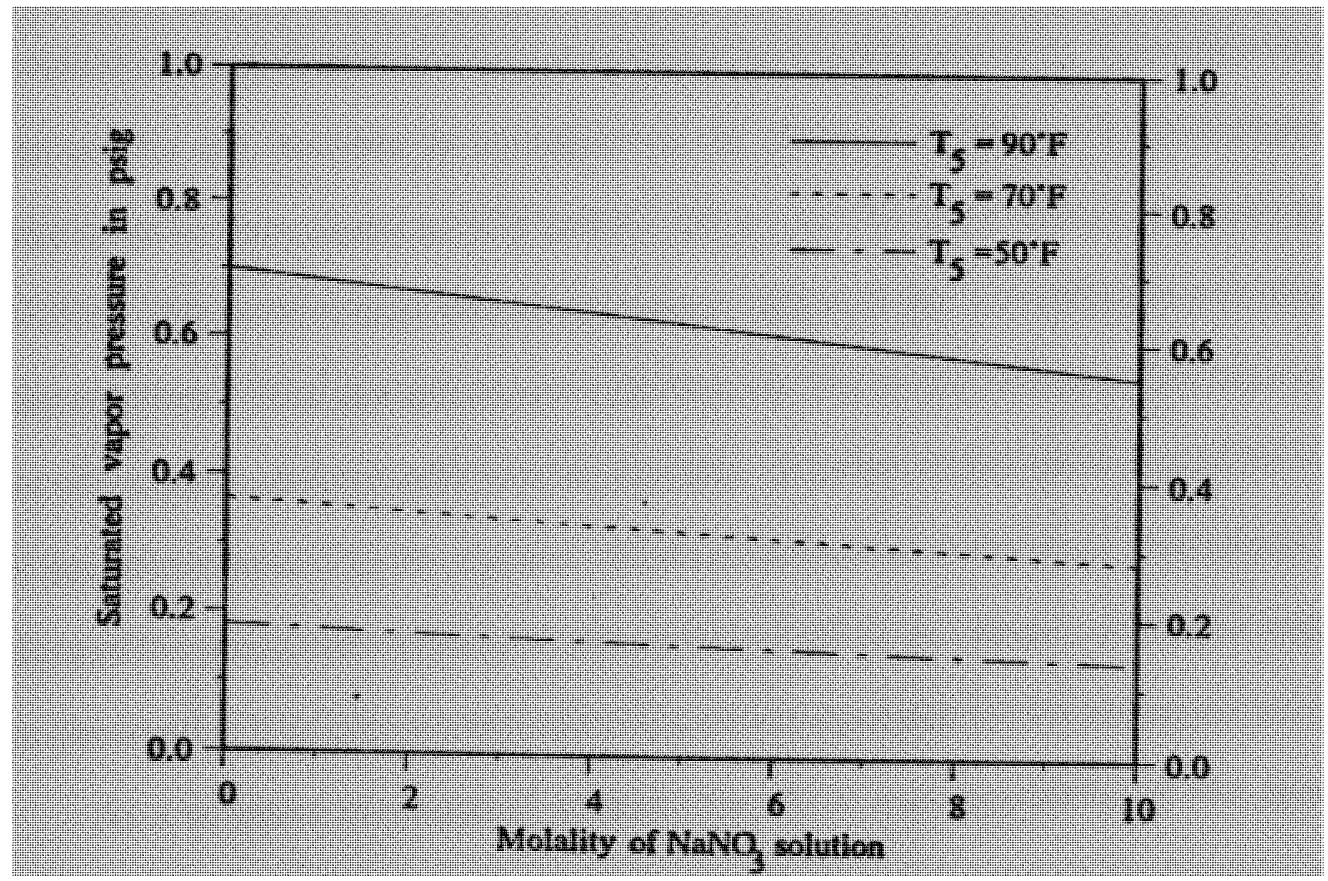

Figure 17. Saturated vapor pressure lowering of water versus $\mathrm{NaNO}_{3}$ concentration as a function of liquid temperature. 


\section{F. Precipitation and Crystallization \\ I. Introduction}

One of the complications in the sparging procedure was the clogging of the sparging tube. The solution appeared to flux back into the inlet of the sparging tube, where it collected and ultimately halted the sparging process. These precipitate blockages were removed from the sparging tube and saved for compositional analysis on the $\mathrm{X}$-ray diffractometer and Scanning Electron Microscope.

\section{Observations}

The rate at which the color changes in the solution is an observation dependent on the temperature of the liquid. At a solution temperature of $50^{\circ} \mathrm{F}$, the SNW supernatant changed from a clear, transparent color to a turbid, opaque color within minutes of sparging. Whereas, at a solution temperature of $90^{\circ} \mathrm{F}$, the solution did not change from this initial color until several hours of sparging time had progressed. This effect is partially explained by the increase in solubility of the sodium nitrate with temperature. The solubility of sodium nitrate at $50^{\circ} \mathrm{F}$ is $80 \%(80 \mathrm{gr}$ per $100 \mathrm{gr}$ of water $)$, whereas at $90^{\circ} \mathrm{F}$ it is $97.8 \%$. This color change of the supernatant indicates that something is precipitating out of the solution. This precipitate not only was visible in the solution, but also along the sides of the graduated clyinder in small patches. Another observation should be noted that was not demonstrated in the figures. Crystal formations were most predominant on the surface of the graduated cylinder of the unfiltered SNW in comparison to the supernatant. This observation was independent of the solution temperature and sparging air temperature.

At a solution temperature greater than $70^{\circ} \mathrm{F}$ and regardless of the sparging air temperature, the SNW supernant had the beginnings of precipitate formations in the sparging tube within one hour of sparging. These formations were noticeable in the sparging tube of the unfiltered SNW solution, however, their occurrence was not as frequent as in the supernatant. Although the blockages of both samples seemed to occur at 
the same rate, the unfiltered SNW precipitate blockages were easily disrupted by the agitation of the sparging air. This was observed as the volume flow rate on the flow meter decreased slightly and then in the next moment returned to its original volume flow rate; indicating that the precipitates were being dislodged by the agitation of the sparging air.

As each experiment progressed during the day, the crystal precipitates in the sparging tubes occurred more frequently and persistently. The decrease in evaporation of the SNW supernatant and unfiltered is partially attributed to the clogging of the sparging tube. The formation of precipitates in the sparging tube results in a reduction of the crosssection of the inlet sparging tube, and simultaneously, a decrease in the volume flow rate of the sparging air. Ultimately, if the blockages are not eliminated, the sparging tube becomes completely clogged and the sparging process comes to a complete stop.

Precipitation blockages in the sparging line occurred most frequently with the liquid temperature at $90^{\circ} \mathrm{F}$. Yet, at a liquid temperature of $50^{\circ} \mathrm{F}$, the sparging line never clogged, with the exception of bone-dry sparging air. Similarly, at a liquid temperature of $90^{\circ} \mathrm{F}$, precipitate blockages in the sparging tube occurred more frequently in comparison to the solution temperature of $70^{\circ} \mathrm{F}$. The solution reaches a more concentrated state with total sparging time at a liquid temperature of $90^{\circ} \mathrm{F}$ rather than $70^{\circ} \mathrm{F}$. A greater rate of evaporation corresponds to a more concentrated solution. Thus, the solubilites of the components are reached at a quicker rate at the higher liquid temperature corresponding to an increased rate of clogging in the sparging tube.

At a liquid temperature of 50 or $90^{\circ} \mathrm{F}$, with relatively bone-dry sparging air, the precipitate blockages formed in the sparging tube with the greatest frequency. This is probably a combination of the smaller flow rate of $0.0205 \mathrm{scfm}$ and the bone-dry surface inside the sparging tube, allowing crystal formations. 


\section{Analysis}

It is one of the purposes of this section to identify the precipitation that formed in the sparging tube and in the solution. The crystallization that occurred in the sparging tube of the two samples of the SNW, supernatant and unfiltered, differed in sodium nitrate concentration, as will be demonstrated in this section. However, both samples identify sodium nitrate as the major constituent.

The crystallization process consists of three stages (Mullin, 1972):

(1) achievement of supersaturation,

(2) formation of crystal nuclei, and

(3) growth of the crystal.

In most cases, all three of these stages are occurring simultaneously in the system.

The condition of supersaturation is not sufficient cause for the system to begin crystallization. There must exist centers of crystallization, or seeds, upon with nucleation may begin. The formation of crystal nuclei is a complicated process. The constituent molecules must not only be able to coagulate, they must also orientate themselves in fixed lattices.

The first signs of nucleation occur where there is a local high degree of supersaturation. It is also not uncommon to find crystallization occurring at the point of most activity, the very explanation for the precipitation blockage formations inside the sparging tube. Glass surfaces and metals may also act as a catalyst for nucleation. Thus, a future suggestion may be to replace the current boroscillicate glass sparging tubes with stainless steel or teflon tubing.

The presence of impurities in a system have a considerable effect on the nucleation behavior. Ions, such as $\mathrm{Fe}^{3+}, \mathrm{Al}^{3+}, \mathrm{Na}^{2+}$, and $\mathrm{Ca}^{2+}$, all present in the $\mathrm{SNW}$ unfiltered, have strong inhibiting effects. It is explained (Mullin, 1972) that the effects of these impurities on the growth of the crystal is a phenomenon not completely explainable; 
however, a few patterns of behavior stand out. For one, the higher the charge of the cation, the more powerful is its inhibiting effect. In addition, these large molecular weight substances are known to deposit themselves on the heteronuclei, and as a result,they disrupt the formation of growth layers across the surfaces. Furthermore, these impurities change the properties of the solution and the equilibrium saturation concentration. Thus, one is provided with an explanation for the frequent clogging of the sparging tube of the supernatant of SNW, where the majority of these impurities have been filtered out, in comparison to the unfiltered SNW.

One method of obtaining detailed pictures of the crystal lattice is through X-ray diffractometry. The Bragg condition is the basic equation of X-ray diffractometry (Atkins, P. W.,1982):

$$
\mathrm{n} \lambda=2 \mathrm{~d} \sin \theta,
$$

where $\mathrm{n}$ is an integer, $\lambda$, is the wavelength, $\theta$, is the angle of incidence and $\mathrm{d}$ is the layer spacing between a set of planes. The Bragg equation determines the spacing, $d$, between layers in the lattice of the crystal. By finding the angle $\theta$ at which maximum intensity is observed, the unique d-spacing of the crystal structure may be calculated.

$\mathrm{X}$-ray diffractometer results indicate that sodium nitrate is the major cause of the precipitation blockages. Table XXIII exhibits the d-spacing and relative intensities of a pure Aldrich sodium nitrate sample. The sample serves as the 'control'. An additional column is presented to demonstrate the identical match of the experimental sample of sodium nitrate d-spacings with the JCPDS powder diffraction file 7-271 of sodium nitrate. 


\section{TABLE XIII}

\section{X-Ray Diffraction Results of Pure Aldrich Sodium Nitrate}

\begin{tabular}{|c|c|c||c|c||}
\hline \multicolumn{3}{|c|}{ Experimental } & \multicolumn{2}{c|}{ d- spacing } \\
\hline \hline Sequence & $2 \theta$ & $\begin{array}{c}\text { Relative } \\
\text { Intensity }\end{array}$ & Experimental & $\begin{array}{c}\text { JCPDS } \\
\text { File 7-271 }\end{array}$ \\
\hline 2 & 29.479 & 100.00 & 3.0276 & 3.03 \\
\hline 5 & 48.050 & 12.80 & 1.8920 & 1.90 \\
\hline 3 & 39.084 & 9.47 & 2.3029 & 2.31 \\
\hline 12 & 31.961 & 8.20 & 2.7979 & 2.81 \\
\hline 1 & 61.700 & 6.80 & 1.5022 & 1.51 \\
\hline 6 & 22.910 & 6.53 & 3.8788 & 3.89 \\
\hline 4 & 42.657 & 5.93 & 2.1179 & 2.12 \\
\hline 8 & 35.482 & 5.73 & 2.5280 & 2.53 \\
\hline 13 & 48.481 & 4.67 & 1.8762 & 1.88 \\
\hline 9 & 63.599 & 3.93 & 1.4618 & 1.46 \\
\hline 10 & 55.777 & 3.80 & 1.6468 & 1.65 \\
\hline 11 & 56.686 & 1.93 & 1.6225 & 1.63 \\
\hline 18 & 59.942 & 2.33 & 1.5419 & 1.54 \\
\hline 16 & 99.172 & 1.93 & 1.0605 & 1.06 \\
\hline 17 & 93.167 & 1.40 & 1.0534 & 1.05 \\
\hline
\end{tabular}


The X-ray diffraction results of the precipitate blockages formed in the sparging tube of a pure $4.35 \mathrm{M}$ sodium nitrate solution is shown in Table XXIV. An additional column exhibits the matching of d-spacing with $\mathrm{NaNO}_{3}$, JCPDS diffraction powder file 7 271.

\section{TABLE XXIV}

\section{X-Ray Diffraction Results of the Precipitated Blockages in the Sparging Tube of $4.35 \mathrm{M} \mathrm{NaNO}_{3}$ Solution}

\begin{tabular}{|c|c|c|c|c|}
\hline \multicolumn{3}{|c|}{ Experimental } & \multicolumn{2}{|c|}{ D. Spacing } \\
\hline Sequence & $2 \theta$ & $\begin{array}{l}\text { Relative } \\
\text { Intensity }\end{array}$ & Experimental & $\begin{array}{c}\text { JCPDS } \\
\text { File } 7-271 \\
\end{array}$ \\
\hline 3 & 29.386 & 100.00 & 3.0370 & 3.03 \\
\hline 4 & 31.950 & 22.37 & 2.7989 & 2.81 \\
\hline 10 & 47.989 & 21.01 & 1.8943 & 1.90 \\
\hline 6 & 38.993 & 7.98 & 2.3080 & 2.31 \\
\hline 7 & 42.536 & 4.19 & 2.1236 & 2.125 \\
\hline 9 & 46.661 & 4.09 & 1.9450 & 1.3979 \\
\hline 1 & 22.853 & 3.94 & 3.888. & 3.89 \\
\hline 14 & 56.478 & 3.48 & 1.6280 & 1.63 \\
\hline 5 & 35.385 & 3.33 & 2.5347 & 2.53 \\
\hline 11 & 48.404 & 2.88 & 1.8790 & 1.88 \\
\hline 15 & 60.991 & 2.68 & 1.5079 & -- \\
\hline 2 & 26.472 & 2.58 & 3.3643 & $\ldots$ \\
\hline 13 & 55.628 & 2.37 & 1.6509 & 1.65 \\
\hline 16 & 66.653 & 1.72 & 1.4020 & 1.40 \\
\hline 8 & 45.949 & 1.21 & 1.9735 & $\ldots$ \\
\hline 18 & 93.900 & 1.03 & 1.0541 & 1.05 \\
\hline 17 & 82.445 & 1.01 & 1.1689 & 1.17 \\
\hline 12 & 50.797 & 0.96 & 1.7959 & $-\cdots$ \\
\hline
\end{tabular}

Notice the similarity of the relative intensities of each of these diffraction patterns. There is a major peak of $100 \%$ intensity and the remaining peaks have an intensity of $25 \%$ 
and less. Also notice the experimental d-spacings that have no match, i.e., 1.5170, $3.3643,1.9735$, and 1.7959. These unmatched $d$-spacings are noticeable in the succeeding diffraction patterns. Tables XXV and XXVI present the diffraction patterns of the precipitate blockages in the sparging tube of the SNW, supernatant and unfiltered, respectively. An immediate observation is the small intensities of the d-spacings for the unfiltered synthetic nuclear waste. With the X-ray diffractometer, the intensities of the diffracted beams are dependent on the arrangement of the atoms in the unit cell. As a result, from these tables it can be concluded that the crystalline structures of the precipitate differ for the two samples, SNW unfiltered and supernatant. In the unfiltered SNW, heavy molecular weight cations are present (in the supernatant, they have been filtered out), which disrupt the formation of the growth layers and as a result, affect the position of the atoms in the unit cell. 
TABLE XXV

X-Ray Diffraction Results of the Precipitate Blockages in the

Sparging Tube of SNW Supernatant

\begin{tabular}{|c|c|c|c|c|}
\hline \multicolumn{3}{|c|}{ Experimental } & \multicolumn{2}{|c|}{ D- Spacing } \\
\hline Sequence & $2 \theta$ & $\begin{array}{l}\text { Relative } \\
\text { Intensity } \\
\end{array}$ & Experimental & $\begin{array}{c}\text { JCPDS } \\
\text { File } 7-271 \\
\end{array}$ \\
\hline 3 & 29.371 & 100.00 & 3.0385 & 3.03 \\
\hline 7 & 39.005 & 15.26 & 2.3074 & 2.31 \\
\hline 11 & 47.968 & 9.92 & 1.8950 & 1.90 \\
\hline 4 & 31.853 & 8.25 & 2.8072 & 2.81 \\
\hline 6 & 35.420 & 5.98 & 2.5323 & 2.53 \\
\hline 1 & 22.840 & 5.28 & 3.8904 & 3.89 \\
\hline 8 & 42.559 & 4.80 & 2.1225 & 2.12 \\
\hline 14 & 55.626 & 4.47 & 1.6509 & 1.65 \\
\hline 2 & 26.438 & 3.94 & 3.3685 & $\ldots$ \\
\hline 12 & 48.354 & 3.61 & 1.8808 & 1.88 \\
\hline 10 & 46.650 & 21.91 & 1.9455 & 1.95 \\
\hline 15 & 56.505 & 2.64 & 1.6273 & 1.63 \\
\hline 5 & 34.016 & 2.43 & 2.6334 & $\ldots$ \\
\hline 16 & 63.622 & 1.43 & 1.4613 & 1.46 \\
\hline 9 & 45.999 & 1.67 & 1.9715 & $\cdots$ \\
\hline 13 & 49.938 & 1.32 & 1.8248 & $-\cdots$ \\
\hline 18 & 91.282 & 1.02 & 1.0774 & $\cdots$ \\
\hline 17 & 87.861 & 0.97 & 1.1103 & $\ldots$ \\
\hline
\end{tabular}




\section{TABLE XXVI}

X-Ray Diffraction Results of the Precipitate Blockages in the

Sparging Tube of SNW Unfiltered

\begin{tabular}{|c|c|c|c|c|}
\hline \multicolumn{3}{|c|}{ Experimental } & \multicolumn{2}{|c|}{ D- Spacing } \\
\hline Sequence & $2 \theta$ & $\begin{array}{l}\text { Relative } \\
\text { Intensity }\end{array}$ & Experimental & $\begin{array}{c}\text { JCPDS } \\
\text { File } 7-271 \\
\end{array}$ \\
\hline 3 & 29.352 & 100.00 & 3.0404 & 3.03 \\
\hline 4 & 31.900 & 3.42 & 2.8031 & 2.81 \\
\hline 10 & 47.914 & 3.00 & 1.8971 & 1.90 \\
\hline 7 & 38.972 & 2.46 & 2.3092 & 2.31 \\
\hline 2 & 26.454 & 1.55 & 3.3666 & $\ldots$ \\
\hline 8 & 42.546 & 1.39 & 2.1231 & 2.12 \\
\hline 1 & 22.831 & 1.16 & 3.8920 & 3.89 \\
\hline 6 & 35.376 & 1.10 & 2.5352 & 2.53 \\
\hline 11 & 48.383 & 1.05 & 1.8797 & 1.88 \\
\hline 16 & 63.532 & 0.88 & 1.4632 & 1.46 \\
\hline 14 & 60.933 & 0.75 & 1.5192 & 1.52 \\
\hline 5 & 32.352 & 0.70 & 2.7650 & $\ldots$ \\
\hline 12 & 55.625 & 0.54 & 1.6509 & 1.65 \\
\hline 9 & 45.445 & 0.45 & 1.9942 & $\ldots$ \\
\hline 15 & 61.632 & 0.45 & 1.5037 & 1.50 \\
\hline 13 & 56.530 & 0.45 & 1.6267 & 1.63 \\
\hline 17 & 68.754 & 0.37 & 1.3642 & 1.36 \\
\hline 19 & 99.008 & 0.29 & 1.0129 & 1.01 \\
\hline 18 & 92.931 & 0.26 & 1.0625 & 1.06 \\
\hline
\end{tabular}


TABLE XXVII

\section{X-Ray Diffraction Results of the Precipitate Formations in \\ SNW Supernatant Solution After Eight Hours of Sparging}

\begin{tabular}{|c|c|c|c|c|}
\hline \multicolumn{3}{|c|}{ Experimental } & \multicolumn{2}{|c|}{ D- Spacing } \\
\hline Sequence & $2 \theta$ & $\begin{array}{l}\text { Relative } \\
\text { Intensity } \\
\end{array}$ & Experimental & $\begin{array}{c}\text { JCPDS } \\
\text { File } 7-271 \\
\end{array}$ \\
\hline 3 & 29.449 & 100.00 & 3.0306 & 3.03 \\
\hline 6 & 39.052 & 18.09 & 2.3047 & 2.31 \\
\hline 9 & 48.024 & 15.44 & 1.8929 & 1.90 \\
\hline 10 & 48.450 & 9.39 & 1.8776 & 1.88 \\
\hline 5 & 35.498 & 7.24 & 2.5268 & 2.53 \\
\hline 7 & 42.619 & 6.362 & 2.1196 & 2.12 \\
\hline 1 & 22.887 & 5.12 & 3.8825 & 3.89 \\
\hline 12 & 55.693 & 4.05 & 1.6491 & 1.65 \\
\hline 13 & 56.554 & 3.47 & 1.6260 & 1.6 \\
\hline 8 & 46.731 & 2.81 & 1.9423 & 1.95 \\
\hline 25 & 93.931 & 2.77 & 1.0538 & 1.05 \\
\hline 18 & 63.596 & 2.43 & 1.4619 & 1.46 \\
\hline 22 & 77.814 & 2.29 & 1.2265 & 1.23 \\
\hline 2 & 26.500 & 2.25 & 3.3608 & $\cdots$ \\
\hline 19 & 66.700 & 2.22 & 1.4012 & 1.40 \\
\hline 16 & 61.650 & 2.22 & 1.5033 & 1.50 \\
\hline 20 & 68.678 & 2.11 & 1.3656 & 1.36 \\
\hline 17 & 62.403 & 2.11 & 1.4869 & 1.49 \\
\hline 15 & 61.025 & 20.8 & 1.5172 & 1.52 \\
\hline 26 & 94.250 & 1.84 & 1.0511 & 1.06 \\
\hline 14 & 59.969 & 1.70 & 1.5413 & 1.54 \\
\hline 27 & 99.064 & 1.52 & 1.0125 & 1.01 \\
\hline
\end{tabular}


Again, the predominant component is sodium nitrate. Quantitative and qualitative results on the precipitate blockages from the scanning electron microscope are presented in Figs. 18 and 19. The blockages resulting from the supernatant of SNW are presented if Fig 18; the unfiltered SNW blockages are presented in Fig. 19; and Fig. 20 demonstrates the control, pure Aldrich $\mathrm{NaNO}_{3}$.

Nitrogen was not picked up in the quantitative or qualitative analysis. Nitrogen would appear as a peak to the left of oxygen. Looking at the spectrum, it is assumed that the nitrogen peak was dominated by the oxygen peak. Furthermore, the control, pure Aldrich $\mathrm{NaNO}_{3}$ of Fig. 20, did not pick up the nitrogen peak either; this further justifies this assumption.

In the control, $86.52 \%$ was found to be pure $\mathrm{Na}_{2} \mathrm{O}$. As explained in the previous paragraph, combining the results form the X-ray diffractometer, it is assumed to be $\mathrm{NaNO}_{3}$. In addition, $\mathrm{Al}_{2} \mathrm{O}_{3}$ and $\mathrm{K}_{2} \mathrm{O}$ are also picked up in the background of the control, SNW unfiltered and supernatant. Most importantly, sodium nitrate is the major percentage component in the analysis of the synthetic nuclear waste. 


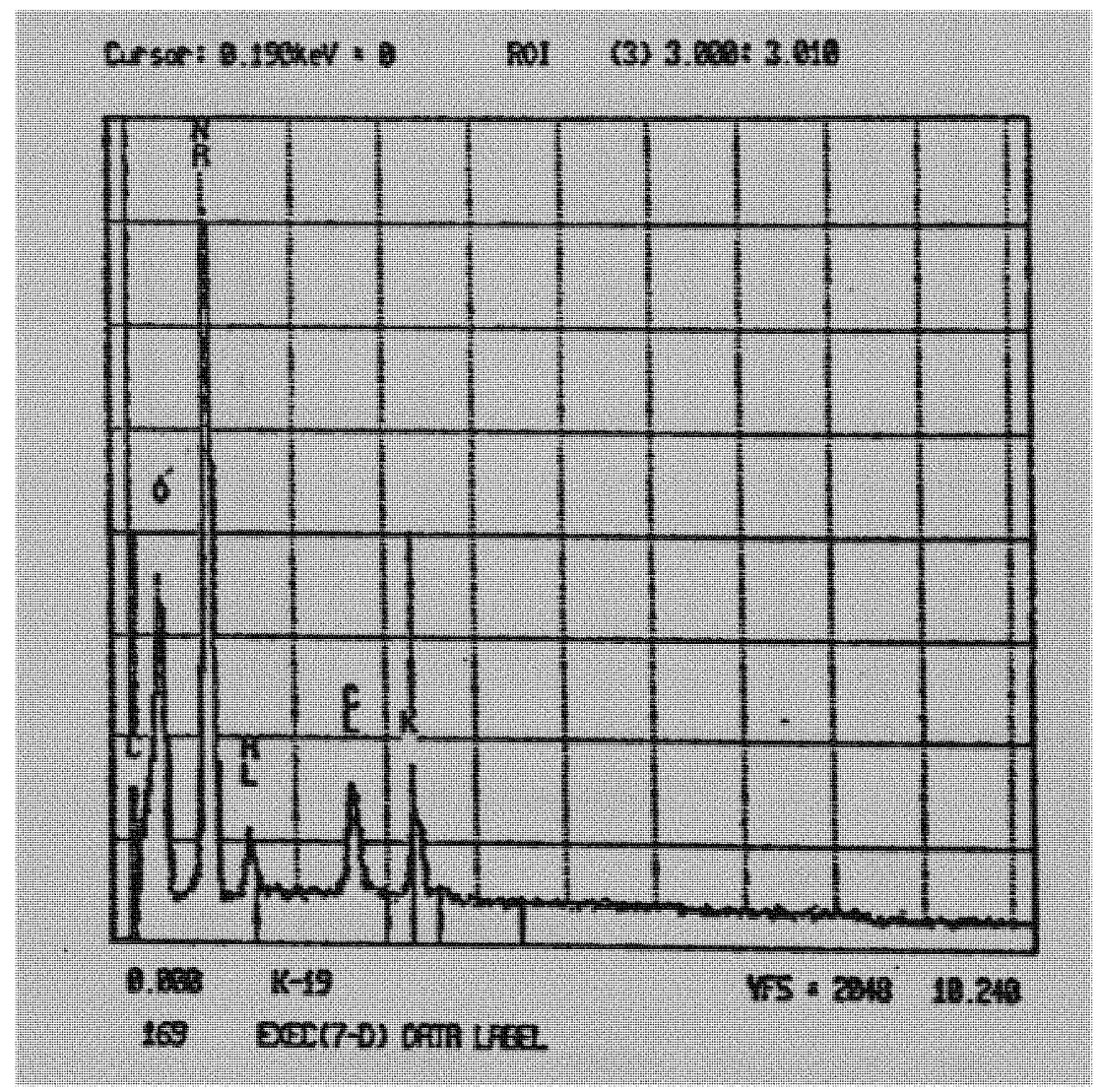

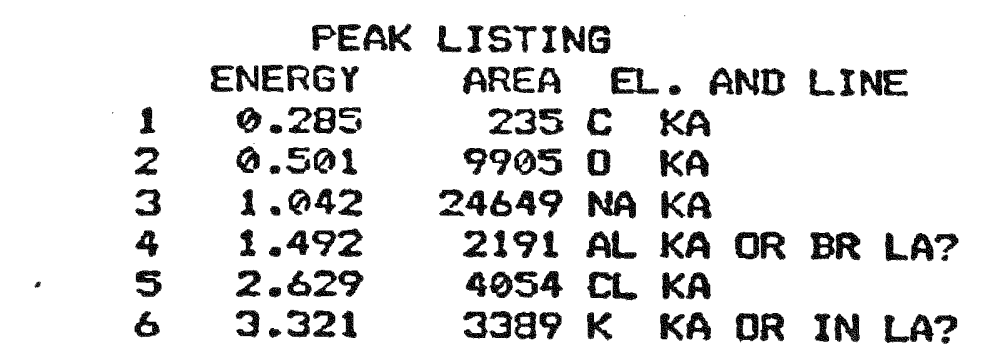

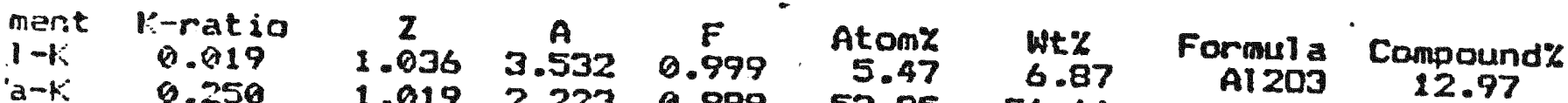

$$
\begin{aligned}
& a-k \quad 0.250 \\
& \text {-K } 0.031 \\
& 1-k \quad 0.038 \\
& -k \quad 0.079 \\
& 1.019 \quad 2.223 \\
& 0.99952 .95 \\
& 1.075 \quad 1.226 \\
& 1.076 \\
& 0.928 \\
& \text { 1. } 421 \\
& 3.625 \\
& 1.000 \\
& 56.61 \\
& 12.97 \\
& 2.24 \quad 4.07 \\
& 0.997 \quad 3.53 \\
& 0.998 \\
& 35.81 \\
& 5.82 \\
& \text { Total }=100.60 \%
\end{aligned}
$$

Figure 18. Scanning electron microscope results on the SNW supernatant, $\mathrm{T}_{5}=90^{\circ} \mathrm{F}, \mathrm{T}_{3}=125^{\circ} \mathrm{F}$. 

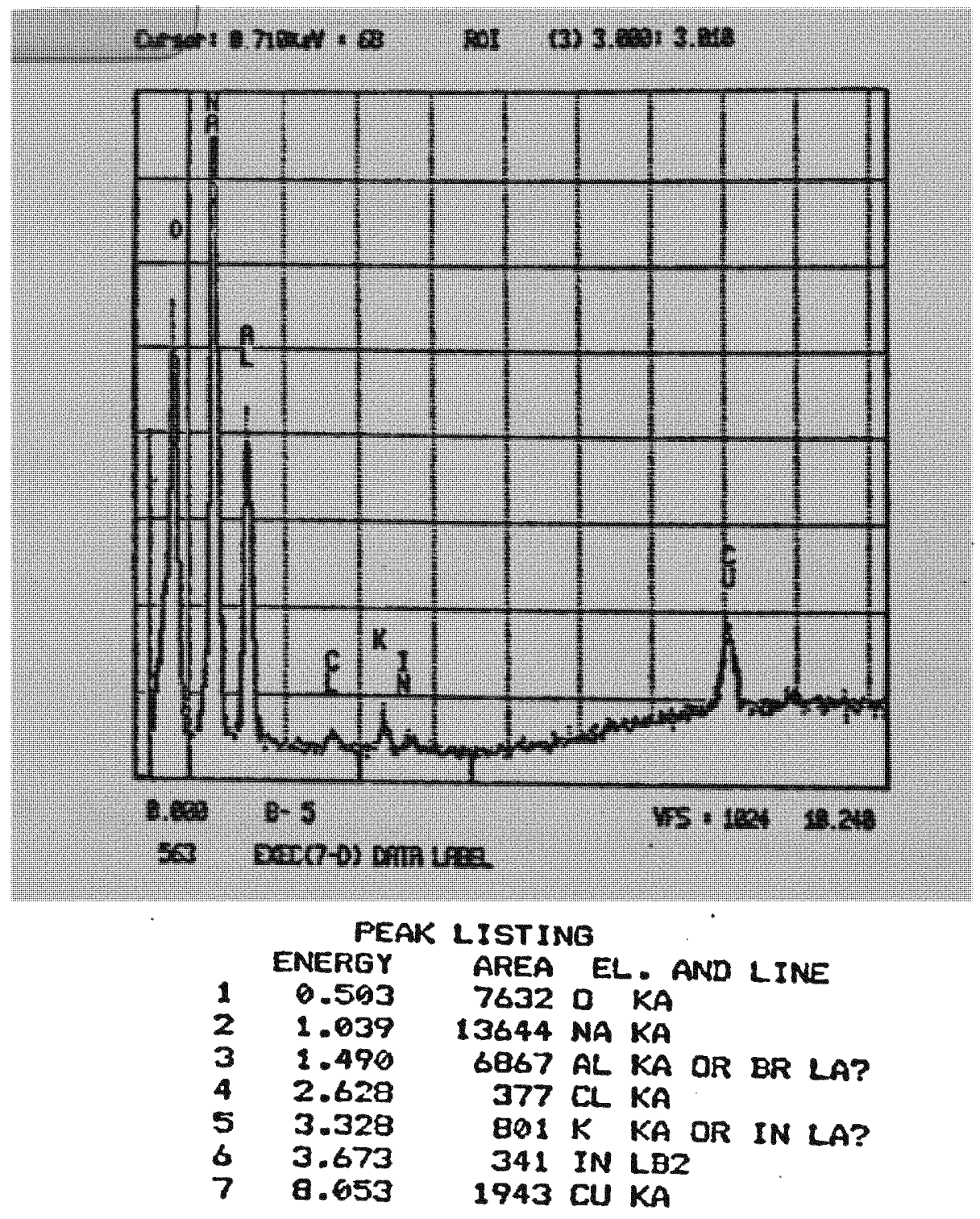

\begin{tabular}{|c|c|c|c|c|c|c|c|c|}
\hline $\begin{array}{c}\text { Element } \\
A l-K \\
N a-K \\
C u-K \\
K-K \\
C I-K \\
0-K\end{array}$ & $\begin{array}{c}\text { K-ratio } \\
0.058 \\
0.224 \\
0.060 \\
0.007 \\
0.004 \\
0.115\end{array}$ & $\begin{array}{c}z \\
1.033 \\
1.017 \\
1.212 \\
1.071 \\
1.071 \\
0.918\end{array}$ & $\begin{array}{c}A \\
3.227 \\
3.698 \\
0.985 \\
1.220 \\
1.519 \\
3.126\end{array}$ & $\begin{array}{c}F \\
1.000 \\
0.998 \\
1.000 \\
0.999 \\
0.999 \\
0.998\end{array}$ & $\begin{array}{r}\text { Aton\% } \\
15.60 \\
36.60 \\
2.43 \\
0.54 \\
0.43 \\
44.40 \\
\text { Total }=\end{array}$ & $\begin{array}{c}\text { Wt\% } \\
19.46 \\
38.89 \\
7.15 \\
0.97 \\
0.71 \\
32.84 \mathrm{~s} \\
100.00 \%\end{array}$ & $\begin{array}{l}\text { Formul a } \\
\text { Al } 203 \\
\text { Na20 } \\
\text { CuD } \\
\text { K } 20 \\
\text { Cl } \\
\text { Total = }\end{array}$ & $\begin{array}{c}\text { Compound\% } \\
36.76 \\
52.42 \\
6.95 \\
1.17 \\
0.71 \\
100.00 \%\end{array}$ \\
\hline
\end{tabular}

Figure 19. Scanning electron microscope results on the SNW unfiltered, $\mathrm{T}_{5}=90^{\circ} \mathrm{F}, \mathrm{T}_{3}=125^{\circ} \mathrm{F}$. 


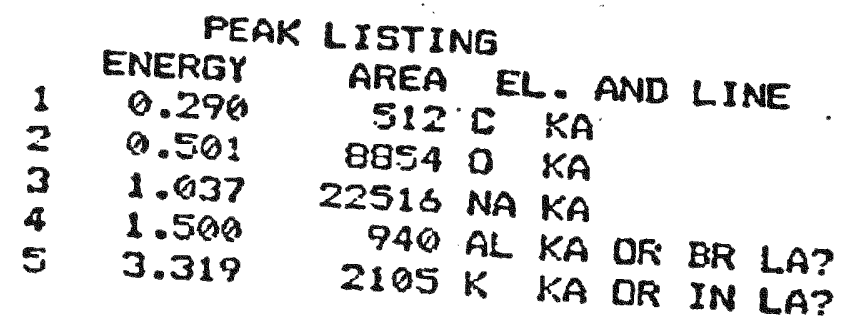

\begin{tabular}{|c|c|c|c|c|c|c|c|c|}
\hline $\begin{array}{c}\text { Elment } \\
A 1-K \\
N a-K \\
K-K \\
0-K\end{array}$ & $\begin{array}{c}\text { K-ratio } \\
0.012 \\
0.299 \\
0.027 \\
0.102\end{array}$ & $\begin{array}{c}2 \\
1.041 \\
1.024 \\
1.080 \\
0.932\end{array}$ & $\begin{array}{c}A \\
3.852 \\
2.097 \\
1.176 \\
2.964\end{array}$ & $\begin{array}{c}F \\
1.000 \\
0.989 \\
1.000 \\
0.990\end{array}$ & $\begin{array}{c}\text { Atonz } \\
3.81 \\
58.45 \\
1.87 \\
35.87 \\
\text { Total }=\end{array}$ & $\begin{array}{c}\text { Wtz } \\
4.91 \\
64.19 \\
3.49 \\
27.42 \mathrm{~s} \\
100.00 \%\end{array}$ & $\begin{array}{c}\text { Formula } \\
\text { A1203 } \\
\text { Na20 } \\
K 20 \\
\text { Total = }\end{array}$ & $\begin{array}{c}\text { Compound } \\
9.20 \\
86.52 \\
4.20 \\
100.002\end{array}$ \\
\hline
\end{tabular}

Figure 20. Scanning electron microscope results on pure Aldrich sodium nitrate.

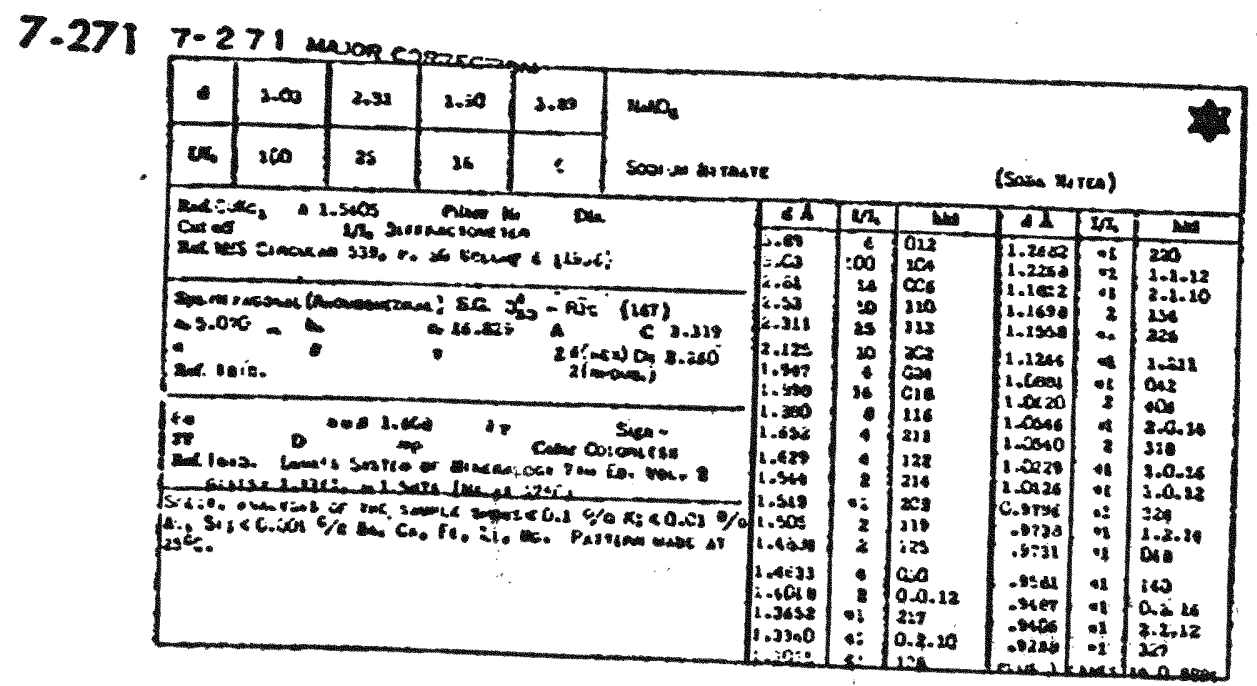

Figure 21. JCPDS diffraction powder file on sodium nitrate. 


\section{Chapter 4 \\ LARGE SCALE SIMILITUDE MODEL}

\section{A. Introduction}

The small-scale experiments were used to characterize the chemical and evaporative changes of the liquid waste. The next step in the analysis was to test the evaporative theories in the similitude model. In order to determine the correct size of the experimental setup of the similitude model, dimensional analysis was carried out. The dynamic and geometric similarities to the actual case are followed to obtain valid measurable data.

I. Dimensional Analysis:

The most important parameter affecting the in-tank evaporation project is the evaporation rate, which depends on heat and mass transfer coefficients between the bubble chain and the surrounding liquid nuclear waste. These coefficients in dimensionless form are given through the Nusselt and Sherwood numbers.

$$
\begin{aligned}
& \mathrm{Nu}=\mathrm{f}(\operatorname{Re}, \mathrm{Pr}, \text { Geometry }) \\
& \mathrm{Sh}=\mathrm{f}(\operatorname{Re}, \mathrm{Sc}, \text { Geometry })
\end{aligned}
$$

It should be apparent from the above relations that the Reynolds number and the geometric relation of the actual model and prototype must match so that the results obtained in the prototype can be transferred to the actual model. The Reynolds number is easily calculated by the sparging air velocity, sparging air pipe diameter, and the dynamic viscosity of the sparging air at ambient condition.

$$
\operatorname{Re}=\frac{\mathrm{vD}}{v}
$$


Thus, it is customary practice in the dimensional analysis procedure to calculate these significant parameters first from the actual MVSTs, and then build a prototype based on these parameters. 


\section{Actual Model of MVSTs:}

The flow parameters and geometries are presented below :

$$
\begin{array}{lll}
\dot{\mathrm{m}}_{3}= & 0.05875=\text { sparging air mass flow rate } \\
\dot{\mathrm{v}}_{35}= & 0.047=\text { sparging air volume flow rate for five pipes } \\
\dot{\mathrm{v}}_{3}= & 0.0094=\text { sparging air volume flow rate for one pipe } \\
\mathrm{D}_{3}= & 1 \mathrm{in} .=2.54 \mathrm{~cm}=\text { internal diameter of sparging pipe } \\
\mathrm{D}_{\text {tank }}= & 11.7 \mathrm{ft} .=356.616 \mathrm{~cm}=\text { diameter of storage tank. }
\end{array}
$$

The following equations are applied:

$$
\begin{aligned}
& v_{3}=\frac{\dot{v}_{3}}{\frac{D_{3}^{2}}{4}}=\text { velocity of the sparging air for one pipe } \\
& \operatorname{Re}=\frac{v_{3} D_{3}}{v_{3}}=\text { Reynolds number of the sparging air } \\
& D_{b}=\left(\dot{v}_{3}\right)^{0.4}\left(\frac{7.3}{\mathrm{~g}}\right)^{0.2}=\text { bubble chain diameter } \\
& v_{b}=\frac{\dot{v}_{3}}{\frac{\pi}{4} D_{b}^{2}}=\text { bubble chain velocity } \\
& \frac{D_{\text {tank }}}{D_{3}}=\text { geometric relation }
\end{aligned}
$$

Applying equations (36) through (40) to the actual model, the following relations are obtained:

$$
\begin{aligned}
& \frac{D_{\text {tank }}}{D_{3}}=140.4 \\
& \operatorname{Re}=33418 .
\end{aligned}
$$

These two parameters, $\operatorname{Re}$ and $\mathrm{D}_{\text {tank }} / \mathrm{D}_{3}$, must be kept constant and identical for both the actual and prototype models, i.e.:

$$
[\mathrm{Re}]_{\text {Actual Model }}=[\mathrm{Re}]_{\mathrm{FIU}} \text {. }
$$




\section{Experimental Model:}

The prototype model has been designed and constructed with a height of $D_{\operatorname{tank}}=70$ in. and the sparging tube diameter, $\mathrm{D}_{3}=0.5 \mathrm{in}$. Thus, the relationship given by Eq. (42) is warranted. The sparging air tube is $67.3 \mathrm{in}$. in length at $3.73 \mathrm{in}$. above the outlet, and consists of 48 staggered holes with a diameter of $5 / 32$ in. each. A spacing of 5/16 in. between each center has been added. The sparging air, filtered by an air dryer/extractor, is driven by a $5 \mathrm{HP}$ compressor. The sparging air entering the tank is bone dry. The volume flow rate of the sparging air is adjusted by a control valve. Two thermometers are installed in a by-pass channel to measure the dry and wet bulb temperatures of the sparging air and to verify the bone dry condition of the sparging air. Two pressure probes are installed in the piping to measure: a.) the static pressure , and b.) the total pressure. An air preheater, equipped with a thermostat regulates the sparging air temperature. The sparging air temperature is also measured at the entrance of the sparging tube by an installed thermocouple. The humidity ratio and the temperature of the exhausted air are measured by a humidity transmitter and an additional thermocouple is located on the off-gas pipe. The liquid temperature of the tank is controlled with an internal heater, plus thermostat. 


\section{B. Experimental Procedure}

Composition of the synthetic nuclear waste, (SNW), as provided by the Chemical and Technology Division of ORNL, is presented in Table I. The electrolyte solution was made up in deionized water in several seven liter containers. These containers were sealed and the solid components were allowed to dissolve into solution overnight. The following day, this solution was filtered and added to the tank. In approximately one week the tank was full.

The actual liquid nuclear waste Melton Valley Storage Tank, with a geometric size of length, $L=62 \mathrm{ft}$, and diameter, $D=11.7 \mathrm{ft}$, has a total volume of 50,000 gallons, or $6,684 \mathrm{ft}^{3}$. Assuming an optimum scenario of the nuclear waste occupying $90 \%$ of the tanks actual volume, calculates to a total of 45,000 gallons of nuclear waste per tank. According to the tank height of $11.7 \mathrm{ft}$, a $90 \%$ capacity calculates to a liquid height of $11.114 \mathrm{ft}$. Thus, if a total of 26,0000 gallons of waste must be evaporated per year, or 3,250 gallons from each of the eight tanks, the final volume of the tank is $(45,000-3,250)$ 41,750 gallons. Thus the height of the liquid is only reduced from $11.114 \mathrm{ft}$ to $10.7 \mathrm{ft}$, or a difference in height of $0.414 \mathrm{in}$. However, it should be mentioned that the level of the liquid waste will never be this low since if the liquid waste is always being added to the tanks.

The geometric scale relation of the experimental tank to the real tank is $1: 2$. Accordingly, the initial level of the liquid nuclear waste in the experimental tank should be

one-half that of the real tank. As such, the initial waste level in the experimental tank was $\frac{1}{2}$ of $11.114 \mathrm{ft}$ or 66.7 in.. As discussed in the previous paragraph, the greatest reduction in height of the liquid in one year period is approximately $5 \mathrm{in}$. for the real tank, or $2.5 \mathrm{in}$. for the experimental model. 
Accordingly, the experiment was run at an initial level of 66.7 in. in height and run for a duration of 120 hours. A bone-dry sparging air volume flow rate of $\dot{v}_{3}=12.064$ scfm was used based on the Reynolds number of 33418 .

The sparging air remained saturated during the entire experimental time of 120 hours. This $100 \%$ saturated air corresponds thermodynamically to a maximum evaporation rate and is function of the height of the waste solution in the tank. In fact, even when the initial level of the liquid in the tank was reduced to the lower level of $(66.7-2.5)$ in., or a level of $64.2 \mathrm{in}$., the sparging air remained saturated. In conclusion, the sparging air always remained satured in the prototype model, even at the lower liquid level, which corresponds to $10.7 \mathrm{ft}$ in the real model.

\section{Results and Discussion}

For both water or liquid nuclear waste, the sparging air at the exit of the tank was saturated. This saturated condition of the effluent air corresponds to a maximum rate of evaporation. Even under the worst scenario of no additional waste added to the tank in one year, the sparging air remained saturated. 


\section{Chapter 5 \\ CONCLUSION}

In the 1960's the Department of Energy at Oak Ridge National Laboratory designed eight 50,000 gallon storage tanks for the liquid nuclear waste. Each tank was designed with its own ventilation system to purge radiolytic hydrogen and oxygen from the tank. This design induced water removal and necessitated the additional requirement of entraining radioactivity from the exiting system by the use of demisters and HEPA filters.

In the transfer of the liquid waste to the holding tanks, large amounts of water is used to prevent line clogging and solid biuld up in the pipes. Utilizing the existing system, this thesis explores the posibilities of sparging the waste with air and heating the tank temperature in order to evaporate the excess water. This thesis has identified a method of optimizing the existing tanks by examining the following fundamental principles in bench scale experiments.

\section{1.) The determination of the evaporation rate as a function of sparging air temperature and liquid temperature.}

Results have shown that a solution temperature increase of $20^{\circ} \mathrm{F}$, from $70^{\circ} \mathrm{F}$ to $90^{\circ} \mathrm{F}$, causes the rate of evaporation to double. However, sparging ambient condition air into a liquid temperature of $50^{\circ} \mathrm{F}$ created an inverse effect, whereby a condensation process dominated. In addition, a sparging air temperature increase of $50^{\circ} \mathrm{F}$, from $73.5^{\circ} \mathrm{F}$ to $125^{\circ} \mathrm{F}$, has a negligible effect on the evaporation rate. Two difficulties occured when heating the sparging air : A) The process of heating the sparging air lowers its density and consequently lowers its mass flow rate. The evaporation rate is strongly dependent on the mass flow rate; thus, the volume flow rate must be increased accordingly with temperature in order to keep the mass flow rate invariant. B) The sparging pipe, immersed in the 
solution, behaves as a heat exchanger; by the time the air had traveled the length of the sparging pipe and is released into the solution, the temperature of the sparging air had decreased to the temperature of the solution.

\section{2.) The effect of the solution $\mathrm{pH}$ as the solution evaporates.}

The initial solution $\mathrm{pH}$ is basic, at a $\mathrm{pH}$ between 11.0 and 12.0. Due to the fact that the sparging air contains $\mathrm{CO}_{2}$, as the solution evaporates, the $\mathrm{pH}$ decreases to a value of approximately $\mathrm{pH} 10.0$. Carbon dioxide is a catalyst in the reaction causing the sodium carbonates to precipitate out of solution thereby lowevering the overall $\mathrm{pH}$ of the solution. As to be expected, when the $\mathrm{CO}_{2}$ was removed from the sparging air, the solution $\mathrm{pH}$ remained invariant with air sparging time.

\section{3.) The effect of changing salt concentration and solubilities on the evaporation rate.}

As a solution becomes more concentrated, the vapor pressure of the solution is decreased. Thus, as would be expected, the evaporation rate decreases with increasing concentration. The difficulty in determining the effect of the salt concentration on the evaporation rate is reflected in parameter defined as the activity coefficient. Electrolyte solutions do not behave as an ideal solution. In fact, electrolyte solutions, due to their charged environment, have increased solubilities. This information is vital to the operators of the existing holding tanks in predicting the total evaporation of the liquid nuclear waste.

\section{4.) Analysis of the precipitation blockages in the sparging tube, i.e. chemical analysis and crystal morphology, using the X-Ray Diffractometer and Scanning Electron Microscope.}


Results have shown that sodium nitrate is the main cause of the formation of precipitate blockages in the sparging line. 


\section{BIBILIOGRAPHY}

Atkins, P. W.: PhysicalChemistry, 2nd ed., W. H. Freeman and Company, CA, 1982.

Brown, T. L. and H. E. LeMay, Jr.: Chemistry, The Central Science, 2nd ed., Prentice-Hall, Inc., N.J., 1948.

Ceo, R. N., Mattus, A. J. and J. T. Shor, "A Summary of Data on the Chemical, Physical, and Radiochemical Characterization of Melton Valley Storage Tank W-26," Correspondence with ORNL, 1989.

Dobos, D.: Electrochemical Data, A Handbook for Electrochemists in Industry and Universities, Elsevier Scientific Publishing Company, NewYork, 1975.

Ebadian, M. A. etal., "Mathematical Modeling of Liquid Waste Evaporation From the Melton Valley storage Tanks Using Heat and Mass Transfer in a Bubble Chain," Nuclear Engineering and Design, to be published in 1991 .

Ebadian, M.A., et al.,"Evaporation of Water from the MVSTs for the Purpose of Producing Liquid Concentrate Storage Capacity, Final Report," Martin-Marietta, Deparment of Energy, Oak Ridge Natinal Laboratory, Oak Ridge, Tennessee (June, 1990), 101 pages.

Ford, D.: The Cult of the Atom, The Secret Papers of the Atomic Energy Commision, Simon and Schuster, Inc, NewYork, 1984.

Glasstone S. and W. H. Jordan: Nuclear Power and its Environmental Effects, American Nuclear Society, IL, 1980.

Holman, J. P. and W. J. Gajda, Jr.: Experimental Methods for Engineers, 5th ed., McGraw-Hill Book Company, NewYork, 1989.

Horwitz, E. P.: New Radioactive - Waste Treatment Could Save Taxpayers Billions, LOGOS Argonne National Laboratory - Progress Through Science, 4:3, pp. 6-9. 
Incropera, F. P. and D. P. DeWitt: Introduction to Heat Transfer, John Wiley and Sons, Inc., NewYork, 1985.

Kusik, C. L. and H. P. Meissner: "Vapor Pressure of Water Over Aqueous Solutions of Strong Electrolytes, “Ind. Eng. Chem. Process Des. Develop., 12:1, pp. 112-115, 1973.

Meissner, H. P. and J. W. Tester, "Activity Coefficients of Strong Electrolytes in Aqueous Solutions," Ind. Eng. Chem. Process Des. Develop., 12:1, pp. 128-133, 1972.

Miller, F. J., "Use of Models to Determine Ionic Interactions in Natural Water," ThalassiaJugoslavica, 18:(1-4), pp. 253-291, 1982.

Pitzer, K. S. and J. J. Kim, "Thermodynamics of Electrolytes, IV: Activity and Osmotic Coefficients for Mixed Electrolytes," Joumal of the American Chemical Society, 96:18, 1974.

Pitzer, K.. S., "Thermodynamics of Electyrolytes, I: Theoretical Basis and General Equations," Joumal of Physical Chemistry, 77:2, 1973.

Pitzer, K. S., "Theory: Ion Interaction Approach," Chapter 7 in R.M. Pytkowicz (ed.), ActivityCoefficients in Electrolyte Solutions, Vol. I, CRC Press, Boca Raton, FL, pp. 157-2089, 1979.

Reid, R. C., Prausnitz, J. M. and B. E. Poling: The Properties of Gases and Liquids, 4th ed., McGraw Hill Book Company, NewYork, 1987.

Reina, P.: Concrete Vaults Clean up a Dump, Low-Level Nuclear Waste Repositories will be Covered with Vegetation, ENR, March 2, 1989, pp. 26 - 27.

Schreiner, F., "Research Shows Two Ways to Dispose of Nuclear Waste; Subseadbed Disposal," LOGOS Argonne National Laboratory - Progress Through Science, 1:3, pp. 12-19. 
Seitz,M. G., "Research Shows Two Ways to Dispose of Nuclear Waste; Geological Repository," LOGOS Argonne National Laboratory - Progress Through Science, 1:3, pp. 12-17.

Snider, J., Proposal for Evaporating Water from the MVSTs for the Purpose of Producing Liquid Concentrate Storage Capacity, Correspondence with ORNL, 1988.

Spalding, B.J., "A Process to Downsize Nuclear Wastes," Chemical Week, December 24, 1986, p. 30.

VanWylen, G.J. and R. E. Sonntag: Fundamentals of Classical Thermodynamics, 3d ed., John Wiley and Sons,Inc., NewYork, 1985.

Walker,Jr., J. F.: In Tank Evaporation Start-Up and Evaluation, Correspondence with ORNL, 1990.

Walker, J. F. and T. J. Abraham: Bench - Scale Testing in Support of the In-Tank Evaporation(ITE) Process, Correspondence with ORNL, 1989. 


\section{Appendix A}

\section{Instrumentation : Methods and Modes of Measurement}

\section{Small Scale Evaporative Model}

\section{A. AIR DRYER}

50-70Experiment: Sodium hydroxide pellets were placed in an erlenmeyer flask; the air was sparged into an inlet tube, through the pellets, and released out the top of the flask. The effluent air was monitored with a drying tube containing self-indicating silica gel desiccant.

\section{B. BALANCE}

In order to keep a constant recording of the rate of evaporation with sparging time, the system, (solution plus container) was weighed hourly on a Mettler balance.

\section{Flow RATE}

70-90 Experiment Three Kobold flow meters were used to control the flow rates from the GAST compressor. These flow meters have the special function of operating up to temperatures of $250^{\circ} \mathrm{F}$ and up to pressure of $100 \mathrm{PSI}$.

D. PH METER

HANNA portable microprocessor $\mathrm{pH}$ meter consists of a double-junction, epoxy body electrode and a temperature probe. This $\mathrm{pH}$ meter features a digitized readout and has automatic temperature compensation.

E. SCANNING ELECTRON MICROSCOPE

JEOL JSM-35CF, scanning electron microscope provides many notable attachments : an Energy Dispersal X-Ray Spectrometer( EDS), capable of light element detection; a Wavelength Electron microprobe; and Backscatter Electron Imaging (BEI). The EDS allows microscope expansion to on-line data transfer to a computer for qualitative and quantitative elemental analysis. The BEI provides composition, or topographical image 
display. Thus, the SEM provides elemental analysis of the crystal formations in question, along with high resolution of crystal morphology.

F. SOLUTION COOLING/HEATING METHOD:

i. 50-90 Experiment: A LANDAU recirculating water bath, with thermostat, provided an accurate control of the temperature of the liquid. The $100 \mathrm{ml}$ graduated cylinders were not completely immersed in the solution.

ii. 70-90 Experiment: The $100 \mathrm{ml}$ graduated cylinders were completely immersed in this thermostatically controlled recirculating water bath; this is important for uniform temperature distribution.

G. SOLUTION FILTERINGMETHOD

One of the experimental samples is the supernatant of synthetic nuclear waste. The supernatant was obtained by vacuum filtering the solution with a medium-fritted scintered glass filter.

\section{H. SOLUTION SPARgING CONTAINERS}

The liquid was placed in a one-hundred milliliter graduated cylinder.

i. 50-90 Experiment: The boroscillicate sparging tube simply rested at the bottom of the graduated cylinder for the first experiment.

ii. 70-90 Experiment: However, for the second experiment the boroscillicate sparging and outlet tubes are held in place with a rubber stopper.

I. SPARGING AIR

i. 50-90 Experiment: Individual small air pumps provided $0.0375 \mathrm{cfm}$ of sparging air. The sparging air was room condition with a temperature of $74.5^{\circ} \mathrm{F}$ and with a relative humidity of approximately $70 \%$. This held true unless the air was dryed, as discussed under air-dryer, which had a relative humidity of $9 \%$. 
ii. 70-90 Experiment: A one-sixth horsepower GAST pressure/vacuum compressor provided the sparging air. The flow was divided into three separate lines that were monitored by KOBOLD flow meters.

\section{J. TEMPERATURE MEASUREMENT AND RECORDING}

70-90 Experiment: Thermocouples are placed at the inlet of the sparging tubes to measure the sparging air temperature. Thermocouples were also installed in the solution to measured and record its temperature. An OMEGA thermocouple strip recorder provided a continuous recording of the temperature along with a digitized read out.

K. VARIABLETEMPERATURE OF THE SPARGING AIR

70-90 Experiment: In order to obtain a variable temperature of the sparging air, a 104 Watt silicone rubber extruded heating tape ( 1 in. $x 4 \mathrm{ft}$ ) is wrapped around a steel pipe, ( $3.5 \mathrm{~cm}$ in diameter), and insulated with $100 \%$ fiberglass cloth tape. The heating tape is connected to a Thermolyne Stepless Temperature Controller in order to maintain a constant sparging air temperature. This setup allows a temperature range from room temperature up to $300^{\circ} \mathrm{F}$.

\section{X-RAY DIFFRACTOMETER}

70-90 Experiment: SEIMENS D-500, provides information on compound analysis. Used to determine that which was precipitating in the sparging process and halting the evaporation rate.

\section{Large Scale Similitude Model}

A. AIR COMPRESSOR:

The 5HP SUNBURN air compressor provides an air volume flow rate of 12.7 scfm and 40 psig. 


\section{B. AIR DRYER/EXTRACTOR :}

The LA-MAN air dryer consists of two-stage filters. The air passes through the first stage coalescing filter which causes moisture to form larger droplets. The air velocity slows down as it enters the dryer/extractor chamber, allowing moisture, oil, and contaminants to be removed through the drain valve. The second-stage filter cartridge removes any remaining moisture, oil, contaminants, and particles in the air lines. The exhaust air is clean and free of harmful oil and water.

\section{PRessure TRANSDUCERS DP154 AND DP1033 :}

The Valdyne DP15 pressure transducer is designed for low and medium pressure measurement with an accuracy of $\pm 0.25 \%$ FS (including effects of linearity, hysteresis and repeatability). The standard ranges are \pm 0.08 psid FS to 3200 psid FS. In typical AC excited bridge circuits, the system delivers a full scale output of 35 multivolts per volt at $3000 \mathrm{~Hz}$. This transducer measures the total pressure of the sparging air in the pipe.

The Valdyne DP103 wet differential pressure transducer is designed for exceedingly low differential pressure measurement. With the full-scale range down to \pm $0.008 \mathrm{psid}\left( \pm 0.56 \mathrm{~cm} \mathrm{H}_{2} 0\right)$, this instrument is used in the measurement of very low flow rates of air. The standard ranges for the Valdyne DP 103 is \pm 0.008 psid FS to \pm 12.5 psid FS. This transducer, also with an accuracy of $0.25 \% \mathrm{FS}$, measures the dynamic pressure of the sparging air in the pipe. Each transducer is connected to a Valdyne CD233 digital transducer indicator. This transducer indicator can be switched to a selected input of zero and span control for each input. In addition, the output signal from this indicator is transferred to the HP - 3852A model data acquisition system.

\section{AIR PREHEATER:}

The air preheater was designed and built by the Florida International University research team to accommodate the requirements of the experiment. It consists of a $750 \mathrm{~W}$ 
finned strip heater juxtaposed inside a steel pipe. In addition, an external thermostat is installed to control the air temperature.

E. LIQUIDHEATER:

The immersion liquid heater is installed directly into the tank. The temperature is controlled by an integral thermostat, adjustable from $60-250^{\circ} \mathrm{F}$. The material of the heating coil is 800 Incoloy alloy (stainless steel); this material is non-corrosive to caustic liquids.

F. HeWlett PACKARD DATA ACQUisition SyStem(HP - 3852A):

Electronic signals from the pressure transducers, thermocouples and the humidity transmitterare transmitted to a HP data acquisition system. This system, through various types of electronic conversions; measures, processes and analyzes data acquired from the experimental instruments. A personal computer, connected to the data acquisition system, continuously displays the data visually on the monitor and stores it on the hard drive.

G. RELATIVEHUMIDITY TRANSMITTER:

An OMEGA HX-550 relative humidity transmitter is installed directly at the exit of the off-gas pipe. It provides linearized and temperature compensated relative humidity output. A thin film polymer capacitor senses relative humidity. A power supply is connected to the transmitter to provide a constant voltage of $16 \mathrm{~V}$. The output of the transmitter is attached to the data acquisition system. 


\section{Appendix B}

\section{Psychometric Chart}

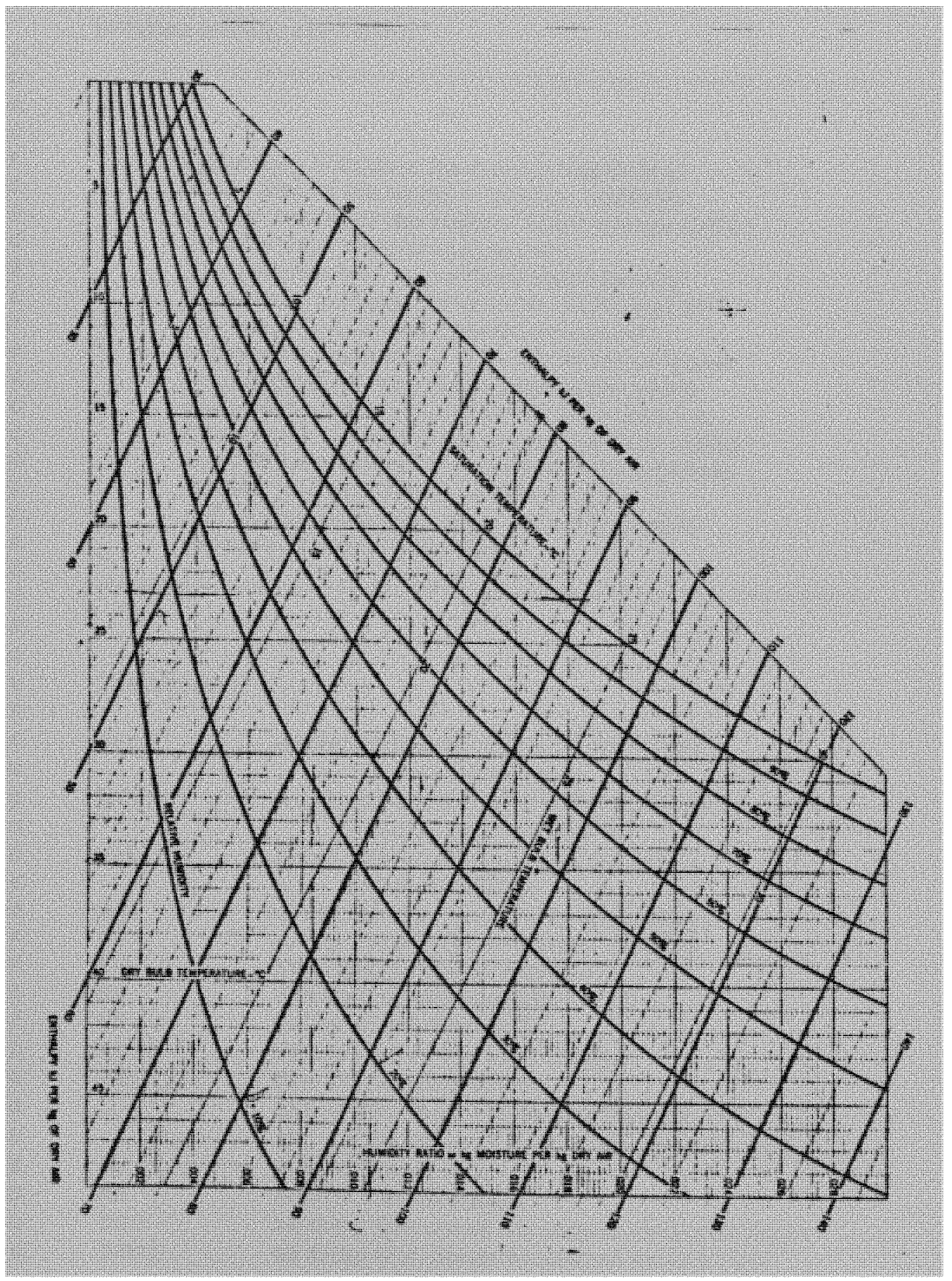




\section{Computer Program for the Calculation of the}

c

c

c

c

c

\section{Activity Coefficient}

program activity coefricient

Objective: Calculate the activity coefficient of the ions in the aqueous solution, synthetic nuclear waste, of the Melton Valley storage tanks at Oak Ridge National Laboratory. The program has been written user-friendly in order to calculate the activity coefficient of the waste at different concentrations and different compositions. Therefore, the program is applicable for any of the eight tanks which are at different composition and concentration. Comment: At this time the program only works for $1-1$ electrolytes. This only effects strontium nitrate, but has little to no effect on the calculations since the initial strontium nitrate molality is minimal at 0.0002 .

Parameters:

beta0

betal

cphi

a

c

ion

eq

dh sqion step

f

ai

aii

bmx

bmxj
Array storing the values of the second viral coefficients

Array storing the values of the primed second viral coefficients

Array storing the values of the third viral coefricient

Array storing the molality of an anion

Array storing the molality of a cation

Ionic charge of the system

Equivalent ionic molality

Debye-Huckel constant

square root of the ionic charge

step in the calculations

Debye-Huckel coefficient a function of ionic strength and long range Coulomb forces constant equal to 2 step in the calculation

an array that stores the second viral coefficient an array that stores the primed second viral coefficient 


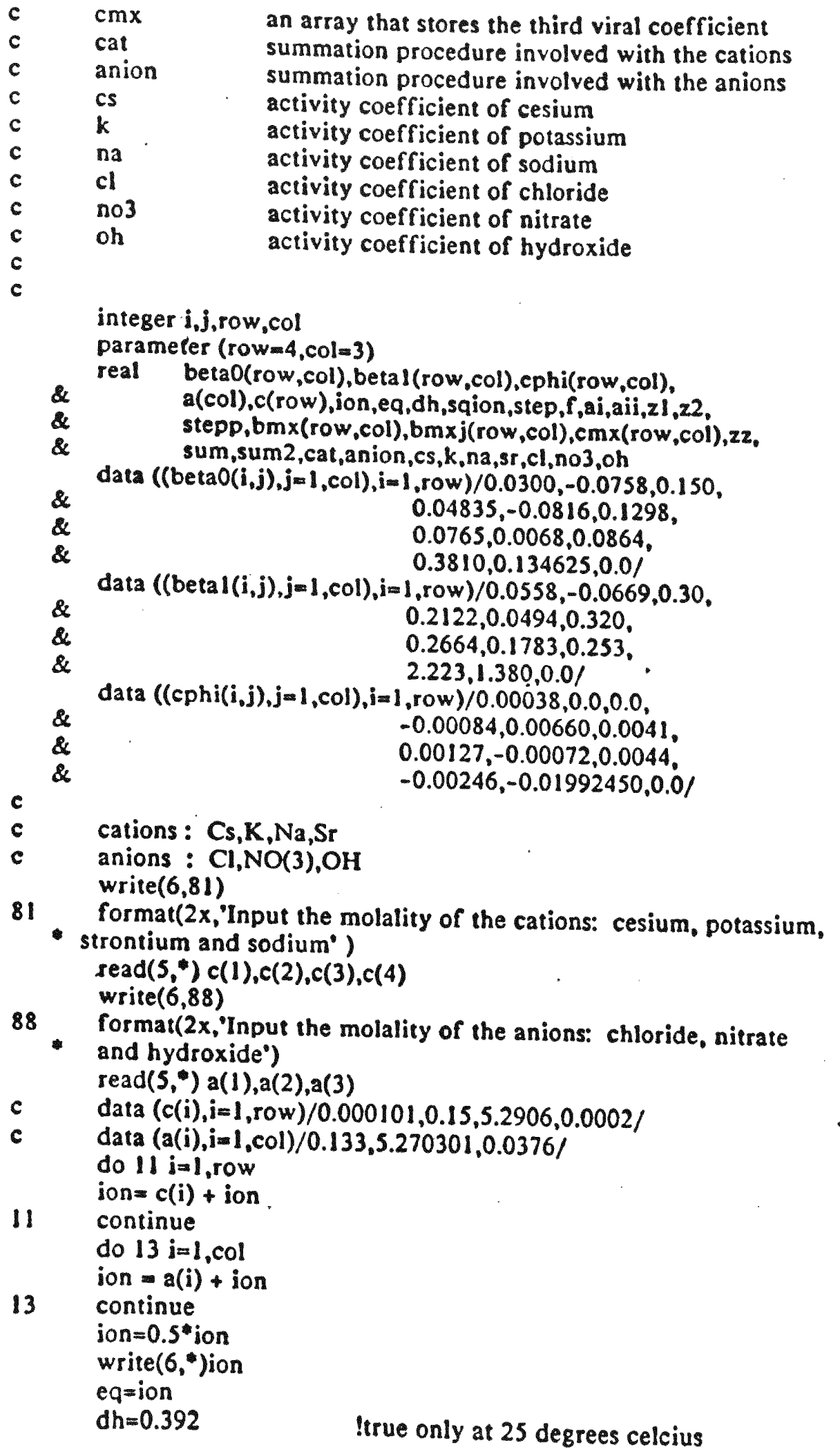




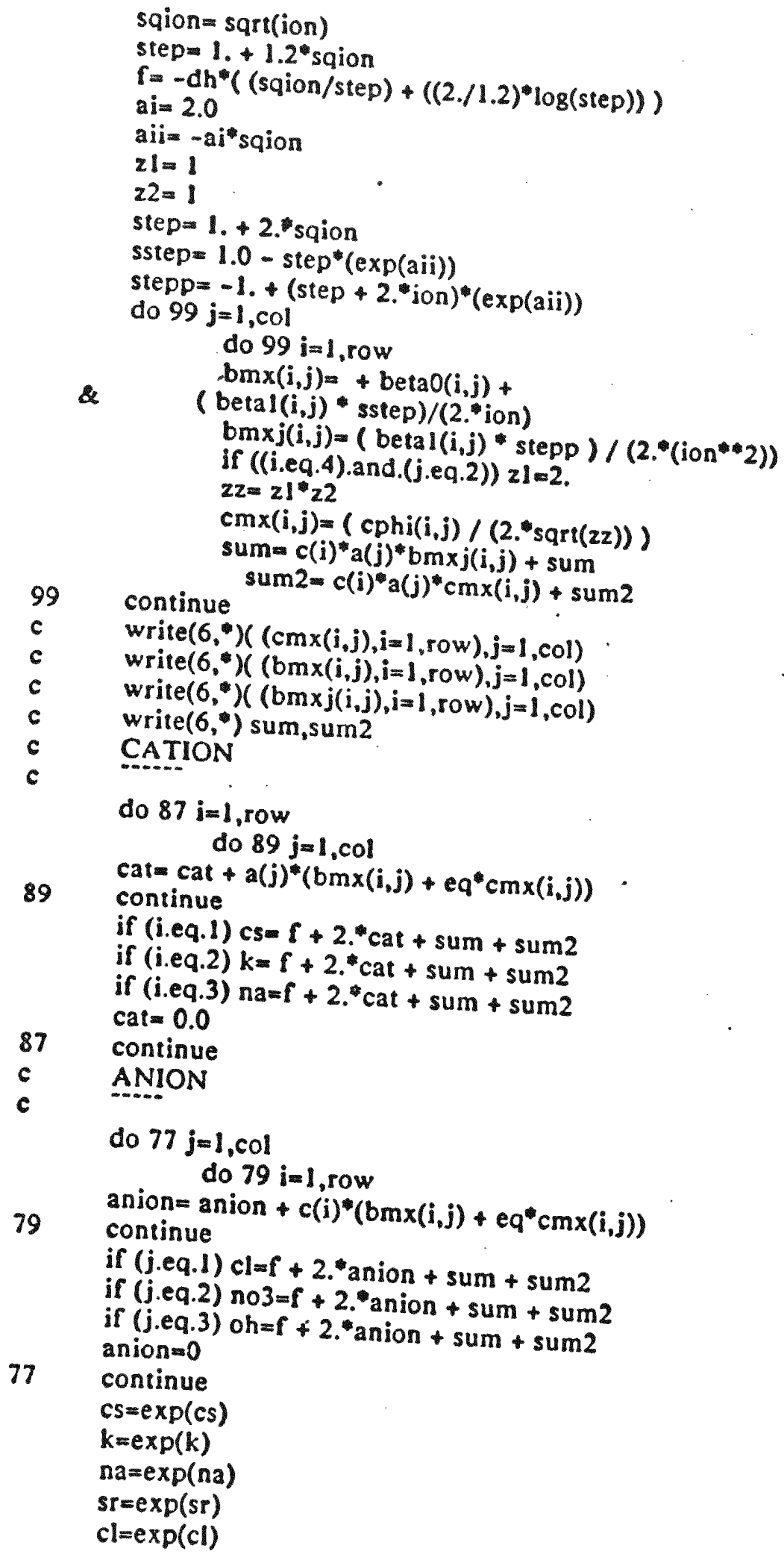


no3 $=\exp ($ no3)

ohmexp(oh)

write $(6,67) \mathrm{cs}, \mathrm{k}, \mathrm{na}, \mathrm{cl}, \mathrm{no}$, oh

67 Cormat $(2 x$, "The activity coef

- 7x, Cesium activity coef ficients :",/./。

- 7x, Potassium :", 13.5,

- 7x, Sodium $\because, 13.5, \%$

$\because 813.5, \%$

$\because f 13.5 \%$

$\because ", 13.5, \%$ end

$\therefore$, $(13.5)$ 
no3 $3 x \exp ($ no3)

oh=exp(oh)

write $(6,67) \mathrm{cs,k,na,cl,no3, \text {oh }}$

67 Cormat $(2 x$, "The activity coef

- 7x, Cesium

- 7x: Potassium : $813.5, \%$

- 7x: Sodium :"f13.5,

-7x. Chloride

$7 x$, Nitrate $\because f 13.5 \%$

$: " 813.5 \%$ end

$\because$ (13.5) 